Florida International University FIU Digital Commons

$6-7-2018$

\title{
Synthesis and Characterization of Fe8-based Materials as Electron Acceptors for Solar Energy Applications
}

\author{
Alan J. Rodriguez-Santiago \\ Florida International University, arodr927@fiu.edu
}

DOI: $10.25148 /$ etd.FIDC006828

Follow this and additional works at: https://digitalcommons.fiu.edu/etd

Part of the Chemistry Commons

\section{Recommended Citation}

Rodriguez-Santiago, Alan J., "Synthesis and Characterization of Fe8-based Materials as Electron Acceptors for Solar Energy Applications" (2018). FIU Electronic Theses and Dissertations. 3805.

https://digitalcommons.fiu.edu/etd/3805 


\section{FLORIDA INTERNATIONAL UNIVERSITY}

Miami, Florida

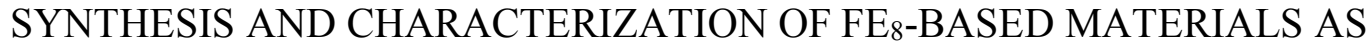 ELECTRON ACCEPTORS FOR SOLAR ENERGY APPLICATIONS}

A dissertation submitted in partial fulfillment of the

requirements for the degree of

DOCTOR OF PHILOSOPHY

in

CHEMISTRY

by

Alan Jamil Rodríguez Santiago

2018 
To: Dean Michael R. Heithaus

College of Arts, Sciences and Education

This dissertation, written by Alan Jamil Rodríguez Santiago, and entitled Synthesis and Characterization of $\mathrm{Fe}_{8}$-based Materials as Electron Acceptors for Solar Energy Applications, having been approved in respect to style and intellectual content, is referred to you for judgment.

We have read this dissertation and recommend that it be approved.

Konstantinos Kavallieratos

John Landrum

Alexander Mebel

Wenzhi Li

Raphael G. Raptis, Major Professor

Date of Defense: June 7, 2018

The dissertation of Alan Jamil Rodríguez Santiago is approved.

Dean Michael R. Heithaus

College of Arts, Sciences and Education

Andrés G Gil

Vice President for Research and Economic Development and Dean of the University Graduate School

Florida International University, 2018 
(C) Copyright 2018 by Alan Jamil Rodríguez Santiago

All rights reserved. 


\section{DEDICATION}

I dedicate this thesis to my family. To my parents who have gone above and beyond to make sure I finished. To my wife who has endured with me the turmoil of this journey.

To my daughter for whom I hope this might be proof that hard work pays off. 


\section{ACKNOWLEDGMENTS}

I am forever indebted to my wife who has borne with me through the rough patches and made the good ones even better. I want to acknowledge my parents for the efforts they have made to motivate me to better myself and for their support in every aspect of my life. I also want to acknowledge the incredible support I have received from my extended family, your love, prayers, help, advice and encouragement have been fundamental to get me through the most difficult times.

I owe a debt of gratitude to Dr. Raphael Raptis who took me in as a pupil and has guided me with patience teaching me along the way how to be a better scientist. I want to thank my committee members, their questions and comments have been a powerful motor that has driven my research as well as my general search for knowledge. Their flexibility and openness is a credit to their vocation as professors and researchers.

I want to thank our collaborators Dr Arturo Hernandez in Puerto Rico and Dr Yiannis Sanakis in Greece for their help not only collecting data for us but also for their helpful discussions and answers regarding our joint project.

Last but not least, I want to thank my lab mates Jessica, Kostas, Shambhu, Kaige and Dave as well as the postdocs and past group members. Research is an always interesting but often frustrating process and having you guys has been a true blessing. Shared joy is double the joy; shared sorrow is just half the sorrow, thanks for sharing these past few years with me. 


\title{
ABSTRACT OF THE DISSERTATION \\ SYNTHESIS AND CHARACTERIZATION OF FE8-BASED MATERIALS AS \\ ELECTRON ACCEPTORS FOR SOLAR ENERGY APPLICATIONS
}

\author{
by \\ Alan Jamil Rodríguez Santiago \\ Florida International University, 2018 \\ Miami, Florida \\ Professor Raphael G. Raptis, Major Professor
}

The urgent need to find alternative sources of energy has been recognized as a major challenge of the $21^{\text {st }}$ century. Many ideas have been proposed, but harvesting the energy of the Sun has been identified by many as the most promising alternative to satisfy the world's increasing energy demand. Among the current technologies to harness solar energy, photovoltaics and artificial photosynthesis (photocatalysis) stand out. Although very different in their strategies, both technologies entail the same core principle, the generation of a charge-separated state. To achieve the charge-separated state, both methods require an electron acceptor that will receive the photo-electron; in most cases this role is played by $\mathrm{C}_{60}$ or its derivatives. Our research group has synthesized and characterized an octanuclear iron-oxo cluster with remarkable electrochemical properties which compares favorably with the reduction potentials of $\mathrm{C}_{60}$ and derivatives. This dissertation explores the use of this octanuclear cluster as electron acceptor for solar energy applications. 
To assess the viability of $\mathrm{Fe}_{8}$ as an electron acceptor in photocatalysis, electron donors that could coordinate to its iron atoms via phenol groups were synthesized and characterized. These electron donors were used in efforts to make molecular dyads, but coordination was not achieved. The alternative strategy studied was the preparation of $\mathrm{Fe}_{8}$-based hybrid materials that can be cast with known polymer electron donors. Several hybrid materials were prepared and their general properties investigated. These materials exhibited the desired electrochemical traits as well as the general castable behavior of the polymer host. These hybrids are now ready to be tested in polymer solar cells. 


\section{TABLE OF CONTENT}

CHAPTER

PAGE

\section{CHAPTER 1:}

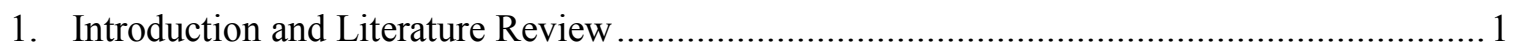

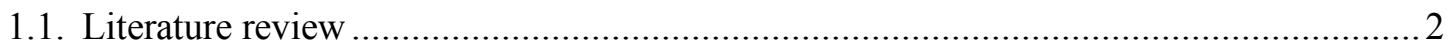

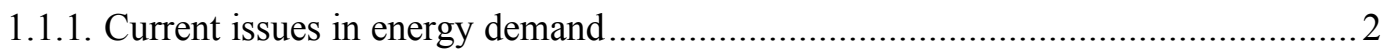

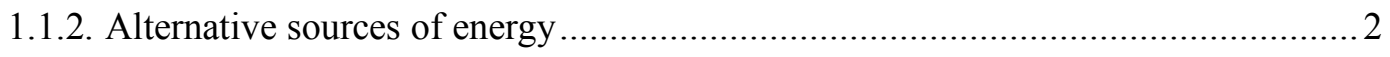

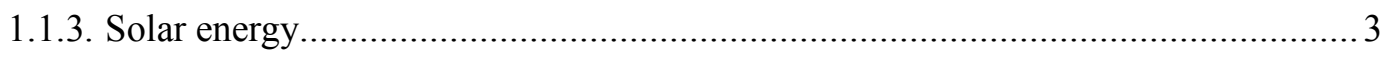

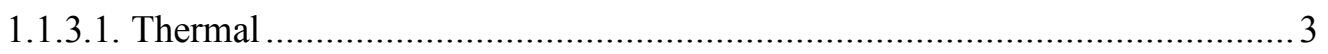

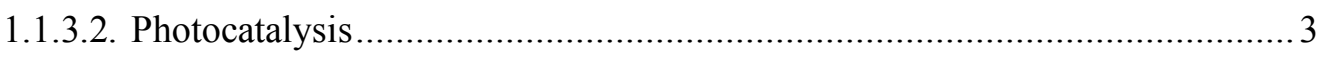

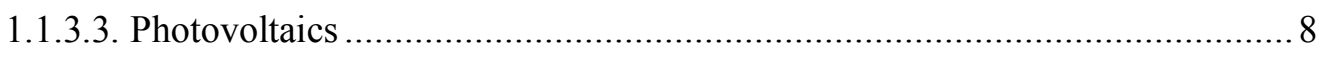

1.1.3.3.1. Dye-Sensitized solar cells .......................................................... 9

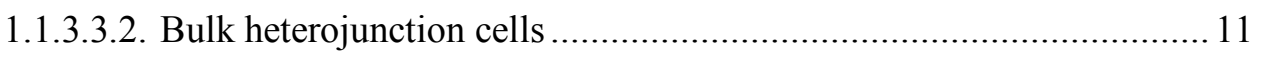

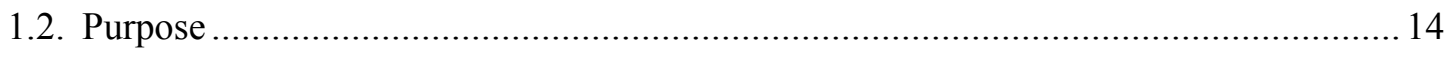

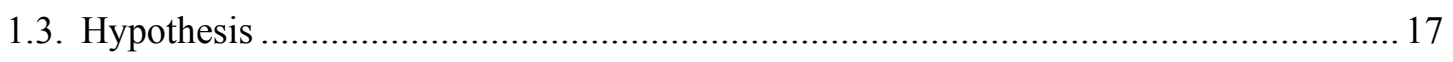

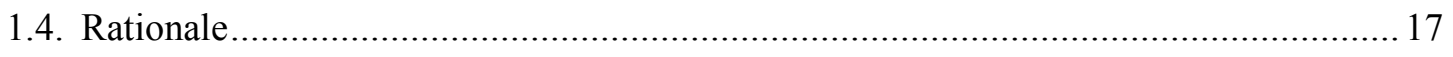

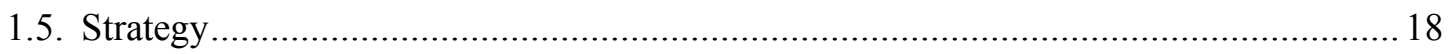

\section{CHAPTER 2:}

2. Porphyrin and ruthenium based materials for applications in photo-catalysis ......................20

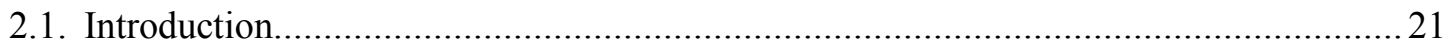

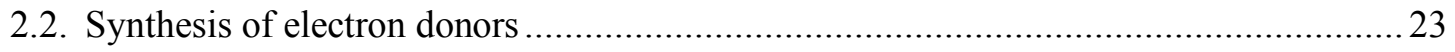

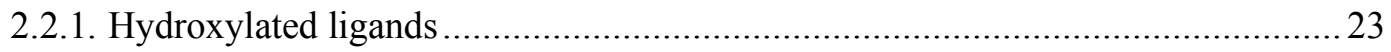

2.2.1.1. Synthesis of 4'-(4-hydroxyphenyl)-2,2':6',2"'-terpyridine $\left(\mathrm{L}^{2}\right) \ldots \ldots \ldots \ldots \ldots . . . . . .23$

2.2.1.2. Synthesis of 4' -(3-hydroxyphenyl)-2,2':6',2"'-terpyridine $\left(\mathrm{L}^{3}\right)$................... 24

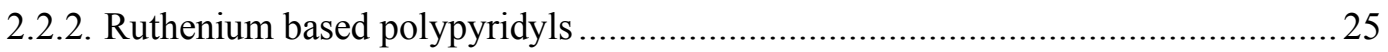

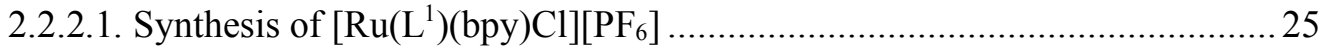

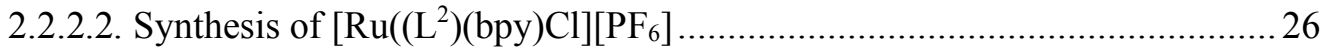

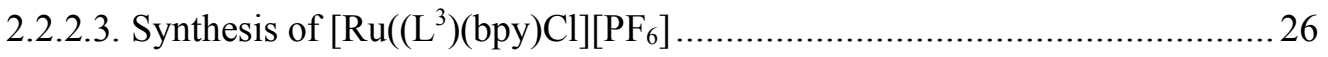

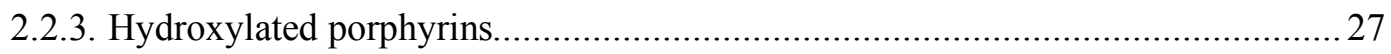

2.2.3.1. Synthesis of tetraphenolporphyrin (TPPOH) …................................. 27 
2.2.3.2. Synthesis of Zn-tetraphenolporphyrin (Zn-TPPOH) ...............................29

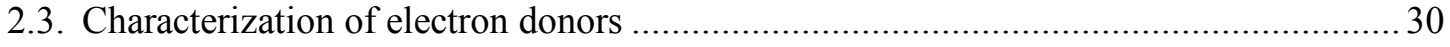

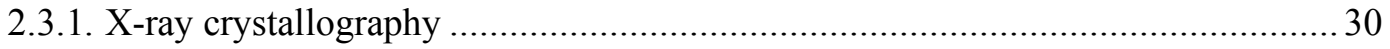

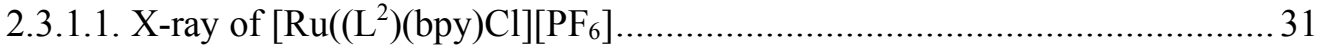

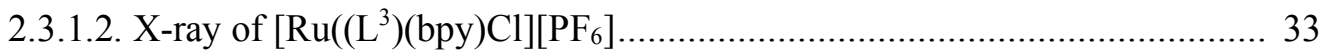

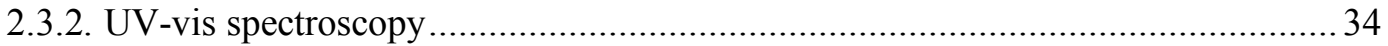

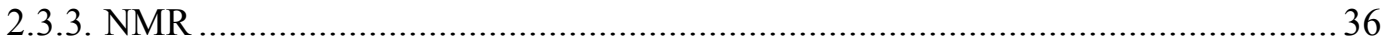

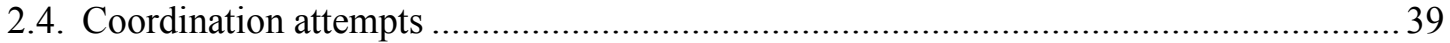

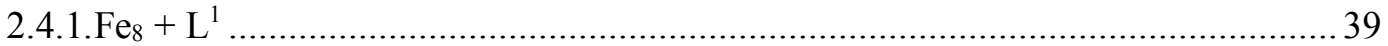

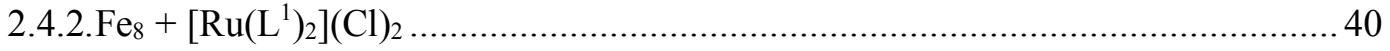

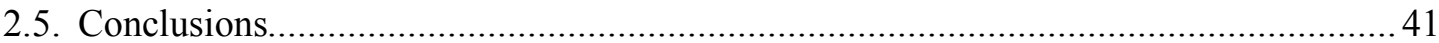

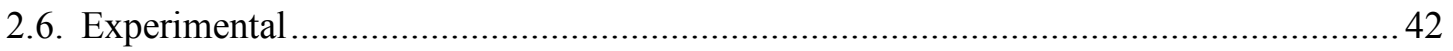

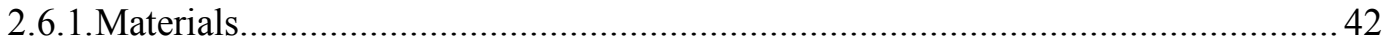

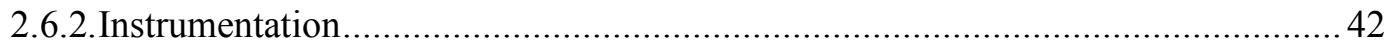

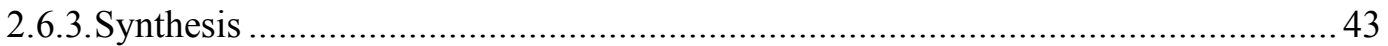

\section{CHAPTER 3:}

3. Synthesis and characterization of transition metal polypyridyls with dihydroxybipyridine ... 50

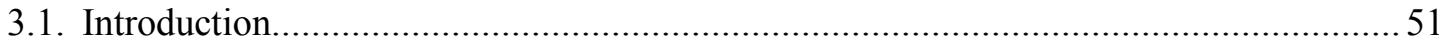

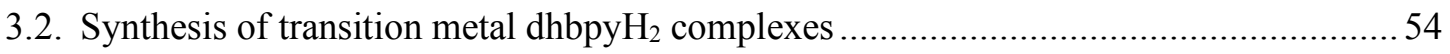

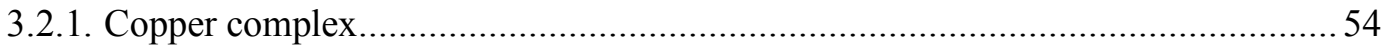

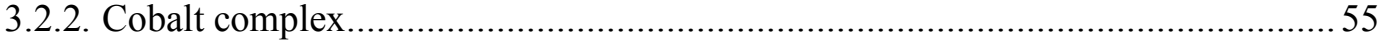

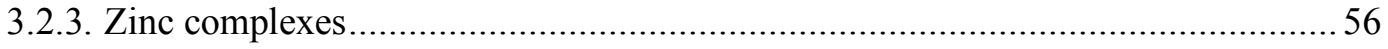

3.3. Characterization of transition metal $\mathrm{dhbpyH}_{2}$ complexes ........................................59

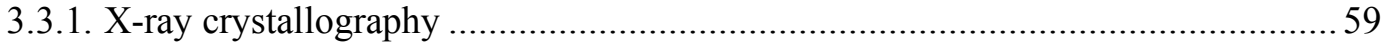

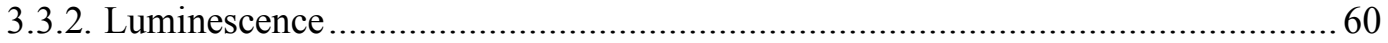

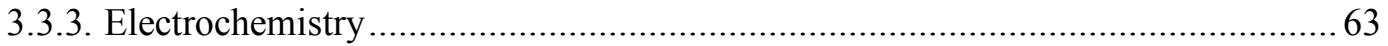

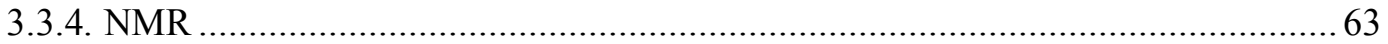

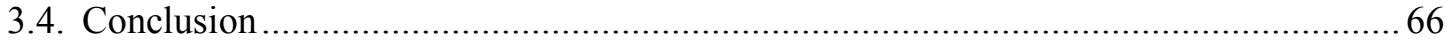

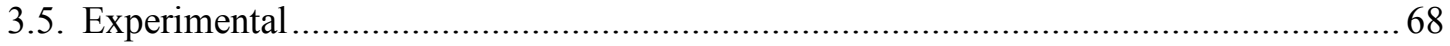

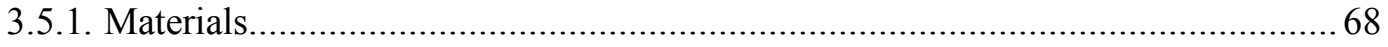

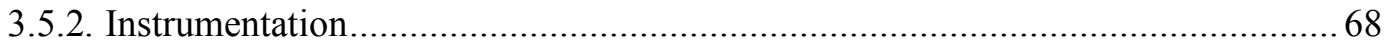




\section{CHAPTER 4:}

4. Preparation and characterization of hybrid materials for solar polymer cell applications ..... 72

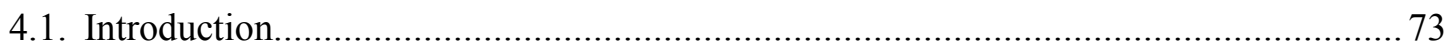

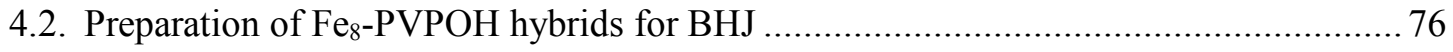

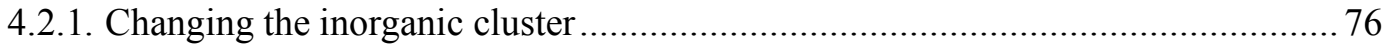

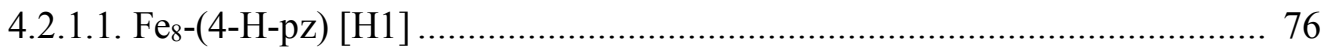

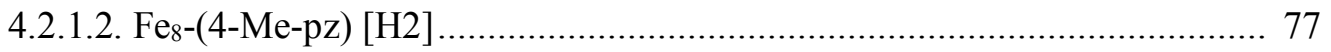

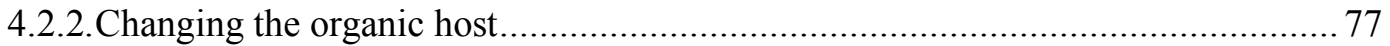

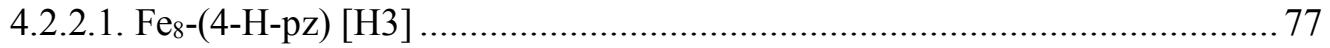

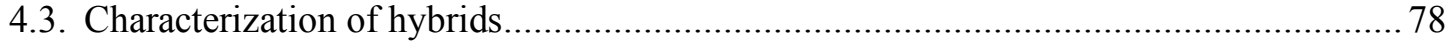

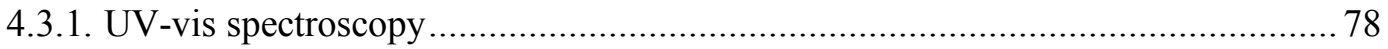

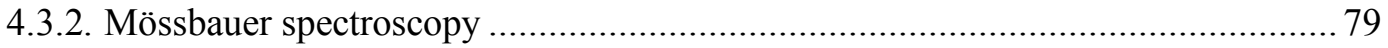

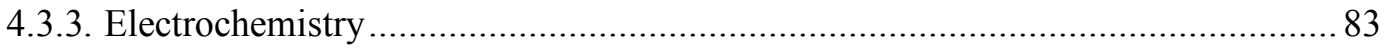

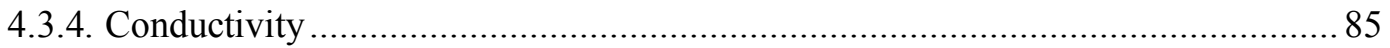

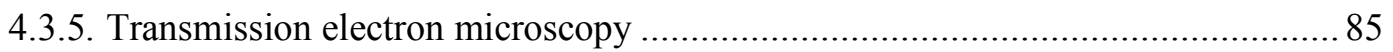

4.3.6. Scanning transmission electron microscopy with energy dispersive spectroscopy 87

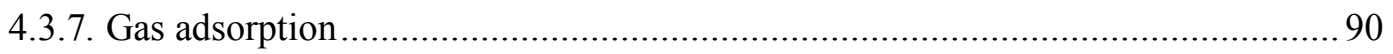

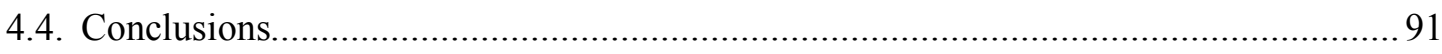

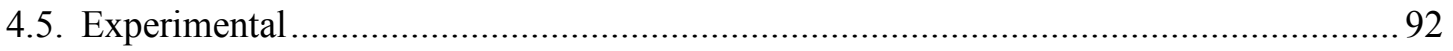

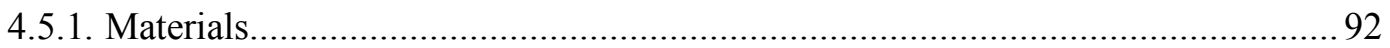

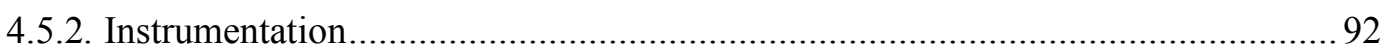

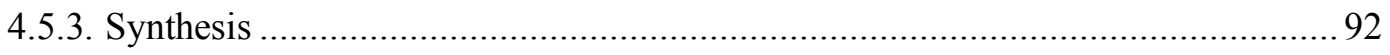

\section{CHAPTER 5:}

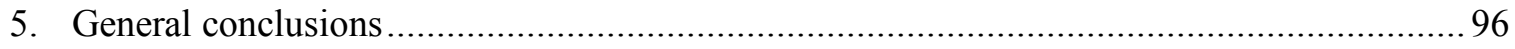

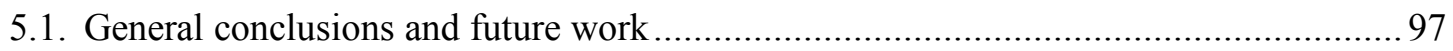

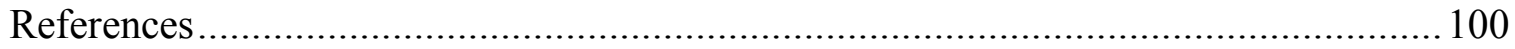

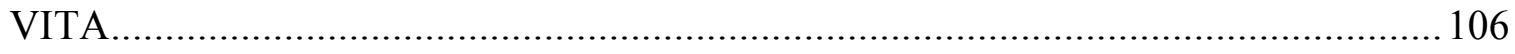




\section{LIST OF TABLES}

TABLE

PAGE

Table 1.1. $\mathrm{E}_{1 / 2}$ values for $\mathrm{Fe}_{8}$ compounds and $\mathrm{C}_{60}, 0.5 \mathrm{M} \mathrm{TBAPF} / \mathrm{CH}_{2} \mathrm{Cl}_{2} \ldots \ldots \ldots \ldots \ldots . . . . . .18$

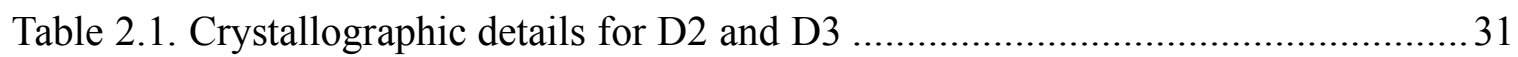

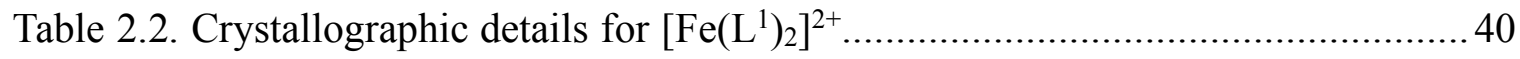

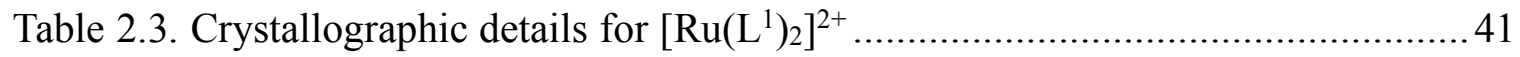

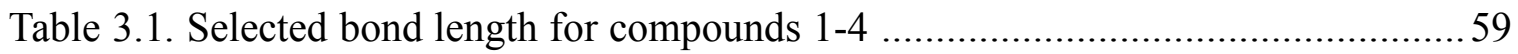

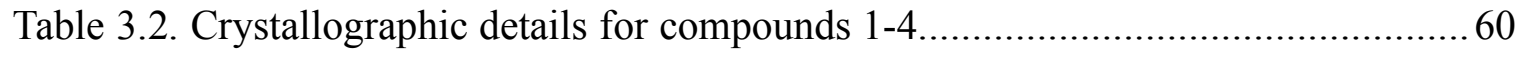

Table 3.3. Comparison of electrochemical and photophysical properties of 1-4 vs

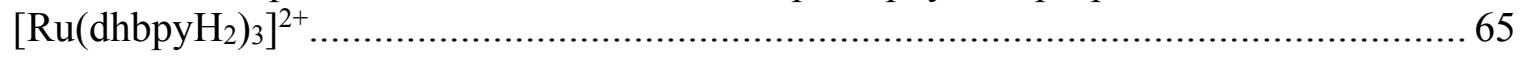

Table 4.1. Composition of the Fes-PVPOH hybrids .............................................. 76

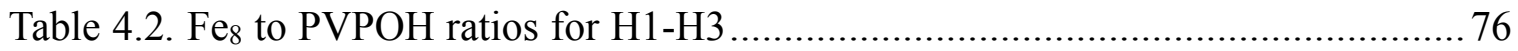

Table 4.3. Mössbauer parameters for the parent $\mathrm{Fe}_{8}$, a phenol substituted $\mathrm{Fe}_{8}$ and $\mathrm{H} 1$.... 82

Table 4.4. $\mathrm{E}_{1 / 2}$ values for $\mathrm{Fe}_{8}$ and phenol substituted $\mathrm{Fe}_{8}, 0.5 \mathrm{M} \mathrm{Bu}_{4} \mathrm{NPF}_{6} / \mathrm{CH}_{2} \mathrm{Cl}_{2} \ldots \ldots . .84$

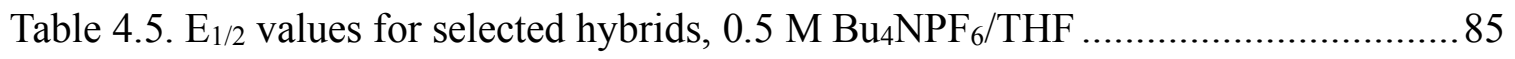




\section{LIST OF FIGURES}

FIGURE

PAGE

Figure 1.1. Example of a molecular dyad ................................................. 8

Figure 1.2. A) General processes involved in a DSSC. B) Electron migration to the anode

Figure 1.3. A) Morphology of current BHJ cells. B) Ideal architecture for BHJ cells... 14

Figure 1.4. Sticks and ball representation of the $\left[\mathrm{Fe}^{\mathrm{III}} 8(\mu-\mathrm{pz}){ }_{12} \mathrm{Cl}_{4}\right]$ cluster and its $\mathrm{Fe}_{8} \mathrm{O}_{4}$ core

Figure 2.1. Ellipsoid model of a) 4'-(4-hydroxyphenyl)-2,2':6',2'-terpyridine ( $\left.\mathrm{L}^{2}\right)$ and b) 4'-(3-hydroxyphenyl)-2,2':6',2'-terpyridine $\left(\mathrm{L}^{3}\right)$ at $50 \%$ probability 30

Figure 2.2. Ellipsoid model of $\left[\mathrm{Ru}\left(\mathrm{L}^{2}\right)(\mathrm{bpy}) \mathrm{Cl}\right]^{+}(\mathrm{D} 2)$ and $\left[\mathrm{Ru}\left(\mathrm{L}^{3}\right)(\mathrm{bpy}) \mathrm{Cl}\right]^{+}(\mathrm{D} 3)$ at $50 \%$ probability

Figure 2.3. Ball-and-stick model of the supramolecular arrangement of $\left[\mathrm{Ru}\left(\mathrm{L}^{2}\right)(\mathrm{bpy}) \mathrm{Cl}\right]^{+}$ 32

Figure 2.4. Ball-and-stick model of the supramolecular arrangement of $\left[\mathrm{Ru}\left(\mathrm{L}^{3}\right)(\mathrm{bpy}) \mathrm{Cl}\right]^{+}$ .33

Figure 2.5. UV-vis spectra of TPPOH (blue) and deprotonated TPPOH (orange)....... 35

Figure 2.6. UV-vis spectra of the zinc metalated TPPOH.................................. 35

Figure 2.7. $400 \mathrm{MHz}{ }^{1} \mathrm{H}$ NMR spectrum of $\left[\mathrm{Ru}\left(\mathrm{p}\right.\right.$-cymene)(bpy)Cl] ${ }^{+}$in $\mathrm{DMSO}-\mathrm{d}_{6} \ldots . .36$

Figure 2.8. $400 \mathrm{MHz}{ }^{1} \mathrm{H}$ NMR spectrum of 4'-(4-hydroxyphenyl)-2,2':6',2”terpyridine $\left(\mathrm{L}^{2}\right)$ in $\mathrm{DMSO}-\mathrm{d}_{6}$

Figure 2.9. $400 \mathrm{MHz}{ }^{1} \mathrm{H} \mathrm{NMR}$ spectrum of $\left[\mathrm{Ru}\left(\mathrm{L}^{2}\right)(\mathrm{bpy}) \mathrm{Cl}\right]^{+}$in $\mathrm{DMSO}-\mathrm{d}_{6} \ldots \ldots \ldots \ldots . . . . .37$

Figure 2.10. $400 \mathrm{MHz}{ }^{1} \mathrm{H}$ NMR spectrum of 4'-(3-hydroxyphenyl)-2,2':6',2”terpyridine $\left(\mathrm{L}^{3}\right)$ in $\mathrm{DMSO}-\mathrm{d}_{6}$ 38

Figure 2.11. $400 \mathrm{MHz}{ }^{1} \mathrm{H}$ NMR spectrum of $\left[\mathrm{Ru}\left(\mathrm{L}^{3}\right)(\mathrm{bpy}) \mathrm{Cl}\right]^{+}$in $\mathrm{DMSO}-\mathrm{d}_{6} \ldots \ldots \ldots . . . .38$

Figure 2.12. $400 \mathrm{MHz}{ }^{1} \mathrm{H}$ NMR spectrum of tetraphenolporphyrin in DMSO-d $6 \ldots \ldots . . .39$

Figure 2.13. Ellipsoid model of $\left[\mathrm{Fe}\left(\mathrm{L}^{1}\right)_{2}\right]^{2+}$ 40 
Figure 2.14. Ellipsoid model of $\left[\mathrm{Ru}\left(\mathrm{L}^{1}\right)_{2}\right]^{2+}$ 41

Figure 3.1. Architecture and mechanism of a DSSC ...............................................53

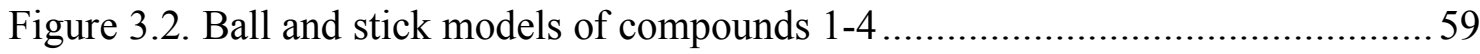

Figure 3.3. A) Absorption spectra and B) Emission spectra for compounds 1-4 in DMF 61

Figure 3.4. Absorption (solid) and emission spectra (broken) of 3 in DMF .................62

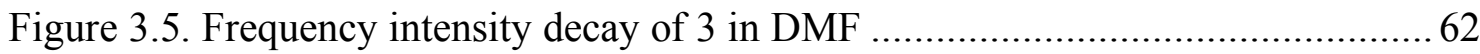

Figure 3.6. Cyclic voltammogram of 1 (solid) and 2 (dashed) ….................................. 63

Figure 3.7. $400 \mathrm{MHz}{ }^{1} \mathrm{H}-\mathrm{NMR}$ of $\left[\mathrm{Co}\left(\mathrm{dhbpyH}_{2}\right)_{3}\right]\left(\mathrm{ClO}_{4}\right)_{3}$ in $\mathrm{CD}_{3} \mathrm{OD} \ldots \ldots \ldots \ldots \ldots \ldots \ldots \ldots . . . . . . . . . . . . .65$

Figure 3.8. $100 \mathrm{MHz}{ }^{13} \mathrm{C}-\mathrm{NMR}$ of $\left[\mathrm{Co}\left(\mathrm{dhbpyH}_{2}\right)_{3}\right]\left(\mathrm{ClO}_{4}\right)_{3}$ in $\mathrm{CD}_{3} \mathrm{OD} \ldots \ldots \ldots \ldots \ldots \ldots \ldots . . . . . . . . . . .65$

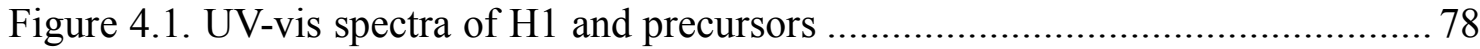

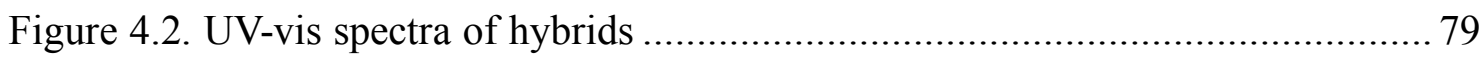

Figure 4.3. A) Ball and stick model of $\left[\mathrm{Fe}^{\mathrm{III}}{ }_{8}(\mu-4-\mathrm{H}-\mathrm{pz}){ }_{12} \mathrm{Cl}_{4}\right]$ B) Mössbauer

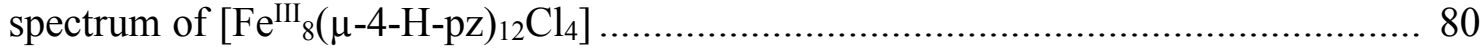

Figure 4.4. A) Ball and stick model of $\left[\mathrm{Fe}^{\mathrm{III}} 8(\mu-4-\mathrm{H}-\mathrm{pz})_{12}\left(\mathrm{O}\left(\mathrm{C}_{6} \mathrm{H}_{4}\right) \mathrm{COH}\right)_{4}\right]$

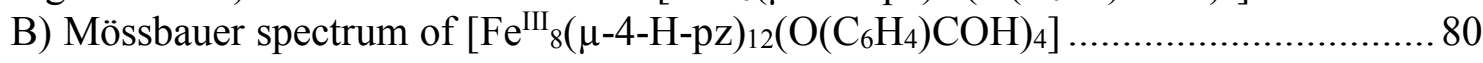

Figure 4.5. Mössbauer spectrum of $\mathrm{H1}$ at room temperature ……….......................... 81

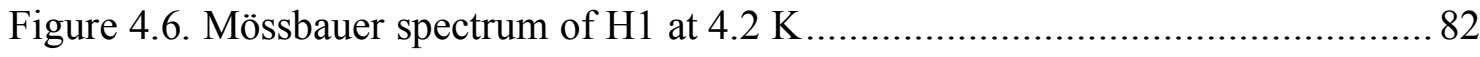

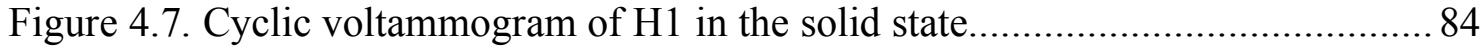

Figure 4.8. Differential pulsed voltammetry of selected hybrids................................. 84

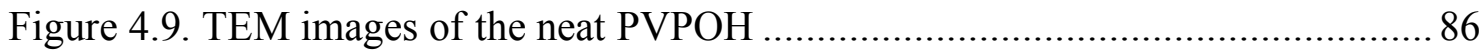

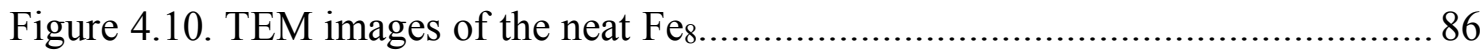

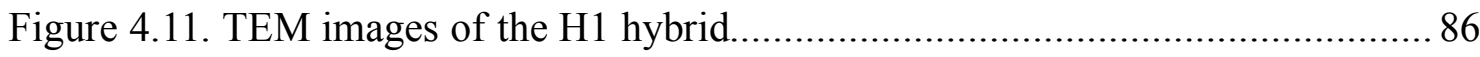

Figure 4.12. STEM images of PVPOH using HAADF and BF detectors..................... 88 
Figure 4.13. STEM images of $\mathrm{Fe}_{8}$ using HAADF and BF detectors ........................ 88

Figure 4.14. STEM images of H1 using HAADF and BF detectors ....................... 88

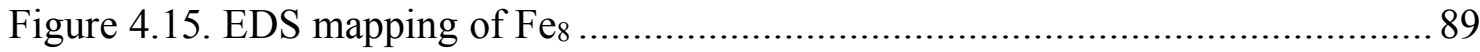

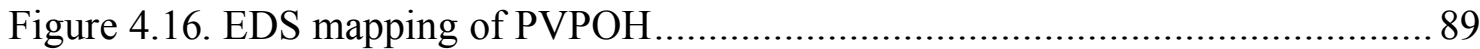

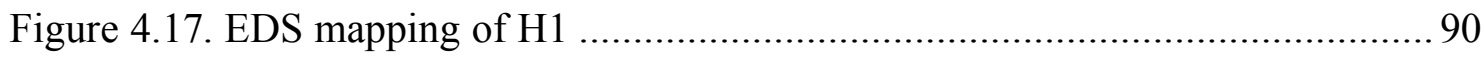

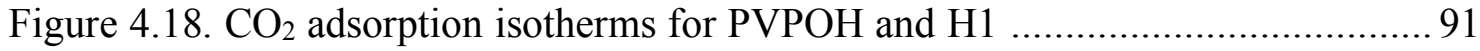

Figure 4.19. $\mathrm{CO}_{2}$ adsorption isotherms for PVPOH-co-MMA and $\mathrm{H} 3$...................... 91 


\section{TABLE OF SCHEMES}

SCHEME

PAGE

Scheme 1.1. Formation of a charge separated state in dyads and triads 5

Scheme 1.2. Thermodynamically allowed and forbidden electron migration processes . 6

Scheme 1.3. Kinetics of the electron migration process for a) dyad and b) triad........... 7

Scheme 1.4. Photo-induced electron transfer in BHJ......................................... 13

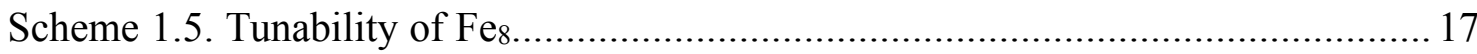

Scheme 2.1. Structures of terpyridine-based hydroxylated ligands $\mathrm{L}^{1}-\mathrm{L}^{3} \ldots \ldots \ldots \ldots \ldots \ldots . . \ldots 22$

Scheme 2.2. Free base tetraphenolporphyrin .................................................. 23

Scheme 2.3. Synthesis of 4'-(4-hydroxyphenyl)-2,2':6',2"'-terpyridine ( $\left.\mathrm{L}^{2}\right)$.............. 24

Scheme 2.4. Synthesis of 4'-(3-hydroxyphenyl)-2,2':6',2”-terpyridine $\left(\mathrm{L}^{3}\right)$.............. 25

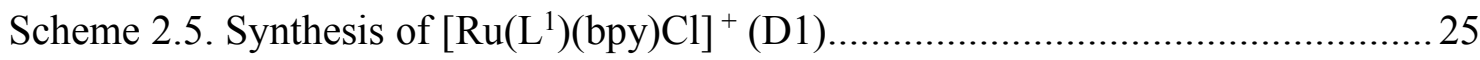

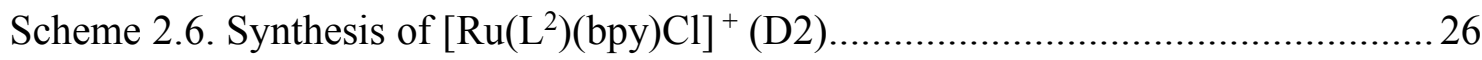

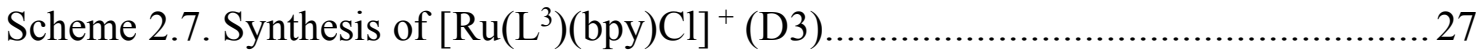

Scheme 2.8. Synthesis of tetraphenolporphyrin (D4) using strategy A ..................... 28

Scheme 2.9. Synthesis of tetraphenolporphyrin (D4) using strategy B .....................29

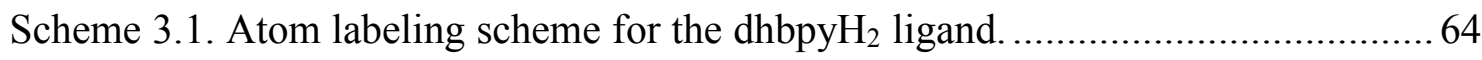

Scheme 4.1. Monomers of a) PVPOH and b) PVPOH-co-MMA............................... 75

Scheme 4.2. Substitution of $\mathrm{Fe}_{8}$ chlorides by phenol ................................... 75 


\section{ABBREVIATIONS AND ACRONYMS}

BHJ

bulk heterojunction

bpy

bipyridine

$\mathrm{C}_{60}$

fullerene

CSP

concentrated solar power

DCM

dichloromethane

dhbpyH $_{2}$

dihydroxybipyridine

DMF

dimethylformamide

DMSO

dimethylsulfoxide

DNA

deoxyribonucleic acid

DSSC

dye sensitized solar cell

EPR

electron paramagnetic resonance

ESI-MS

electrospray ionisation mass spectrometry

EtOH

ethanol

$\mathrm{Fc}$

ferrocene

$\mathrm{Fe}_{8}$

$\left[\mathrm{Fe}^{\mathrm{IIII}} 8(\mu-4-\mathrm{H}-\mathrm{pz}){ }_{12} \mathrm{Cl}_{4}\right]$

HOMO

highest occupied molecular orbital

ITO

indium doped tin oxide

LUMO

lowest unoccupied molecular orbital

$\mathrm{MeOH}$

methanol

NMR

nuclear magnetic resonance

PEDOT:PSS

poly(3,4-ethylenedioxythiophene) polystyrene sulfonate 


$\begin{array}{ll}\text { PS } & \text { photo-sensitizer } \\ \text { py } & \text { pyridine } \\ \text { pz } & \text { pyrazolate } \\ \text { pzH } & \text { pyrazole } \\ \text { qtpy } & \text { quaterpyridine } \\ \text { RBF } & \text { round bottom flask } \\ \text { THF } & \text { tetrahydrofuran } \\ \text { TPPOH } & \text { tetraphenolporphyrin } \\ \text { tpy } & \text { terpyridine } \\ \text { UV-vis } & \text { ultraviolet-visible }\end{array}$


Chapter 1: Introduction and Literature Review 


\subsection{Literature review}

\subsubsection{Current issues in energy demand}

Our world has become as dependent on an immense and ever-increasing amount of energy as it is on oxygen or water. So far, most of our energy requirements have been satisfied by non-renewable sources, such as fossil fuels. The scarcity or abundance of these fuel deposits has been a controversial topic for a while now. Some argue that we will run out of them in a few decades, others argue that we still have a good supply left, but what is indubitable is that we can no longer depend indefinitely on fossil fuels to sustain our demand. Either they will run short on us, or the repercussions of burning whatever deposits we have left will be disastrous to the environment.

\subsubsection{Alternative sources of energy}

Knowing this, substantial amount of time, money and effort have been invested in finding a solution to this fossil fuel dilemma. The alternatives are numerous and there are some obvious places to start. Some of the most promising alternative energy sources proposed include hydro, wind, nuclear, geothermal and solar energy. Some of the proposed alternatives have their own drawbacks, such as a possible life threatening nuclear disaster, or the eolic, hydro and geothermal insufficiency to satisfy the whole demand of energy. On the other hand, Earth receives $10^{5} \mathrm{TW}$ of solar energy each year, an amount that is orders of magnitude larger than the amount of energy consumed in the same lapse of time [1]. This inflow of solar energy will remain so for the foreseable 
future. Solar energy is both safe and sufficient and so, the best alternative to invest our time, money and effort [1].

\subsubsection{Solar energy}

There are three main ways to harness solar energy: thermally, chemically and by photovoltaic devices. Thermal harnessing involves the use of concentrated solar power (CSP) in large farms or fields to heat water [2]. Chemical harnessing involves the use of photo-activated catalysts to generate energy rich compounds that can be used as fuels at a later time (solar fuels) [3-5]. Photovoltaics is the direct conversion of photons into electricity by using well engineered solar cells that take advantage of the photovoltaic effect to produce an electric current [6].

\subsubsection{Thermal}

The most basic way of harnessing solar energy is to use the heat as an energy source to perform work. This is most commonly done by using mirrors to heat either water or a molten salt, which in turn heats the water to convert it into steam to power a steam engine.

\subsubsection{Photocatalysis}

The chemical-energy harnessing strategy, photocatalysis, is not new; it is the process plants, algae and bacteria have been employing for millennia. Light harvesting devices employing this technique seek to mimic Nature's method of creating redox 
equivalents as a way to store energy [1]. The stored energy can be used to perform multielectron reactions. Multi-electron processes can be performed by one N-electron process, where $\mathrm{N}$ electrons are released all at once, or as a cascade of $\mathrm{N}$ one-electron steps, or it can be performed by the cooperation of $\mathrm{N}$ one-electron processes coupled together. For the one N-electron process, a unit in the form of $\mathrm{D}^{\mathrm{N}+}-\mathrm{A}^{\mathrm{N}-}$ is required, whereas for the $\mathrm{N}$ one-electron processes $\mathrm{N} \mathrm{D}^{+}-\mathrm{A}^{-}$units are required, provided that the energy of these units is enough to carry out the desired multi-electron process. Nature has several processes that require multiple electrons, such as:

- Water Oxidation: $2 \mathrm{H}_{2} \mathrm{O} \longrightarrow 4 \mathrm{e}^{-}+4 \mathrm{H}^{+}+\mathrm{O}_{2}$

- Nitrogen fixation: $\mathrm{N}_{2}+8 \mathrm{H}^{+}+8 \mathrm{e}^{-}+16 \mathrm{ATP} \rightarrow 2 \mathrm{NH}_{3}+\mathrm{H}_{2}+16 \mathrm{ADP}+16 \mathrm{P}$

- Photosynthesis: $2 \mathrm{n} \mathrm{CO}_{2}+2 \mathrm{n} \mathrm{H}_{2} \mathrm{O}+2 \mathrm{n} \mathrm{e}^{-}+$photons $\rightarrow 2\left(\mathrm{CH}_{2} \mathrm{O}\right) n+2 \mathrm{n} \mathrm{O}_{2}$

These processes require multiple electron transfer events at a single reaction center [7]. It should be pointed out that Nature has chosen as the required reaction center for these transformations organometallic clusters, in the form of multinuclear metalloproteins.

So far, all the proposed solar energy-harvesting devices have the same basic concept at their core: a charge-separated state. The way to achieve this state varies from strategy to strategy, but it can be represented by a simplified scheme where there is an electron donor (D) and an electron acceptor (A) moiety in the molecule (Scheme 1.1). The arrangement of the electronically coupled acceptor-donor moiety is called a dyad; the second arrangement where the acceptor and donor are not linked directly to each other but rather joined by an antenna is called a triad. 

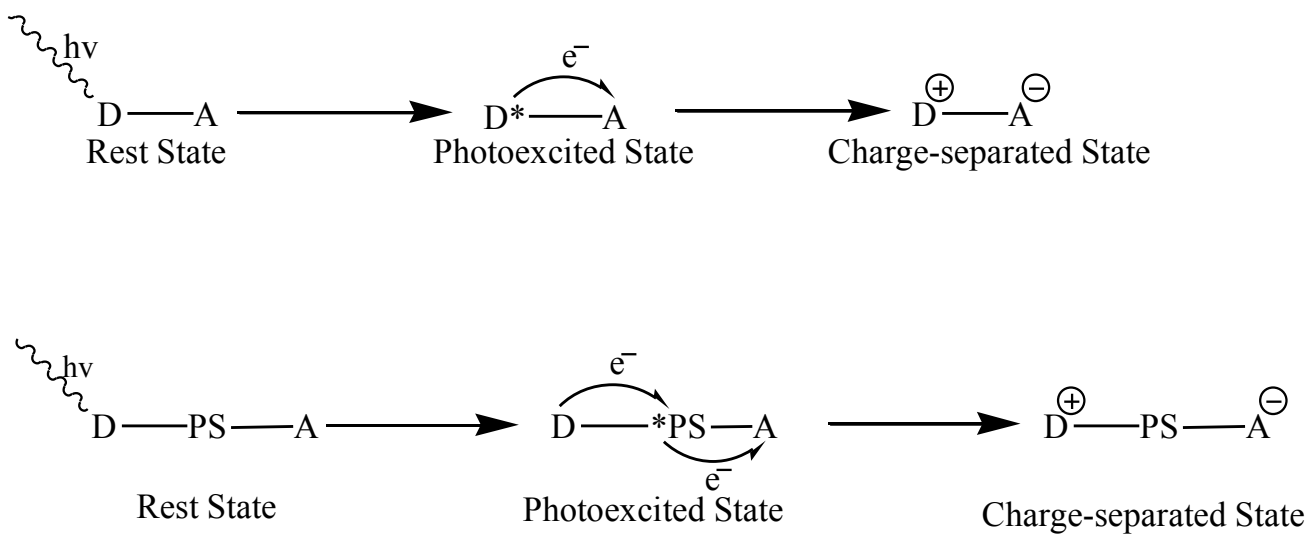

Scheme 1.1. Formation of a charge separated state in dyads and triads.

In the simplest form, with light excitation, the donor can transfer its excited electron to a vacant orbital in the acceptor of the dyad. The electron transfer leaves the donor with an overall positive charge and the acceptor with an overall negative charge. In the second type of complex, the triad, a new entity is placed between the donor and the acceptor. The new entity is called the antenna or photosensitizer (PS) and is a light harvesting moiety that when excited can accept an electron from the donor into its ground state and transfer the excited electron to the acceptor, thus facilitating the electron-hole migration. Antennas are required when a donor will readily give away an electron but is not easily photoexcited. The sequence of these steps has no particular order. An additional advantage of the triad assemblies is that they achieve a larger physical separation between donor and acceptor, discouraging the charge recombination process.

As with any electron transfer reaction, thermodynamics and kinetics dictate the feasibility and timescale of this process. The thermodynamic factor deals with the energy of the orbitals involved in the electron-hole migration. Optimizing the orbital levels in both donors and acceptors is necessary to ensure maximum efficiency. Simple 
thermodynamic analysis will tell us that the electron will only migrate from an orbital in the donor to a lower energy orbital of the acceptor for the dyad or of the photosensitizer for the triad assembly. The electron transfer thermodynamics for the dyad system is represented in the figure below (Scheme 1.2).

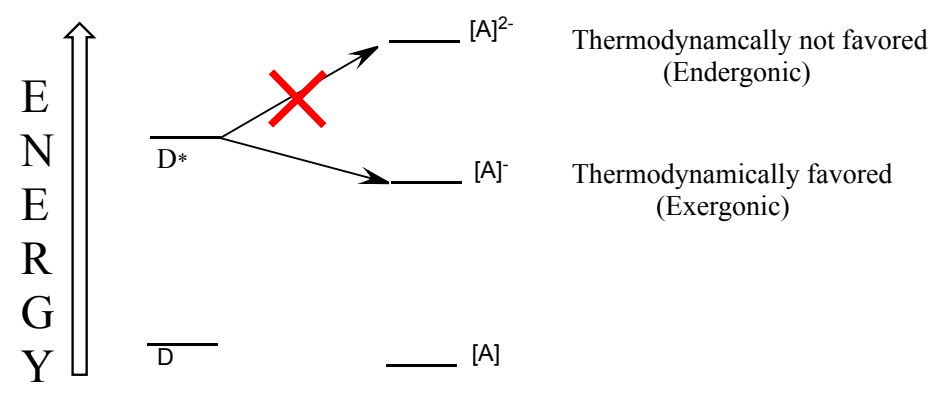

Scheme 1.2. Thermodynamically allowed and forbidden electron migration processes.

While thermodynamics is the first requisite for the process to be carried out, the kinetics will dictate if the process will occur in an appropriate time scale or even if it will occur at all. The kinetics involved in this process are complex as they involve the nonradiative and radiative relaxation of excited electrons back to the donor's ground state, migration of electrons to the acceptor and charge recombination. An a priori test for favorable kinetics is to determine how fast does an excited electron relax back to its ground state vis à vis how fast the electron can migrate to an orbital in either the acceptor or photosensitizer (Scheme 1.3). 


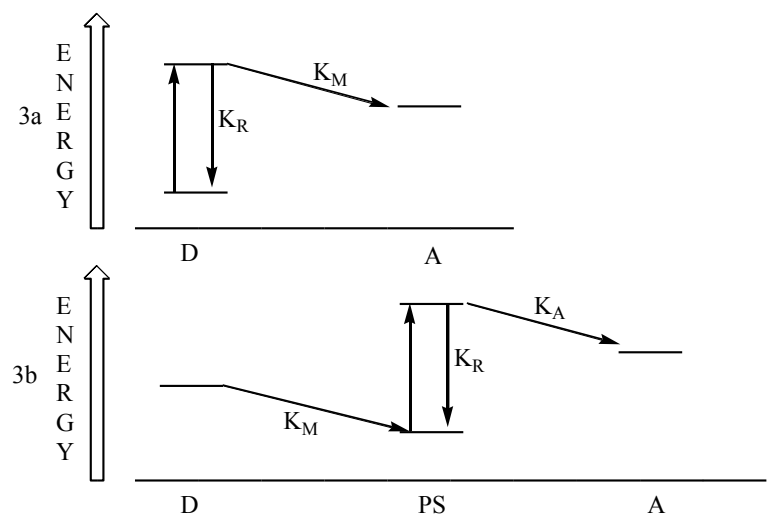

Scheme 1.3. The kinetics of the electron migration process for a) dyad and b)triad.

For the electron migration to be kinetically favored, the forward reaction, $\mathrm{k}_{\mathrm{M}}$, must be faster than the recombination reaction, $\mathrm{k}_{\mathrm{R}}$, and the larger that difference is, the better (Scheme 1.3a). The quantum efficiency of this process is defined as $\mathrm{k}_{\mathrm{M}} /\left(\mathrm{k}_{\mathrm{M}}+\mathrm{k}_{\mathrm{R}}\right)$. As stated above, high quantum efficiency is a highly desirable feature in dyads/triads. The kinetics for the triad assembly (Scheme 1.3b) is complicated because it involves a third species.

Delving into the details of the charge separation process, one can better appreciate some important features that the components of the dyad/triad must possess [8]. The first step mentioned was the photo-excitation of an electron in the donor or antenna, in the dyad or triad, respectively. Efficient light harvesting donors will have excitable electrons in the appropriate, or else, an antenna with the appropriate electrons and empty orbital to allow the electron-hole migration process. The second step in the process is the transfer of an electron from the donor to the acceptor, so a low energy charge migration path for the electron is a desired feature in the molecule; limiting the possible combinations of donors-acceptors to those with suitable orbital energies that will allow the process to occur in a satisfactory yield. Lastly, some of the most crucial factors in the process are 
the intermolecular and intramolecular charge recombination; these have to be taken into account when choosing an efficient donor-acceptor pair. Some of the most common donor in the literature are porphyrin and ruthenium polypyridyl derivatives with fullerenes serving the part of the electron acceptor. An example of such dyads is shown in figure $1.1[9,10]$.

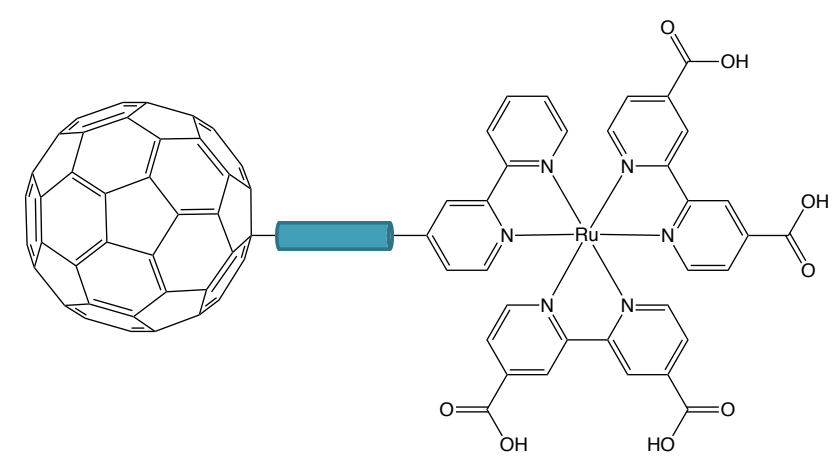

Figure 1.1. Example of a molecular dyad.

\subsubsection{Photovoltaics}

Harnessing solar energy by photovoltaics requires solar cells. Photovoltaic cells come in two very different varieties, polymer and inorganic cells. Inorganic cells, once the benchmark of photovoltaics, have been hampered by the high cost of fabrication, rigidity of the cells and difficult scalability [11]. On the other hand, we have the flexible polymer cells with low manufacturing costs, which make them ideal for mass implementation, but their efficiency only recently reached $15 \%$ [12].

Polymer solar cells can be further divided by their architecture. The most commonly employed designs are the Dye-sensitized solar cell (DSSC) and the bulk heterojunction cell (BHJ). There are some important aspects common to both architectures such as the need for an electron donor and an electron acceptor. 


\subsection{Dye-sensitized solar cells}

In DSSC, the electron donor is adsorbed on the surface of a mesoporous electron acceptor such as $\mathrm{TiO}_{2}$. Upon light excitation, the electron donor can transfer an electron to the acceptor. Ideally, that electron will find a path from the surface of the acceptor to the working electrode on which the acceptor has been grown. That electron will travel to a counter electrode, doing the work on the process, where it will come into close proximity with an electron shuttle, the redox couple. The redox couple will become reduced at the counter electrode and will diffuse until it comes close to the electron donor, which was left with a hole following the electron transfer. The redox couple regenerates the dye and the cycle can begin all over again [13-15]. Figure 1.2a depicts the electron transfer cycle that takes place inside the DSSC. The first step is the excitation of the donor by light followed by the electron transfer into the titania layer. The electron then travels from the anode to the cathode generating work in the process. Figure $1.2 \mathrm{~b}$ details the photo-electron traveling through the titania unto the anode. The selection of donor, acceptor and redox couple involves a delicate balance of trade offs to ensure the maximum efficiency possible.

Typical donors have been ruthenium dyes, with the N3, N719 and black dye as the standard against which other dyes are measured $[16,17]$. Substitution on the pyridine rings is used as a multipurpose tool to: tune orbital energies, anchor the dye to the acceptor, enhance solubility and create a physical separation to reduce charge recombination. Other metal-free dyes have been used with porphyrins reaching the highest efficiencies among them $[18,19]$. Although the specific requirements for a good 
photo-active electron donor are not trivial, the basic requirements include: panchromatic absorption, high molar extinction coefficients, long lived excited states, etc.

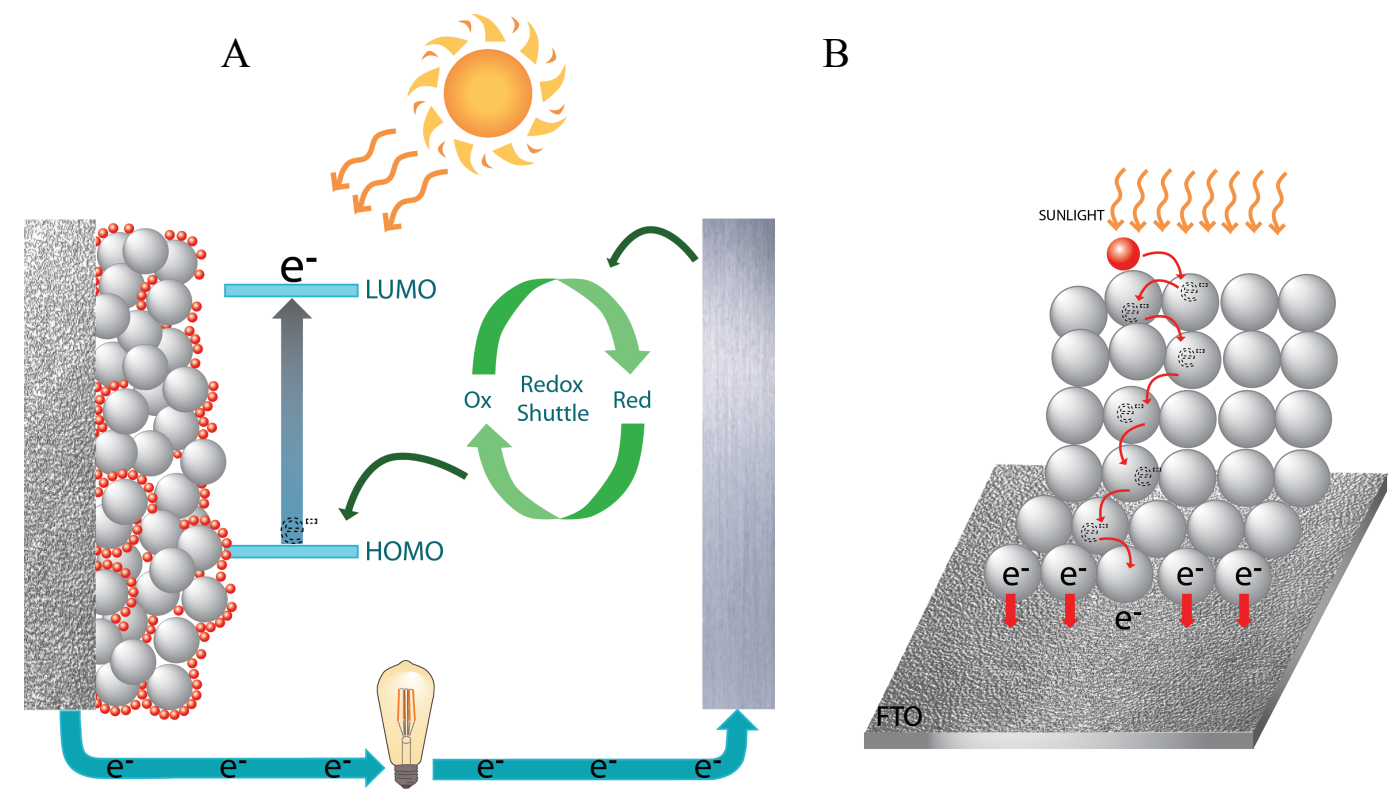

Figure 1.2. A) General processes involved in a DSSC. B) Electron migration to the anode

The electron acceptor of choice for DSSC has been $\mathrm{TiO}_{2}$. Titania exhibits the characteristics required to be an efficient electron donor, namely appropriate bad gap levels that match the available dyes, high electron mobility, mesoporosity and general robustness; with the added benefit of being non-toxic and abundant [20, 21]. Other metal oxides have been used as scaffolds, such as $\mathrm{SnO}_{2}$ and $\mathrm{ZnO}[22,23]$, but their efficiencies have not been as high as that of $\mathrm{TiO}_{2}$.

The last component of the DSSC is the redox shuttle, also known as the electrolyte. The redox shuttle, as the name implies will be in contact with the counter electrode where it will be reduced by the incoming electrons and it will transport that 
charge back into the dye where it will reduce the oxidized dye and in turn it will become oxidized, allowing for the cycle to start anew. As with the other functionalities of the DSSC there are some special requirements for the selection of a good redox shuttle [24]. These requirements include: redox stability, appropriate reduction potentials, slow recombination kinetics, and mobility. For the most part, the $\mathrm{I}^{-} / \mathrm{I}_{3}{ }^{-}$couple has been the preferred redox shuttle but recently other motifs have been tried with improved efficiencies [25]. The most promising so far are $\mathrm{Co}^{\mathrm{II}} / \mathrm{Co}^{\mathrm{III}}$ bipyridine complexes, which offer advantages over the iodide based electrolyte, such as lower overpotential, improved kinetics leading to higher collection efficiencies, lower optical absorption, and the versatility afforded by substituting the pyridine rings [14].

\subsection{Bulk heterojunction cells}

The other type of polymer solar cell is the BHJ cell. Although the same charge separation principle reigns over these cells, the architecture and mechanism to achieve this are different between these two systems. In BHJ cells an electron donor polymer and an electron acceptor polymer are blended to yield a photoactive layer where the donor and acceptor share a much larger interface area than in bi-layer heterojunction cells.

The architecture of a standard bulk-heterojunction solar cell usually consist of a photoactive layer on top of a conducting polymer layer, frequently poly $(3,4-$ ethylenedioxythiophene) polystyrene:sulfonate (PEDOT:PSS), that covers an ITO-coated glass anode. On top of the photoactive layer, the Aluminum/Silver cathode is deposited to 
complete the solar cell [26]. More recent generations of BHJ cells include additional layers as buffers or charge transport polymers to enhance its efficiency [27].

The mechanism by which a BHJ cell generates electricity has the same core charge separation principal as DSSC, but other than that is completely different. In the standard BHJ model, light shines through the transparent anode and irradiates the photoactive layer where, upon absorption, an exciton is generated. As a result of the dielectric nature of the medium, there is little incentive for the exciton to dissociate and generate free charges. With a Coulombic attraction well above thermal excitation at room temperature there is not enough energy to separate this hole-electron pair. The incorporation of an appropriate electron acceptor that has a LUMO with energy suitably located below the LUMO of the acceptor provides the driving force required to dissociate the exciton. Scheme 1.4 shows the photo-electron traveling from the donor to the acceptor and then to the cathode and the hole left by the electron traveling to the anode. These pathways are important as they are the driving forces that counters the charge recombination in this type of cells. Another exciton dissociation mechanism involves the photo-excitation of the electron acceptor. In this case the exciton is dissociated by hole transfer unto the electron donor, in this way both entities can take part in exciton separation. 


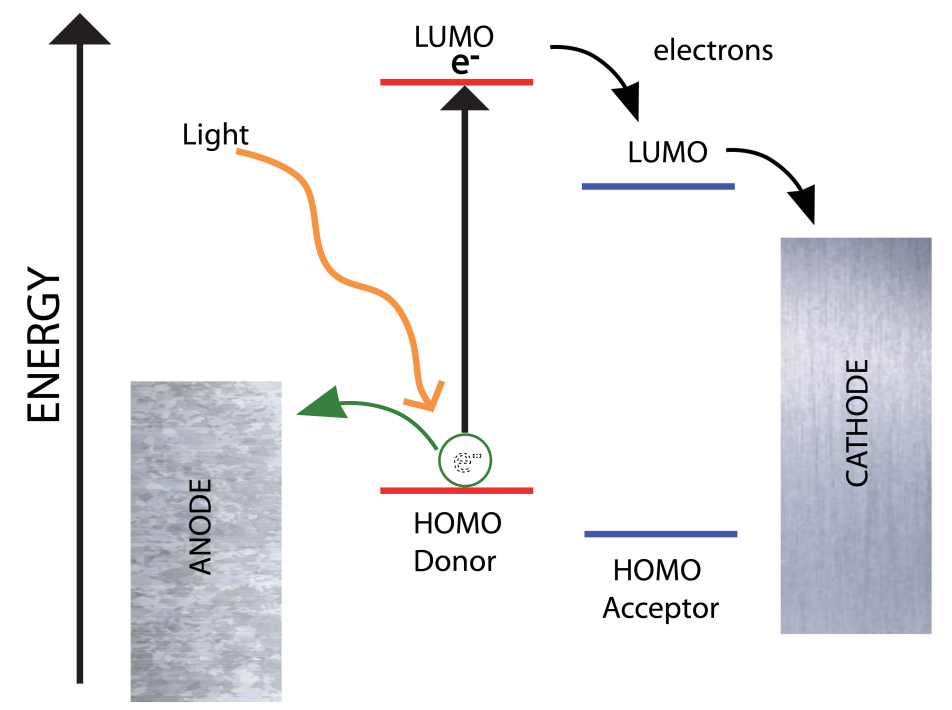

Scheme 1.4. Photo-induced electron transfer in BHJ.

Excitons have a diffusion range of approximately $10 \mathrm{~nm}$, the maximum distance the excited electron or hole can travel to generate the free charge [28]; which requires that the excited donor be within that distance from the nearest donor-acceptor interface. This distance limitation was the main motivation to investigate $\mathrm{BHJ}$ over the original bilayer heterojunction cells. The architecture of BHJ was designed as to maximize the interface area and minimize the lost energy from excitons generated deep inside the donor. Once the exciton has been generated and dissociated, the charges created need to migrate to the appropriate electrode. While BHJs improve the efficiency of exciton diffusion, their main drawback is the poor charge transport in the unorganized network of the donor-acceptor blend [29]. Current BHJ cell preparations result in isolated pockets containing both donors and acceptors that lack a pathway through the blend into the electrode, thus the free charges generated there are lost to recombination (Fig 1.3a). New designs are being studied to include the advantages of BHJ with those of bi-layer heterojunction cells (Fig 1.3b) [30]. 
A)

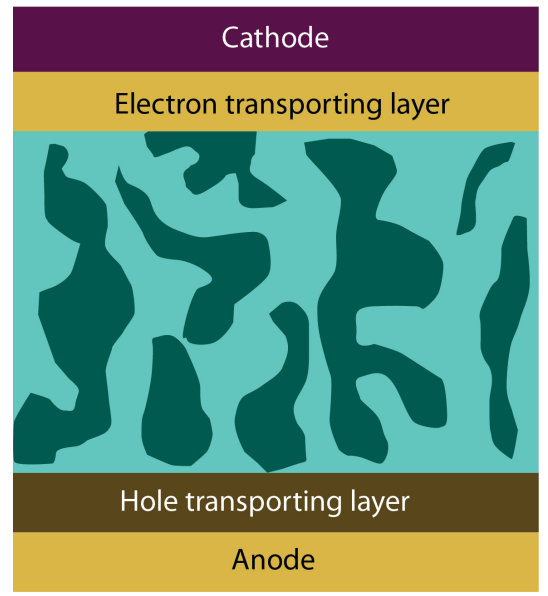

B)

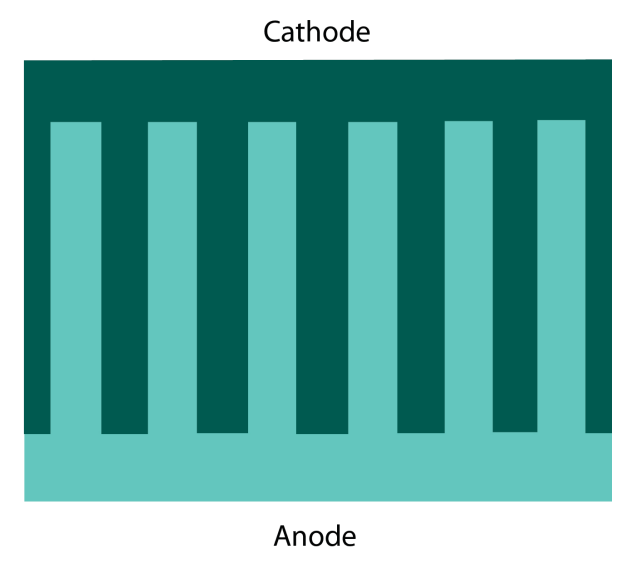

Figure 1.3. A) Morphology of current BHJ cells. B) Ideal architecture for BHJ cells.

\subsection{Purpose}

The ultimate objective of the research project is to demonstrate that an octanculear iron-oxo cluster, with formula $\left[\mathrm{Fe}^{\mathrm{III}} 8(\mu-\mathrm{pz})_{12} \mathrm{Cl}_{4}\right]\left(\mathrm{Fe}_{8}\right)$, and its derivatives are suitable candidates to substitute fullerenes in solar cells. To that end, we prepared $\mathrm{Fe}_{8}$ containing materials that can serve as precursors in photo-catalytic and photovoltaic applications.

The final goal of this research is two-fold: to synthesize molecular dyads with photosensitized electron donors and to prepare polymer-Fe 8 hybrids that are compatible with polymer electron donors.

$\left[\mathrm{Fe}^{\mathrm{III}} 8(\mu-\mathrm{pz})_{12} \mathrm{Cl}_{4}\right]$ acceptor:

As depicted in Figure 1.4, the cluster that our group first synthesized, features a $\mathrm{Fe}_{8} \mathrm{O}_{4}$ core and peripheral chlorides and pyrazolates [31]. Both the core and the 
peripheral substituents present features that make this cluster a superb electron acceptor. A brief description of some properties of the cluster is given to better understand its suitability as an acceptor.
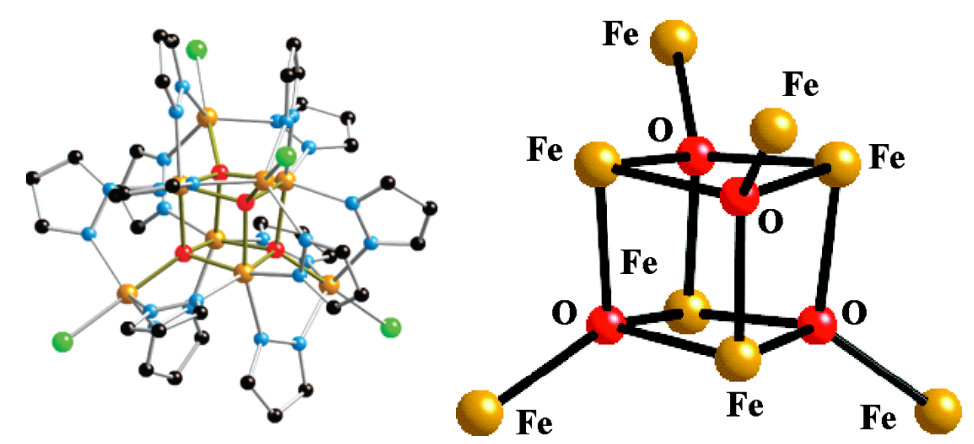

Figure 1.4. Sticks and ball representation of the $\left[\mathrm{Fe}^{\mathrm{III}} 8(\mu-\mathrm{pz}){ }_{12} \mathrm{Cl}_{4}\right]$ cluster and its $\mathrm{Fe}_{8} \mathrm{O}_{4}$ core.

$\mathrm{Fe}_{8} \mathrm{O}_{4}$ core:

The iron-oxygen core functions as an excellent electron sink with up to four reduced states [32]. Although fullerene (a typical electron acceptor used in model dyads and triads) can accept up to six electrons, reduction steps beyond the first one are rendered almost inaccessible because of the high reduction potential needed to achieve them. This iron-oxygen core's striking property is that, unlike fullerene, it can achieve its highly reduced states at a considerably lower reduction potential. Obviously, this vouches for the $\mathrm{Fe}_{8}$ complex as a better candidate for achieving a multiple charge separated state. Peripheral substitution:

The peripheral substitution of $\mathrm{Fe}_{8}$ accomplishes some important features that result in special properties of this cluster. For instance, the pyrazole wrapping prevents irreversible oxidation of the $\mathrm{Fe}_{8}$ core, a vital property for it to be an active redox center [33]. If the $\mathrm{Fe}_{8} \mathrm{O}_{4}$ core addresses the high reduction potential problem in fullerene, the 
peripheral substitution will target the solubility problem. Recalling from Fig. $4, \mathrm{Fe}_{8}$ has 12 pyrazoles bridging the peripheral and cubane irons. These pyrazoles can be and have been substituted at the 4-position [32,34], allowing for more polar or non-polar groups to tune the solubility of the whole cluster in various solvents. With this feature, the solubility problem can be put to rest. The solubility is not the only thing that can be manipulated by substituting the pyrazoles. As hinted above, peripheral substitution (including the 4-position in the pyrazoles) can affect the properties of the core, such as the reduction potential needed for achieving reduced states. In other words, substitutions in the outer shell allow for tunability of the cluster's redox activity, which in turn results in an advantage when coupling different donors, because we can better approach the optimal energy in the cluster's LUMO for efficient electron transfer. Besides the functionalization of the pyrazoles, the capping ligand can also be modified. The parent cluster has terminal chlorides but this can be substituted by other halides and pseudohalides as well as phenolates. The ability of phenolates to substitute chlorides provides a useful synthetic strategy to coordinate interesting motifs to the Fe 8 . Changing the capping ligands can also be used to tune the clusters LUMO orbitals. Recalling from the desired characteristics on the dyad assembly, a low energy charge migration path for the electron is a desired feature in the molecule. The high tunability of the $\mathrm{Fe}_{8}$ acceptor satisfies that requirement. The $\mathrm{Fe}_{8}$ acceptor has tunable energy levels of its reduced states and can thus be modified to improve interactions with any particular donor. The tunability of the $\mathrm{Fe}_{8}$ orbitals can be appreciated in Scheme 1.5. 

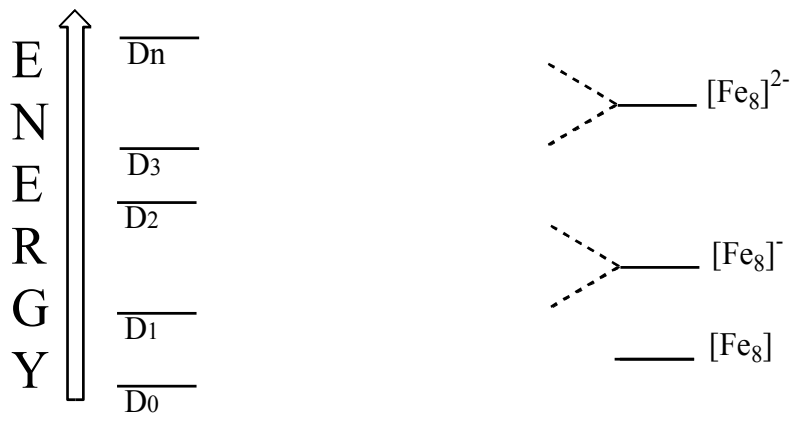

Scheme 1.5. Tunability of Fes.

For the chemical and photovoltaic strategies, an electron acceptor is needed. This work explores the properties of an iron-based electron acceptor and its possible incorporation in one of these strategies.

\section{$1.3 \quad$ Hypothesis}

This project will test the hypotheses that electron donors can be coordinated to $\mathrm{Fe}_{8}$ and that $\mathrm{Fe}_{8}$ hybrids can be formulated to exhibit the casting properties and proper miscibility for BHJ solar cells.

\subsection{Rationale}

The rationale behind this research is that the energy of a photo-excited donor that is not sufficient to carry out a second reduction of a common electron acceptor (e.g. $\mathrm{C}_{60}{ }^{-12-}$ ) should be sufficient to carry out this process on the more easily reduced $\mathrm{Fe}_{8}$ acceptor. A table with the values of these reductions is presented below. The values in bold are the reductions of $\mathrm{Fe}_{8}$ that occur at lower potentials than the first reduction of $\mathrm{C}_{60}$. 


\begin{tabular}{|c|c|c|c|c|c|}
\hline \multicolumn{2}{|l|}{ Potential $\left(\mathrm{V}\right.$, vs. $\left.\mathrm{Fc}^{+} / \mathbf{F c}\right)$} & \multirow[b]{2}{*}{$E_{1 / 2}(2)$} & \multirow[b]{2}{*}{$E_{1 / 2}(3)$} & \multirow[b]{2}{*}{$\begin{array}{l}E_{1 / 2} \\
(4)\end{array}$} & \multirow[b]{2}{*}{ Reference } \\
\hline & $E_{1 / 2}(1)$ & & & & \\
\hline$\left[\mathrm{Fe} 8\left(\mu_{4}-\mathrm{O}\right)_{4}(\mu-4-\mathrm{Me}-\mathrm{pz})_{12} \mathrm{Cl}_{4}\right]$ & -0.58 & -0.91 & -1.20 & -1.55 & 32 \\
\hline$\left[\mathrm{Fe}_{8}\left(\mu_{4}-\mathrm{O}\right)_{4}(\mu-4-\mathrm{H}-\mathrm{pz})_{12} \mathrm{Cl}_{4}\right]$ & -0.43 & -0.78 & -1.07 & -1.38 & 32 \\
\hline$\left[\mathrm{Fe}_{8}\left(\mu_{4}-\mathrm{O}\right)_{4}(\mu-4-\mathrm{Cl}-\mathrm{pz})_{12} \mathrm{Cl}_{4}\right]$ & -0.42 & -0.67 & -0.96 & -1.25 & 32 \\
\hline$\left[\mathrm{Fe}_{8}\left(\mu_{4}-\mathrm{O}\right)_{4}(\mu-4-\mathrm{Cl}-\mathrm{pz})_{12} \mathrm{Br}_{4}\right]$ & -0.33 & -0.62 & -0.89 & -1.16 & 35 \\
\hline$\left[\mathrm{Fe}_{8}\left(\mu_{4}-\mathrm{O}\right)_{4}(\mu-4-\mathrm{Cl}-\mathrm{pz})_{12}(\mathrm{NCS})_{4}\right]$ & -0.02 & -0.25 & -0.62 & -0.95 & 36 \\
\hline $\mathbf{C}_{60}$ & -1.03 & -1.44 & -1.94 & -2.42 & 37 \\
\hline
\end{tabular}

Table 1.1. $\mathrm{E}_{1 / 2}$ values for $\mathrm{Fe}_{8}$ compounds and $\mathrm{C}_{60}, 0.5 \mathrm{M} \mathrm{Bu}_{4} \mathrm{NPF}_{6} / \mathrm{CH}_{2} \mathrm{Cl}_{2}$.

\subsection{Strategy}

To achieve the long term goal of this project we developed two parallel subprojects:

A. Synthesis of electron donors containing functional groups that will allow further coordination to an electron acceptor.

Subproject A will explore the possibility of substituting the terminal chlorides of $\mathrm{Fe}_{8}$ complexes by phenolate-functionalized electron donors that bear the phenolate functionality. Specifically, we will synthesize modified versions of well-known electron donors to bear the required phenol functional group and attempt to coordinate these electron donors to the $\mathrm{Fe}_{8}$ cluster in order to study the electron transfer properties. For this subproject, ruthenium polypyridyl complexes and tetraphenylporphyrins modified with pendant phenol groups will be prepared.

B. Synthesis of $\mathrm{Fe}_{8}$-based electron acceptors.

The synthesis of dyads for photocatalytic applications is not the only way to study $\mathrm{Fe}_{8}$ as an electron acceptor in the field of solar energy. Another strategy is to use $\mathrm{Fe}_{8}$ in 
bulk as an electron acceptor for photovoltaic cells. Subproject B aims to prepare a hybrid material based on $\mathrm{Fe}_{8}$ that can be used as a substitute of common electron acceptors in photovoltaic cells. To this end, $\mathrm{Fe}_{8}$ will be imbedded into a polymer matrix that can be mixed with known polymeric electron donors. 
Chapter 2: Porphyrin and ruthenium based materials for applications in photocatalysis 


\subsection{Introduction}

Ruthenium dyes have been thoroughly studied since first reported as photosensitizers by Grätzel et al. in 1991 [20]. Despite all the research that has already been done, the field remains an active one with a great deal of attention given to the design of ligands that can enhance the photo-physical properties or confer chemical attributes to the complexes that could be used to anchor it to surfaces or other materials. Although the breadth of ligand types explored is wide, it has been dominated mainly by polypyridyls, in particular bipyridine (bpy) and terpyridine (tpy) derivatives. Even among these ligands there are some relatively unexplored areas that are recently being explored. One of these niches is the field of hydroxylated derivatives of polypyridyl ruthenium complexes.

As detailed in the introduction, $\mathrm{Fe}_{8}$ is a versatile motif that can be extensively modified. The pyrazoles can be substituted on the 4-position allowing for the tuning of solubility and electronic properties. Another advantage of the $\mathrm{Fe}_{8}$ cluster is its ability to coordinate phenols to the outer iron atoms by substituting the terminal halides. Unpublished results from our research group have demonstrated that full phenol coordination can be achieved and these new motifs have been structurally and electrochemically characterized. Crystal structures have been determined for most of these complexes, allowing us to establish clear patterns for other characterization methods such as: ${ }^{57} \mathrm{Fe}-\mathrm{Mössbauer}, \mathrm{NMR}, \mathrm{EPR}, \mathrm{IR}$ and UV-vis. These results pave the way for a powerful synthetic strategy to coordinate electron donors and other entities to $\mathrm{Fe}_{8}$ to generate new motifs with interesting properties. 
Our interest in phenol groups led us to synthesize hydroxylated ligands with the goal of preparing photo-active electron donors that can be coordinated to $\mathrm{Fe}_{8}$. Ruthenium is the obvious choice for this purpose, since it makes well-known photo-active electron donor complexes and there is already some literature on its hydroxylated polypyridine complexes [38-41]. After successfully synthesizing the tris-dihydroxybipyridine complex, we faced a synthetic logistic challenge of having six pendant phenolic groups that lead to the formation of an insoluble precipitate, the identity of which has not been determined (presumably by forming extensive intermolecular H-bonded networks). For this reason, 4,4'-dihydroxybipyridine was substituted by 4-hydroxyterpyridine (L $\left.{ }^{1}\right)$, 4-(4hydroxyphenyl)-terpyridine $\left(\mathrm{L}^{2}\right)$, and 4-(3-hydroxyphenyl)-terpyridine $\left(\mathrm{L}^{3}\right)$ (Scheme 2.1). The homoleptic complexes of these ligands were prepared but coordination to $\mathrm{Fe}_{8}$ was also unsuccessful. To discard the possibility of polymers being formed, heteroleptic complexes bearing a chloride, a bipyridine and a hydroxylated terpyridine ligand were prepared and characterized.

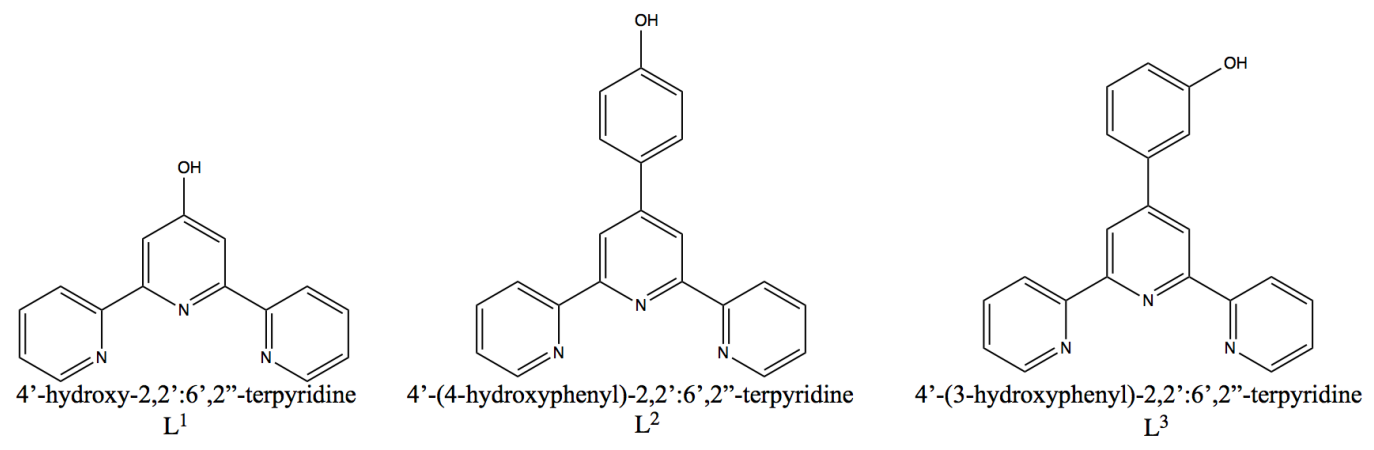

Scheme 2.1. Structures of terpyridine-based hydroxylated ligands $L^{1}-L^{3}$

To widen the options for the preparation of dyads, another type of photo-active electron donors were synthesized. These new type was the meso-substituted porphyrins 
with phenol groups. Porphyrins have long been used as photo-sensitizers and electron donors in dyads systems, either covalently bonded or just in close proximity to the acceptor $[18,19,42]$. Following Adler's method, pyrrole and para-hydroxybenzaldehyde were reacted to yield 4-hydroxyphenyl porphyrin (TPPOH) (Scheme 2.2) [43]. The free porphyrin was subsequently metalated using zinc to prevent any iron from the $\mathrm{Fe}_{8}$ binding to the macrocycle.

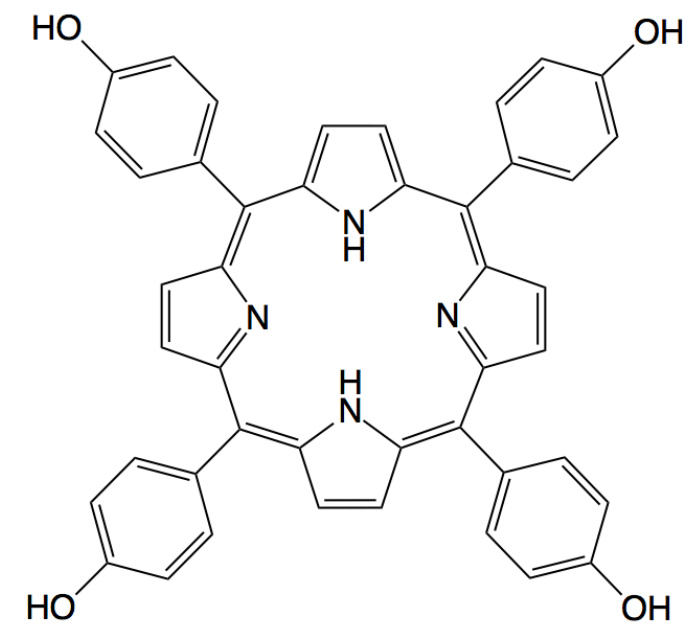

Scheme 2.2. Free base tetraphenolporphyrin

\subsection{Synthesis of electron donors}

\subsubsection{Hydroxylated ligands}

\subsubsection{Synthesis of 4'-(4-hydroxyphenyl)-2,2':6',2'-terpyridine $\left(L^{2}\right)$}

The ligand was synthesized using a modified procedure of that reported by Dares et al. (Scheme 2.3) [44]. The 2-acetylpyridine, 4-hydroxybenzaldehyde, $\mathrm{NH}_{4} \mathrm{OH}$ and $\mathrm{NaOH}$ were mixed, stirred, and refluxed for $48 \mathrm{~h}$. The reaction mixture was then allowed 
to cool to room temperature, and the precipitate formed separated by filtration and suspended and stirred in acetic acid. Afterwards the product was washed with water and diethylether and dried under high vacuum. Crystals were grown from a slow diethylether vapor diffusion into a methanolic solution of the compound.

2

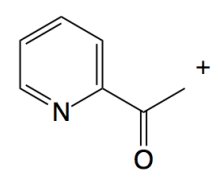

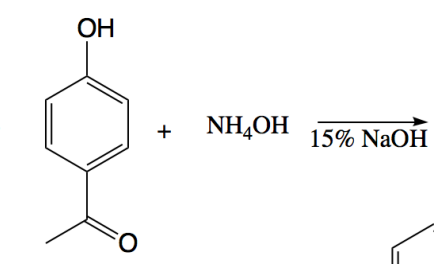

$\overrightarrow{15 \% \mathrm{NaOH}}$

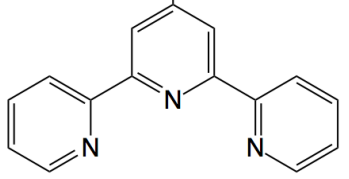

Scheme 2.3. Synthesis of 4'-(4-hydroxyphenyl)-2,2':6',2"'-terpyridine $\left(\mathrm{L}^{2}\right)$

\subsubsection{Synthesis of 4'-(3-hydroxyphenyl)-2,2':6',2"-terpyridine $\left(L^{3}\right)$}

The ligand was synthesized using a modified procedure of that reported by Dares

et al. (Scheme 2.4) [44]. The 2-acetylpyridine, 3-hydroxybenzaldehyde, $\mathrm{NH}_{4} \mathrm{OH}$ and $\mathrm{NaOH}$ were mixed, stirred, and refluxed for $48 \mathrm{~h}$. The reaction mixture was then allowed to cool to room temperature, and the precipitate formed separated by filtration and suspended and stirred in acetic acid. Afterwards the product was washed with water and ether and dried under high vacuum. Crystals were grown from a slow diethylether vapor diffusion into a methanolic solution of the compound. 
2<smiles>[CH2+]C(=O)c1ccccn1</smiles><smiles>CC(=O)c1cccc(OCCOCCOCCO)c1</smiles>

$\overrightarrow{5 \% \mathrm{NaOH}}$<smiles>Oc1cccc(-c2ccccn2)n1</smiles>

Scheme 2.4. Synthesis of 4'-(3-hydroxyphenyl)-2,2':6',2"-terpyridine $\left(\mathrm{L}^{3}\right)$

\subsubsection{Ruthenium based polypyridyls}

\subsubsection{Synthesis of $\left[\mathrm{Ru}\left(\mathrm{L}^{1}\right)(\mathrm{bpy}) \mathrm{Cl}\right][\mathrm{PF} 6](\mathrm{D} 1)$}

$\left[\mathrm{Ru}\left(\mathrm{L}^{1}\right)(\mathrm{bpy}) \mathrm{Cl}\right]\left[\mathrm{PF}_{6}\right]$ was prepared following a modified strategy based on that reported by Marelius et al. (Scheme 2.5) [45]. Dichloro(p-cymene)ruthenium dimer was reacted with $\mathrm{L}^{1}$ in $\mathrm{DCM} / \mathrm{THF}$. The reaction gave a dark red intermediate that was subsequently washed and dried and reacted with a bpy under reflux. The resulting solution was concentrated and $\mathrm{NH}_{4} \mathrm{PF}_{6}$ was added to precipitate the product. Crystals were grown from a slow diethylether vapor diffusion into a methanolic solution of the compound.

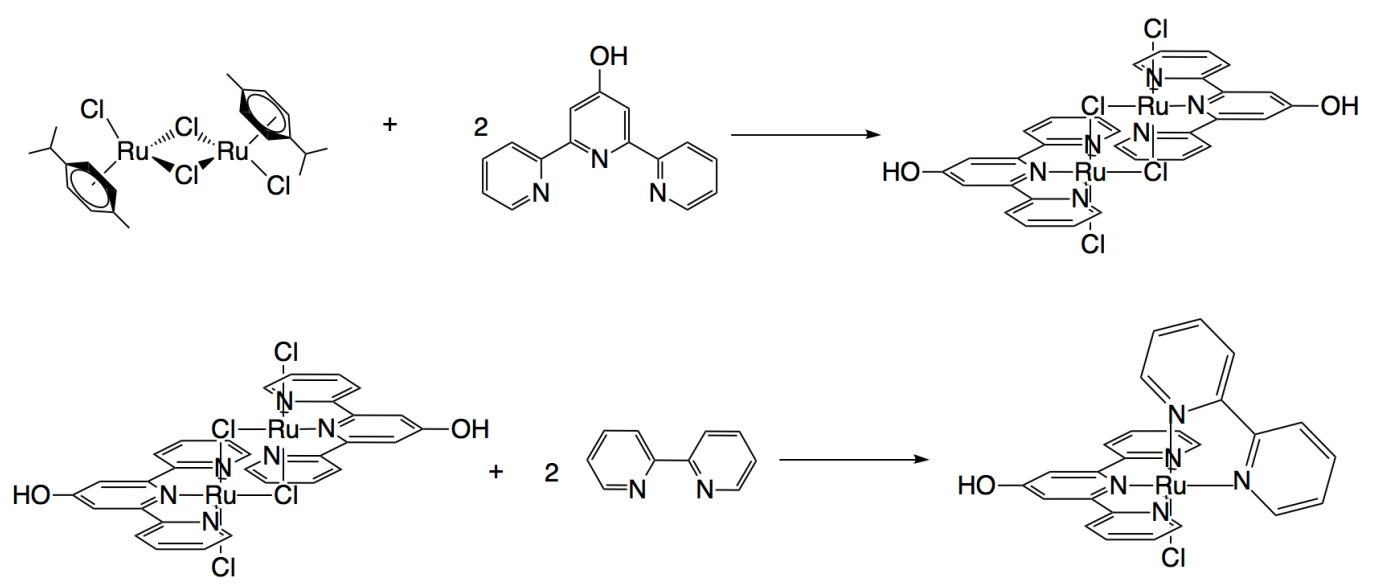

Scheme 2.5. Synthesis of $\mathrm{Ru}\left(\mathrm{L}^{1}\right)(\mathrm{bpy}) \mathrm{Cl}$ (D1) 


\subsubsection{Synthesis of $\left[\mathrm{Ru}\left(\left(\mathrm{L}^{2}\right)(\mathrm{bpy}) \mathrm{Cl}\right]\left[\mathrm{PF}_{6}\right](\mathrm{D} 2)\right.$}

$\left[\mathrm{Ru}\left(\left(\mathrm{L}^{2}\right)(\mathrm{bpy}) \mathrm{Cl}\right]\left[\mathrm{PF}_{6}\right]\right.$ was prepared following a modified strategy based on that reported by Marelius et al. (Scheme 2.6) [45]. Dichloro(p-cymene)ruthenium was reacted with $\mathrm{L}^{2}$ to afford a purple intermediate. The solid was refluxed in methanol with bpy after which the methanol was removed and the solid obtained was dissolved in a minimum amount of water and precipitated as the $\mathrm{PF}_{6}^{-}$salt. Crystals were grown from a slow diethylether vapor diffusion into a methanolic solution of the compound.

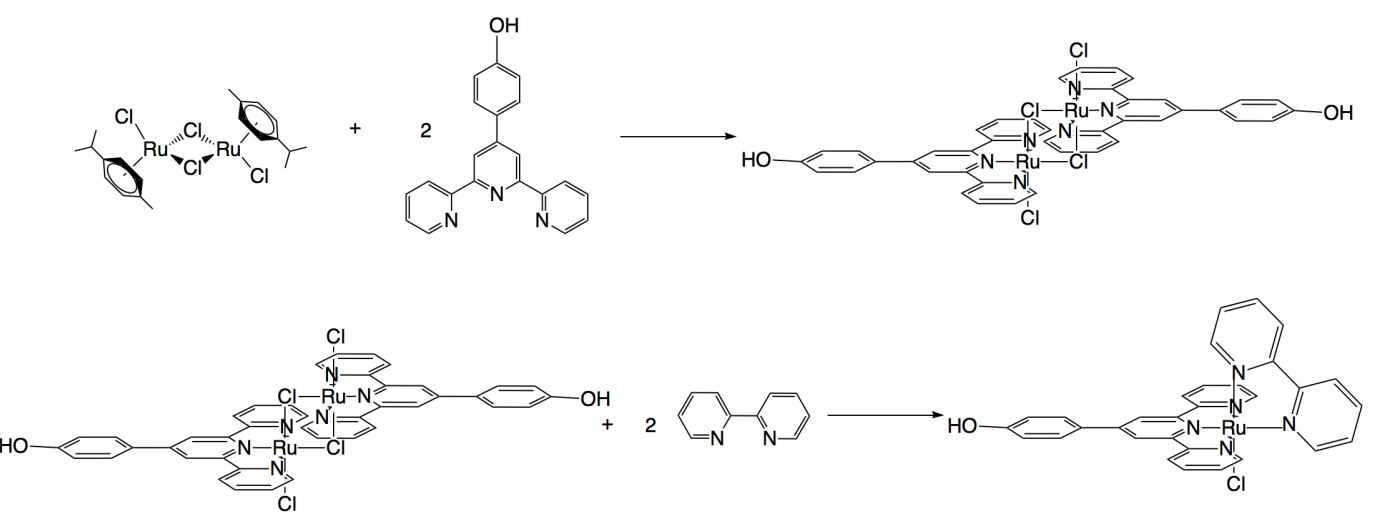

Scheme 2.6. Synthesis of $\mathrm{Ru}\left(\mathrm{L}^{2}\right)(\mathrm{bpy}) \mathrm{Cl}$ (D2)

\subsubsection{Synthesis of $\left[\mathrm{Ru}\left(\left(\mathrm{L}^{3}\right)(\mathrm{bpy}) \mathrm{Cl}\right]\left[\mathrm{PF}_{6}\right](\mathrm{D} 3)\right.$}

$\left[\mathrm{Ru}\left(\left(\mathrm{L}^{3}\right)(\mathrm{bpy}) \mathrm{Cl}\right]\left[\mathrm{PF}_{6}\right]\right.$ was prepared following a modified strategy based on that reported by Marelius et al. (Scheme 2.7) [45]. Dichloro(p-cymene)ruthenium dimer was reacted with $\mathrm{L}^{3}$ to afford a purple intermediate. The solid was refluxed in methanol with bpy after which the methanol was removed and the solid obtained was dissolved in a minimum amount of water and precipitated as the $\mathrm{PF}_{6}{ }^{-}$salt. Crystals were grown from a slow diethylether vapor diffusion into a methanolic solution of the compound. 

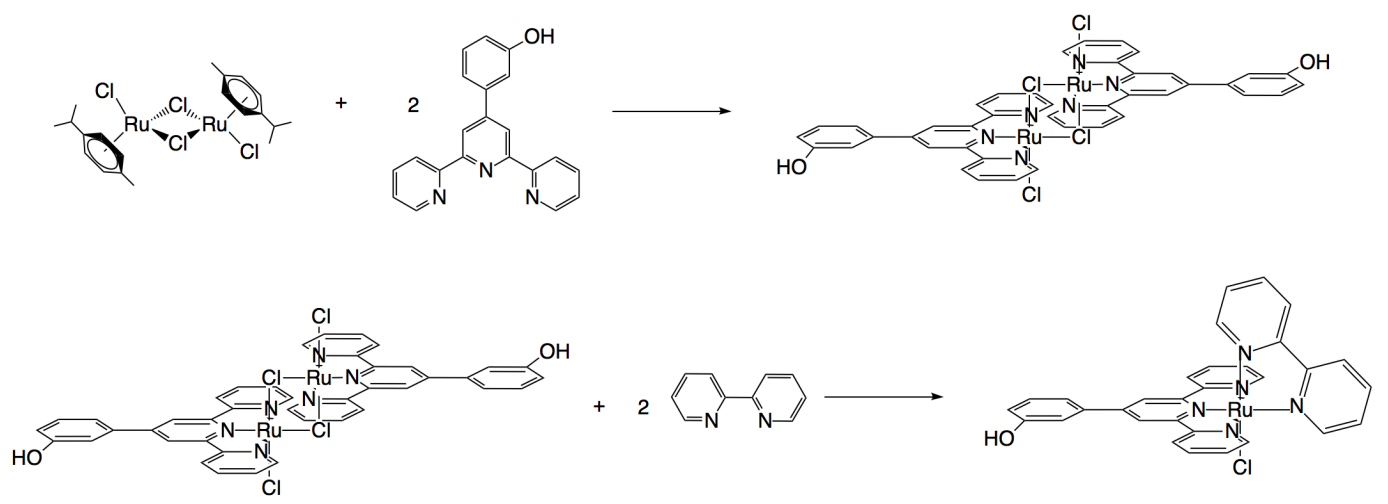

Scheme 2.7. Synthesis of $\mathrm{Ru}\left(\mathrm{L}^{3}\right)(\mathrm{bpy}) \mathrm{Cl}(\mathbf{D} 3)$

\subsubsection{Hydroxylated porphyrins}

\subsubsection{Synthesis of tetraphenolporphyrin (TPPOH) (D4)}

The synthesis of TPPOH was achieved by two different strategies. Strategy A involved the direct preparation of the 4-hydroxyphenylporphyrin via the Adler method (Scheme 2.8) [43]. Strategy A was faster than strategy B and had fewer steps but the

yields were lower and good results were not always consistent. In Strategy B, the 4methoxyphenylporphyrin was first prepared by the Adler method, and subsequently demethylated using aniline hydrochloride (Scheme 2.9).

Strategy A:

Tetraphenolporphyrin was prepared by dissolving 4-hydroxybenzaldehyde in refluxing propionic acid and slowly adding pyrrole was then added dropwise at a rate of 6 drops/min, upon addition of pyrrole the solution changed from light yellow to black. The 
solution was refluxed for 30 mins and allowed to cool to room temperature and further cooled in a refrigerator $\left(4{ }^{\circ} \mathrm{C}\right)$. After 12 hours the solution was filtered and a sticky solid was collected. This material was washed with $\mathrm{CH}_{2} \mathrm{Cl}_{2}$ and redissolved in methanol. The solvent was removed by means of rotary evaporation and a metallic blue microcrystalline solid was obtained.

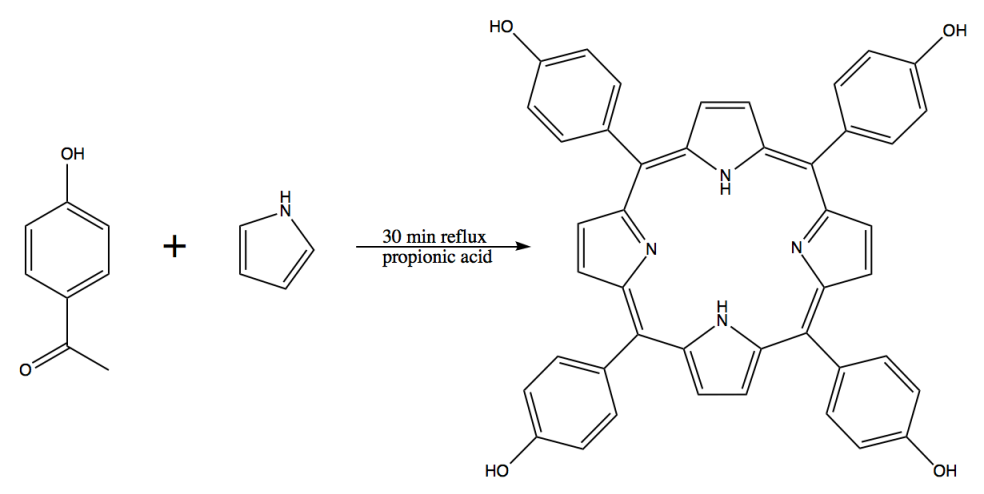

Scheme 2.8. Synthesis of tetraphenolporphyrin (D4) using strategy A.

Strategy B:

The 4-methoxyphenylpoprphyrin was prepared by dissolving 4methoxybenzaldehyde in refluxing propionic acid and slowly adding pyrrole. This solution was refluxed for 30 mins and allowed to cool to room temperature and further cooled in a refrigerator $\left(4{ }^{\circ} \mathrm{C}\right)$. After 12 hours the solution was filtered and washed with copious amounts of water and cold methanol. A microcrystalline purple solid was obtained. Characterization of the material confirmed it was the 4methoxyphenylporphyrin. This product was then dissolved and reacted with refluxing aniline hydrochloride, crashed-out with hot water, filtered and washed. 


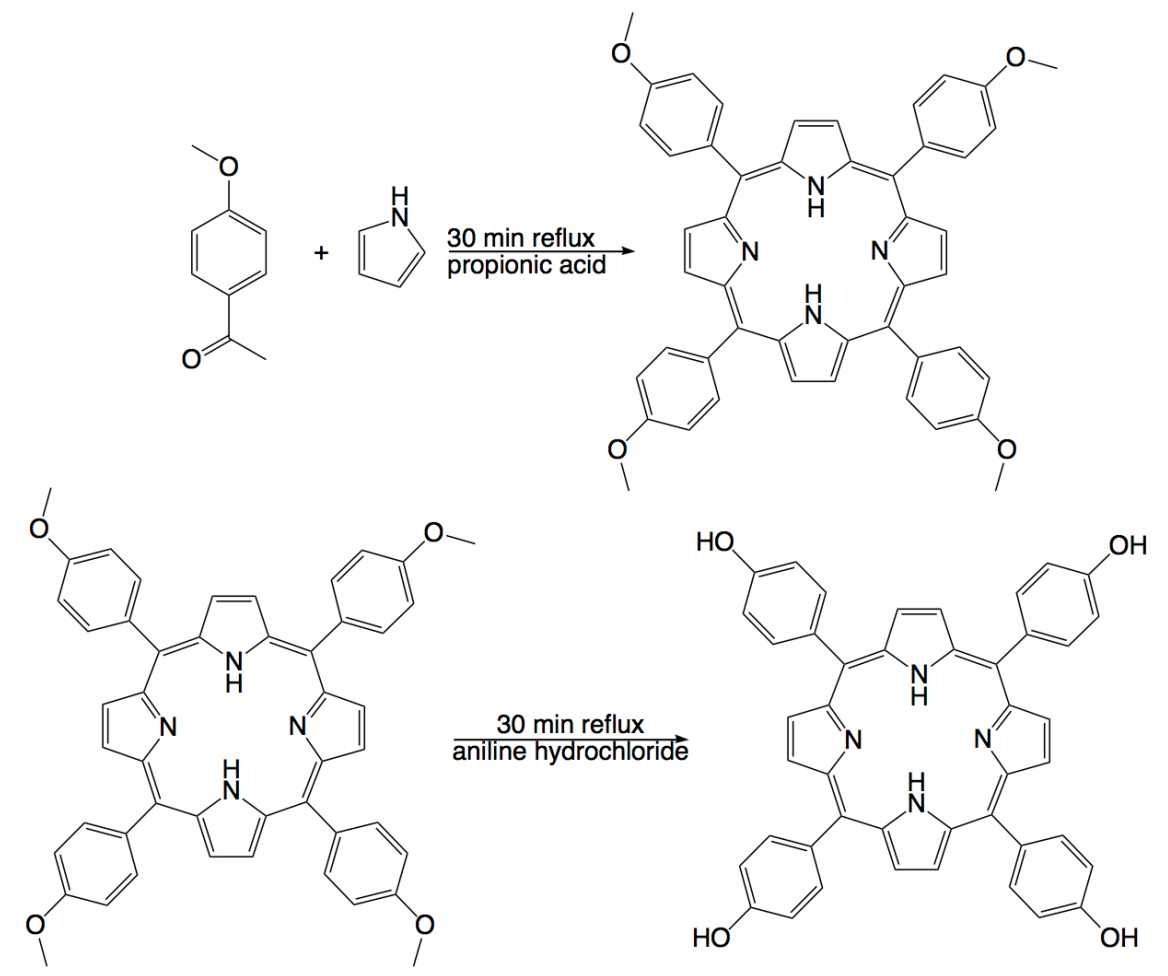

Scheme 2.9. Synthesis of tetraphenolporphyrin using strategy B (D4)

\subsubsection{Synthesis of Zn-tetraphenolporphyrin (Zn-TPPOH)}

Tetraphenolporphyrin and $\left[\mathrm{Zn}\left(\mathrm{CH}_{3} \mathrm{COO}\right)_{2}\right]$ were dissolved in methanol and refluxed overnight. The red colored solution turned dark purple after a few minutes. After allowing it to cool to room temperature, the reaction was filtered and a metallic purple solid was collected. It was washed with cold methanol and dried in vacuo. 


\subsection{Characterization of electron donors}

\subsubsection{X-ray crystallography}

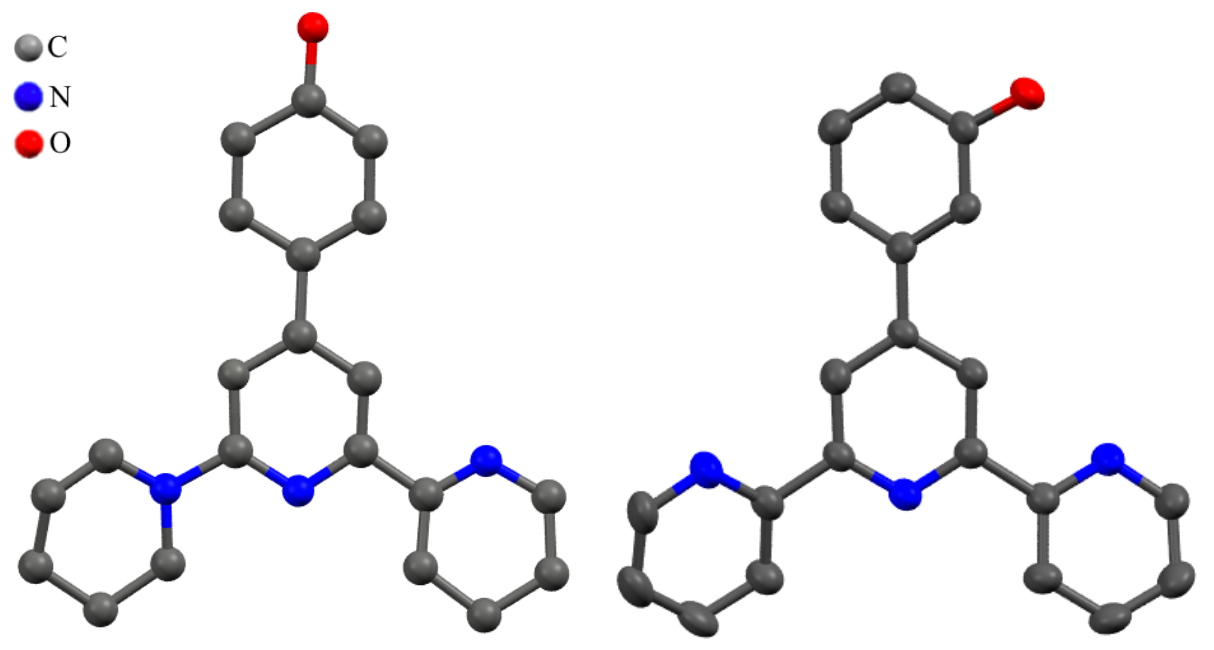

Figure 2.1. Ellipsoid model of a) 4'-(4-hydroxyphenyl)-2,2':6',2'-terpyridine $\left(\mathrm{L}^{2}\right)$ and b) 4'-(3hydroxyphenyl)-2,2':6',2"-terpyridine $\left(\mathrm{L}^{3}\right)$ at $50 \%$ probability
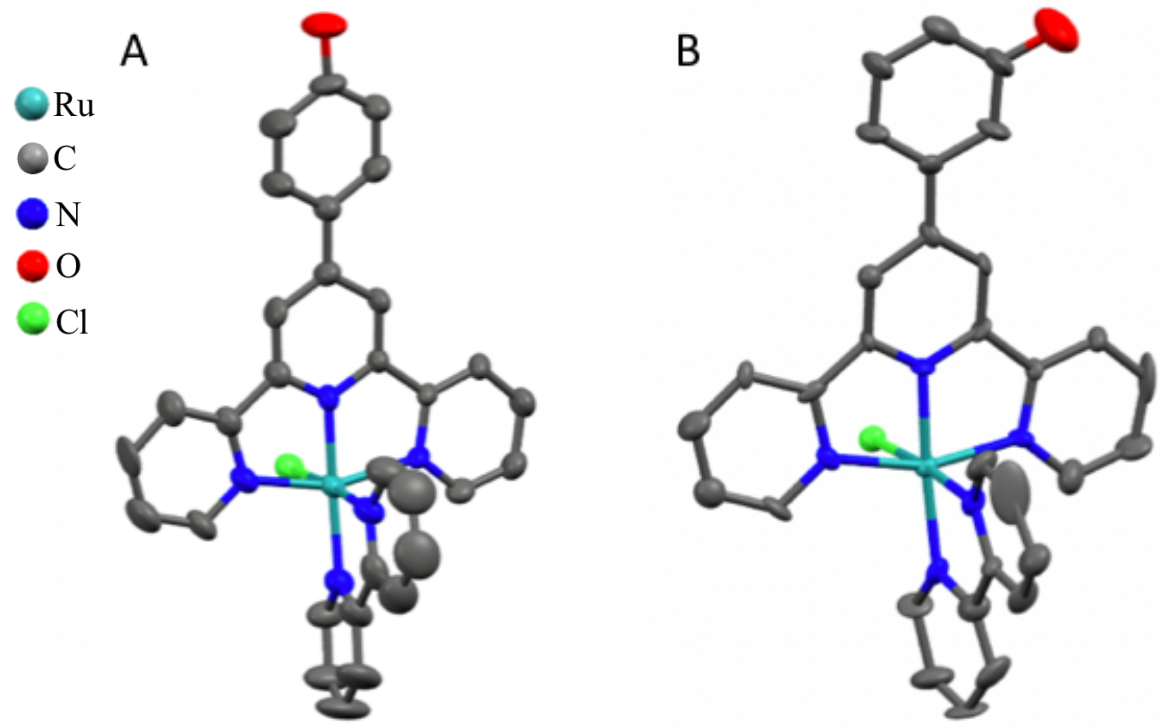

Figure 2.2. Ellipsoid model of a) $\left[\mathrm{Ru}\left(\mathrm{L}^{2}\right)(\mathrm{bpy}) \mathrm{Cl}\right]^{+}$and b) $\left[\mathrm{Ru}\left(\mathrm{L}^{3}\right)(\mathrm{bpy}) \mathrm{Cl}\right]^{+}$at $50 \%$ probability 


\begin{tabular}{|c|c|c|}
\hline Identification code & $\mathrm{Ru}\left(\mathrm{L}^{2}\right)(\mathrm{bpy}) \mathrm{Cl}$ & $\mathrm{Ru}\left(\mathrm{L}^{3}\right)(\mathrm{bpy}) \mathrm{Cl}$ \\
\hline Empirical formula & $\mathrm{C}_{31} \mathrm{H}_{23} \mathrm{ClF}_{6} \mathrm{~N}_{5} \mathrm{OPRu}$ & $\mathrm{C}_{31} \mathrm{H}_{23} \mathrm{ClF}_{6} \mathrm{~N}_{5} \mathrm{OPRu}$ \\
\hline Formula weight & 763.03 & 763.03 \\
\hline Temperature/K & 298.34 & 298.34 \\
\hline Crystal system & monoclinic & monoclinic \\
\hline Space group & $P 2{ }_{l} / c$ & $P c$ \\
\hline $\mathrm{a} / \AA$ & $16.4093(8)$ & $16.651(3)$ \\
\hline $\mathrm{b} / \AA$ & $7.9251(4)$ & $7.9010(16)$ \\
\hline $\mathrm{c} / \AA \AA$ & $24.2671(12)$ & $24.043(4)$ \\
\hline$\alpha /^{\circ}$ & 90 & 90 \\
\hline$\beta /^{\circ}$ & $94.756(2)$ & $95.367(5)$ \\
\hline$\gamma /{ }^{\circ}$ & 90 & 90 \\
\hline Volume $/ \AA^{3}$ & $3145.0(3)$ & $3149.2(10)$ \\
\hline $\bar{Z}$ & 4 & 4 \\
\hline Crystal size $/ \mathrm{mm}^{3}$ & $0.372 \times 0.144 \times 0.084$ & $0.175 \times 0.064 \times 0.064$ \\
\hline $2 \Theta$ range for data collection $/{ }^{\circ}$ & 5.712 to 49.478 & 5.71 to 49.692 \\
\hline Reflections collected & 49731 & 55626 \\
\hline Independent reflections & $\begin{array}{l}5360\left[\mathrm{R}_{\text {int }}=0.1533,\right. \\
\left.\mathrm{R}_{\text {sigma }}=0.1064\right]\end{array}$ & $\begin{array}{l}10639\left[\mathrm{R}_{\text {int }}=0.0656,\right. \\
\left.\mathrm{R}_{\text {sigma }}=0.0494\right]\end{array}$ \\
\hline Data/restraints/parameters & $5360 / 0 / 416$ & $10639 / 2 / 759$ \\
\hline Goodness-of-fit on $\mathrm{F}^{2}$ & 1.063 & 1.052 \\
\hline Final $\mathrm{R}$ indexes $[\mathrm{I}>=2 \sigma(\mathrm{I})]$ & $\begin{array}{l}\mathrm{R}_{1}=0.0806, \mathrm{wR}_{2}= \\
0.1596\end{array}$ & $\begin{array}{l}\mathrm{R}_{1}=0.0501, \mathrm{wR}_{2}= \\
0.1261\end{array}$ \\
\hline Final $\mathrm{R}$ indexes [all data] & $\begin{array}{l}\mathrm{R}_{1}=0.1557, \mathrm{wR}_{2}= \\
0.1868\end{array}$ & $\begin{array}{l}\mathrm{R}_{1}=0.0767, \mathrm{wR}_{2}= \\
0.1407\end{array}$ \\
\hline Largest diff. peak/hole / e $\AA^{-3}$ & $0.86 /-0.57$ & $0.75 /-0.41$ \\
\hline
\end{tabular}

Table 2.1 Crystallographic details for D2 and D3

\subsubsection{X-ray of $\left[\mathrm{Ru}\left(\left(\mathrm{L}^{2}\right)(\mathrm{bpy}) \mathrm{Cl}\right]\left[\mathrm{PF}_{6}\right]\right.$}

Compound $\left[\mathrm{Ru}\left(\left(\mathrm{L}^{2}\right)(\mathrm{bpy}) \mathrm{Cl}\right]\left[\mathrm{PF}_{6}\right]\right.$ crystallizes in the monoclinic $P 2_{l} / c$ space group with one molecule in the asymmetric unit. The crystal structure shows that the supramolecular arrangement is dictated by weak halogen-hydrogen interactions, mainly 
$\mathrm{F}^{\cdots} \mathrm{H}$ but also $\mathrm{Cl} \cdots \mathrm{H}$ to some extent. The $\mathrm{F}$-atoms of the counterion bridge successive ruthenium monomers to create $1 \mathrm{D}$ chains, which are also bridged by the counterions to connect two of such chains into ribbons. Weak $\mathrm{Cl}^{\cdots} \mathrm{H}-\mathrm{Ar}$ interactions hold the ribbons together (Fig 2.3).

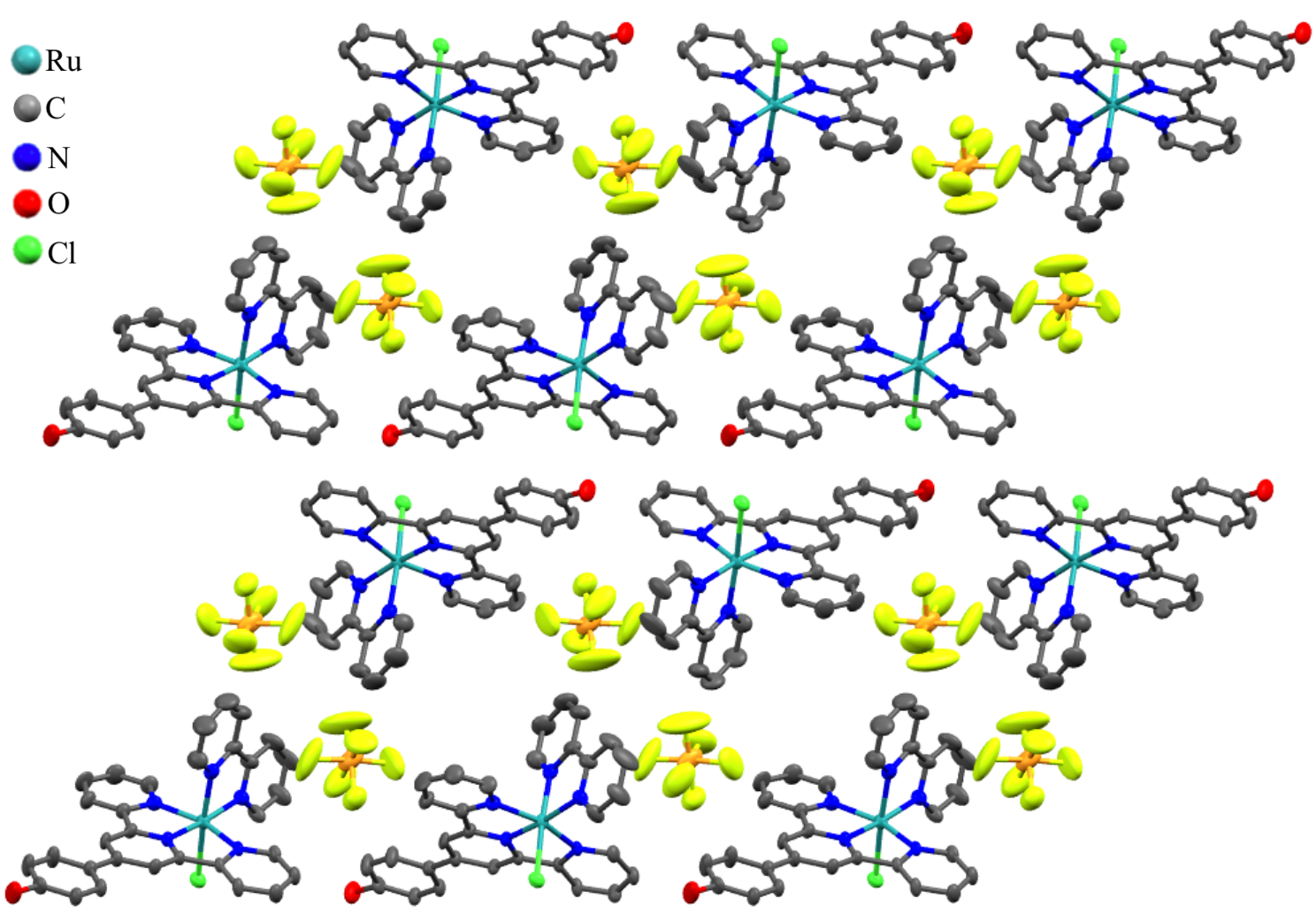

Figure 2.3 Ball-and-stick model of the supramolecular arrangement of $\left[\mathrm{Ru}\left(\mathrm{L}^{2}\right)(\mathrm{bpy}) \mathrm{Cl}\right]\left(\mathrm{PF}_{6}\right)$ 


\subsubsection{X-ray of $\left[\operatorname{Ru}\left(\left(L^{3}\right)(b p y) C l\right]\left[P_{6}\right]\right.$}

Compound $\left[\mathrm{Ru}\left(\left(\mathrm{L}^{3}\right)(\mathrm{bpy}) \mathrm{Cl}\right]\left[\mathrm{PF}_{6}\right]\right.$ crystallizes in the monoclinic Pc space group with two molecules in the asymmetric unit. Similarly to $\left[\mathrm{Ru}\left(\left(\mathrm{L}^{2}\right)(\mathrm{bpy}) \mathrm{Cl}\right]\left[\mathrm{PF}_{6}\right]\right.$, the supramolecular arrangement is dominated by weak halogen-hydrogen interactions, mainly $\mathrm{F}^{\cdots} \mathrm{H}$ but also $\mathrm{Cl}^{\cdots} \mathrm{H}$ to some extent. The $\mathrm{F}$-atoms of the counterion bridge successive ruthenium monomers to create $1 \mathrm{D}$ chains, which are also bridged by the counterion to connect two of such chains into ribbons. In the case of $\left[\mathrm{Ru}\left(\left(\mathrm{L}^{3}\right)(\mathrm{bpy}) \mathrm{Cl}\right]\left[\mathrm{PF}_{6}\right]\right.$, the phenol is the $\mathrm{H}$ donor in the weak $\mathrm{Cl}^{\cdots} \mathrm{H}$ interactions that hold the sheets together (Fig 2.4).

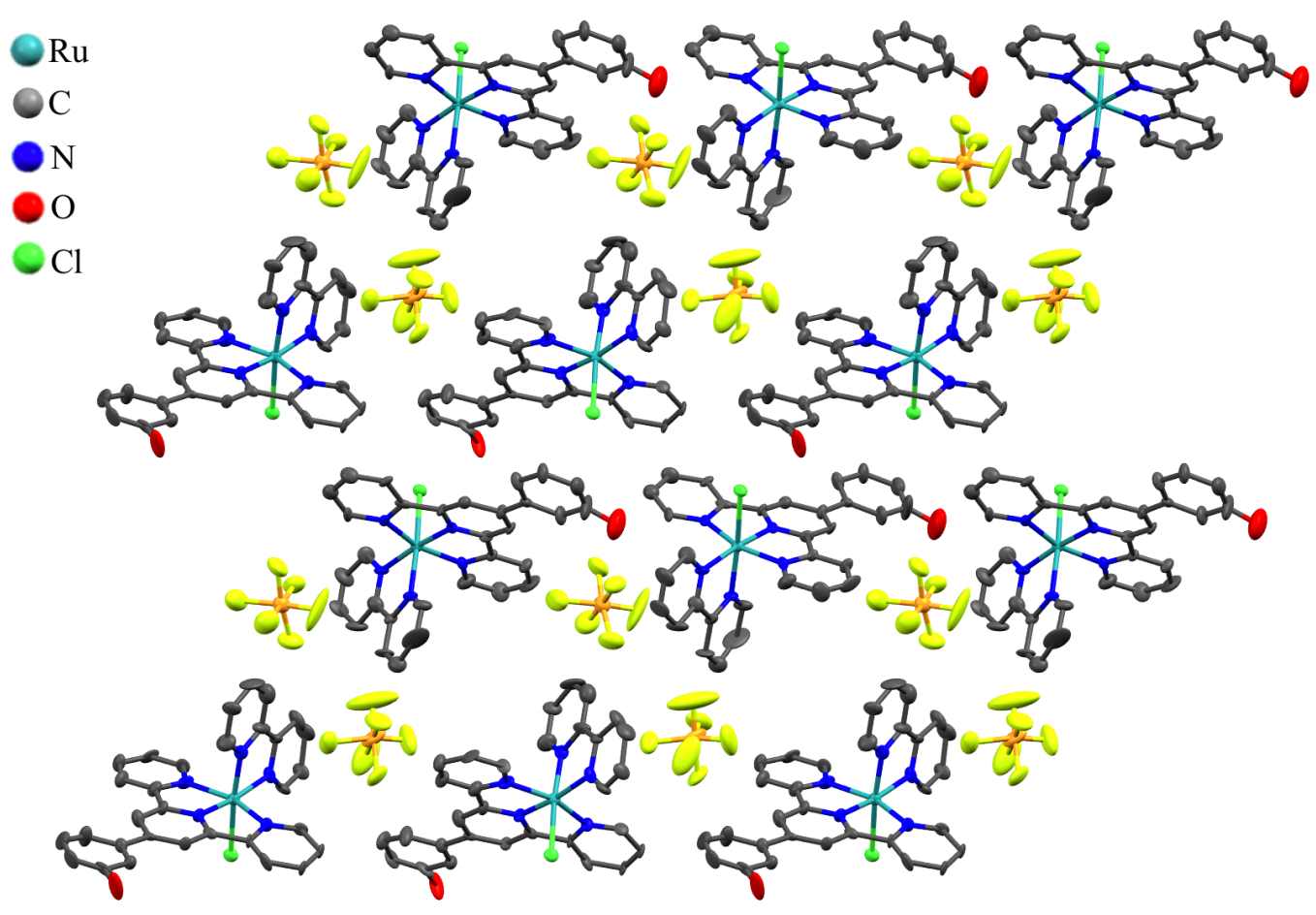

Figure 2.4 Ball-and-stick model of the supramolecular arrangement of $\left[\mathrm{Ru}\left(\mathrm{L}^{3}\right)(\mathrm{bpy}) \mathrm{Cl}\right]\left(\mathrm{PF}_{6}\right)$ 


\subsubsection{UV-vis spectroscopy}

When working with porphyrins, UV-vis spectroscopy is a fast and easy tool to analyze the products. Free base porphyrins have characteristic spectra with a high intensity Soret band and four Q-bands, all of which are assigned to $\pi-\pi^{*}$ transitions. For the TPPOH the Q-bands appeared at $\lambda_{\max }: 650,593,554$, and $517 \mathrm{~nm}$. To see if we could successfully deprotonate the porphyrins, we ran the UV-vis spectrum in $\mathrm{MeOH}$ and then we added triethylamine as a base. Upon the addition of base a slight change in the spectrum was observed, which is indicative of deprotonation (Fig 2.5). The new $\lambda_{\max }$ for the Q-bands were 652, 591, 557, and $518 \mathrm{~nm}$.

After confirmation that the porphyrin could be deprotonated, we decided to metalate the porphyrin with zinc. Again, the UV-vis spectrum proved a fast and reliable tool to probe the product. Upon metalation, it is expected to see just two Q-bands. When the spectrum was recorded the disappearance of Q-bands was evident (Fig 2.6). 


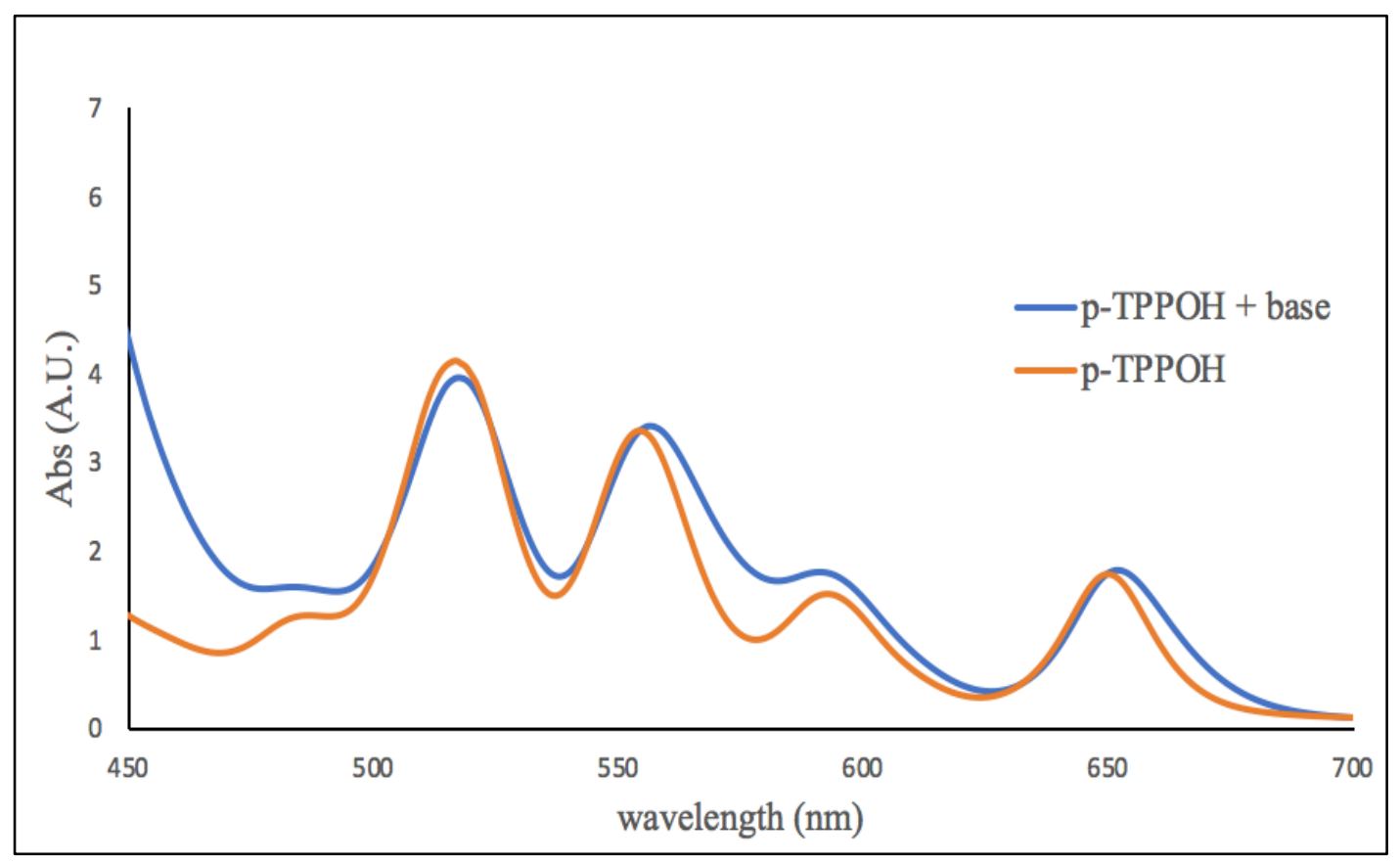

Figure 2.5. UV-vis spectra of TPPOH (blue) and deprotonated TPPOH (orange)

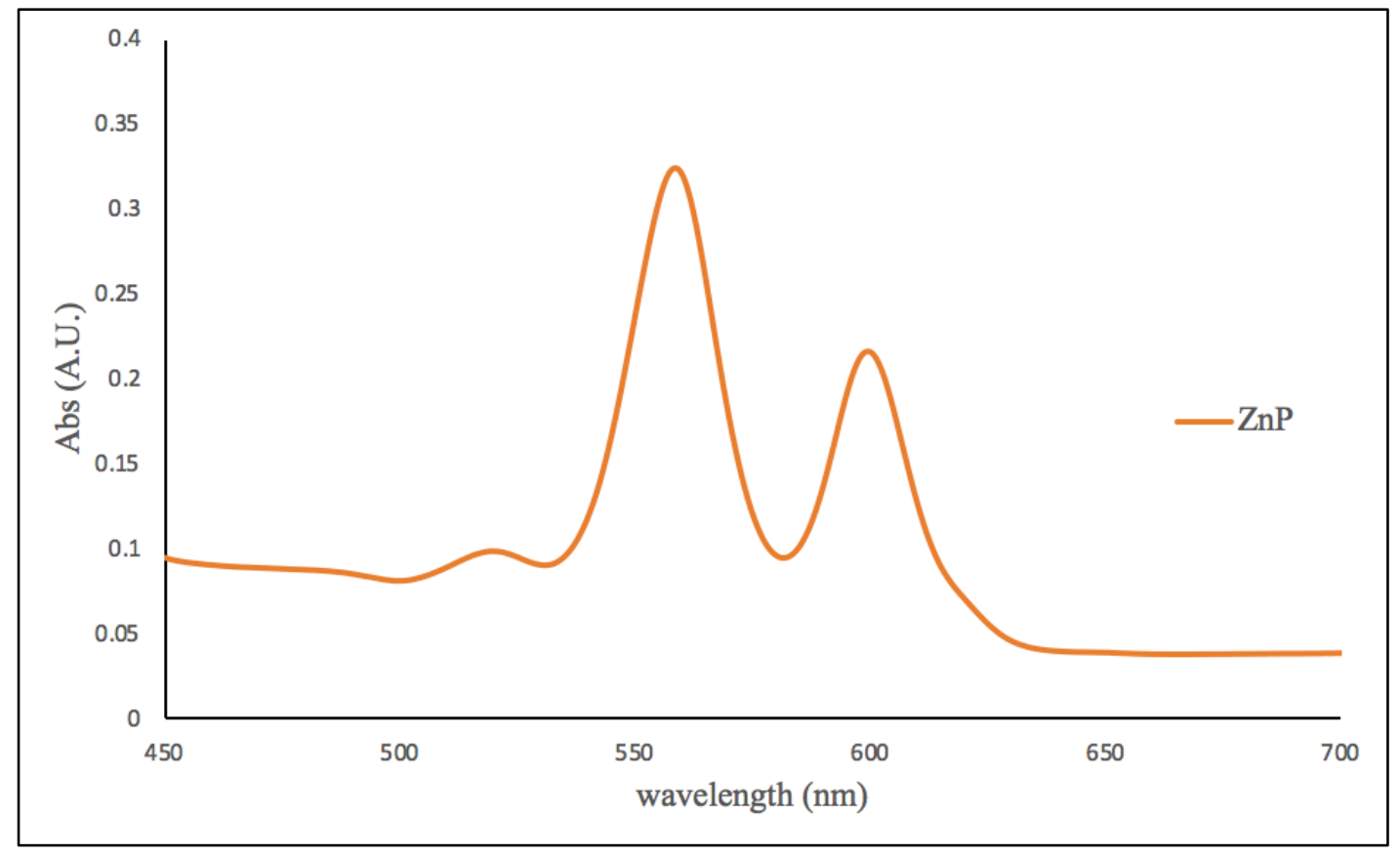

Figure 2.6. UV-vis spectrum of the zinc metalated TPPOH 


\subsubsection{NMR}

The NMR interpretation of $\left[\mathrm{Ru}\left(\mathrm{L}^{2}\right)(\mathrm{bpy}) \mathrm{Cl}\right]^{+}(\mathrm{Fig} 2.9)$ and $\left[\mathrm{Ru}\left(\mathrm{L}^{3}\right)(\mathrm{bpy}) \mathrm{Cl}\right]^{+}(\mathrm{Fig}$ 2.11) was challenging because all the protons in these complexes fall in the aromatic region causing overlap on several cases. In order to facilitate the interpretation of their spectra, the NMR of the hydroxylated ligands, as well as a $\left[\mathrm{Ru}(\mathrm{p} \text {-cymene)(bpy)Cl }]^{+}\right.$ complex (Fig 2.7), were collected and used to assign the peaks in the spectra of the more complicated heteroleptic complexes. As a result of the high symmetry of the porphyrin, its NMR was much more straight forward to solve with just four signals easily assigned. The upfield doublets correspond to the phenyl protons, the singlet that integrates to two H's corresponds to the protons on the $\beta$-position of the macrocycle and the downfield most signal corresponds to the phenol proton (Scheme 2.12).

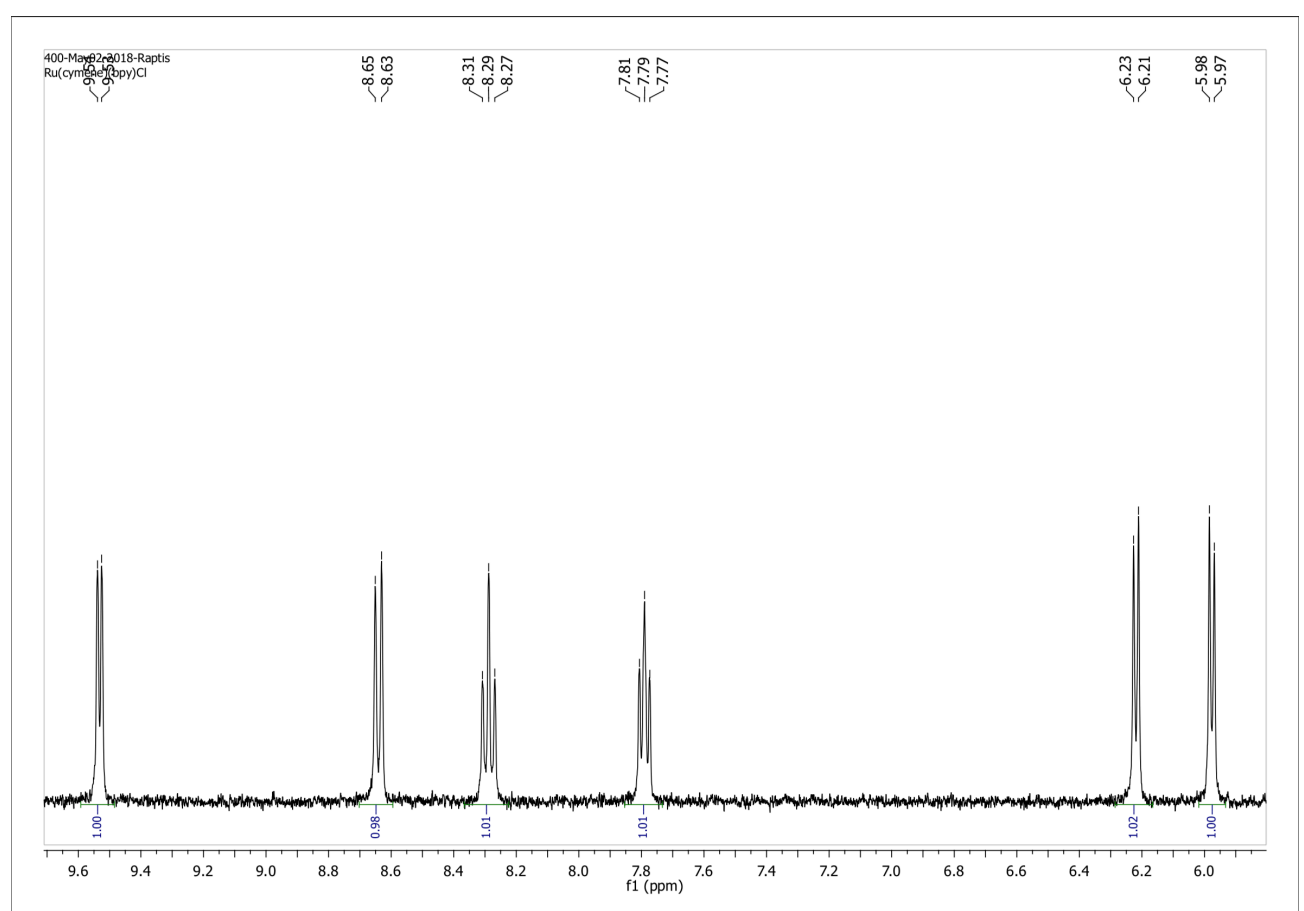

Figure 2.7. $400 \mathrm{MHz}{ }^{1} \mathrm{H}$ NMR spectrum of $\mathrm{Ru}(\mathrm{p}$-cymene)(bpy)Cl in DMSO-d 6 


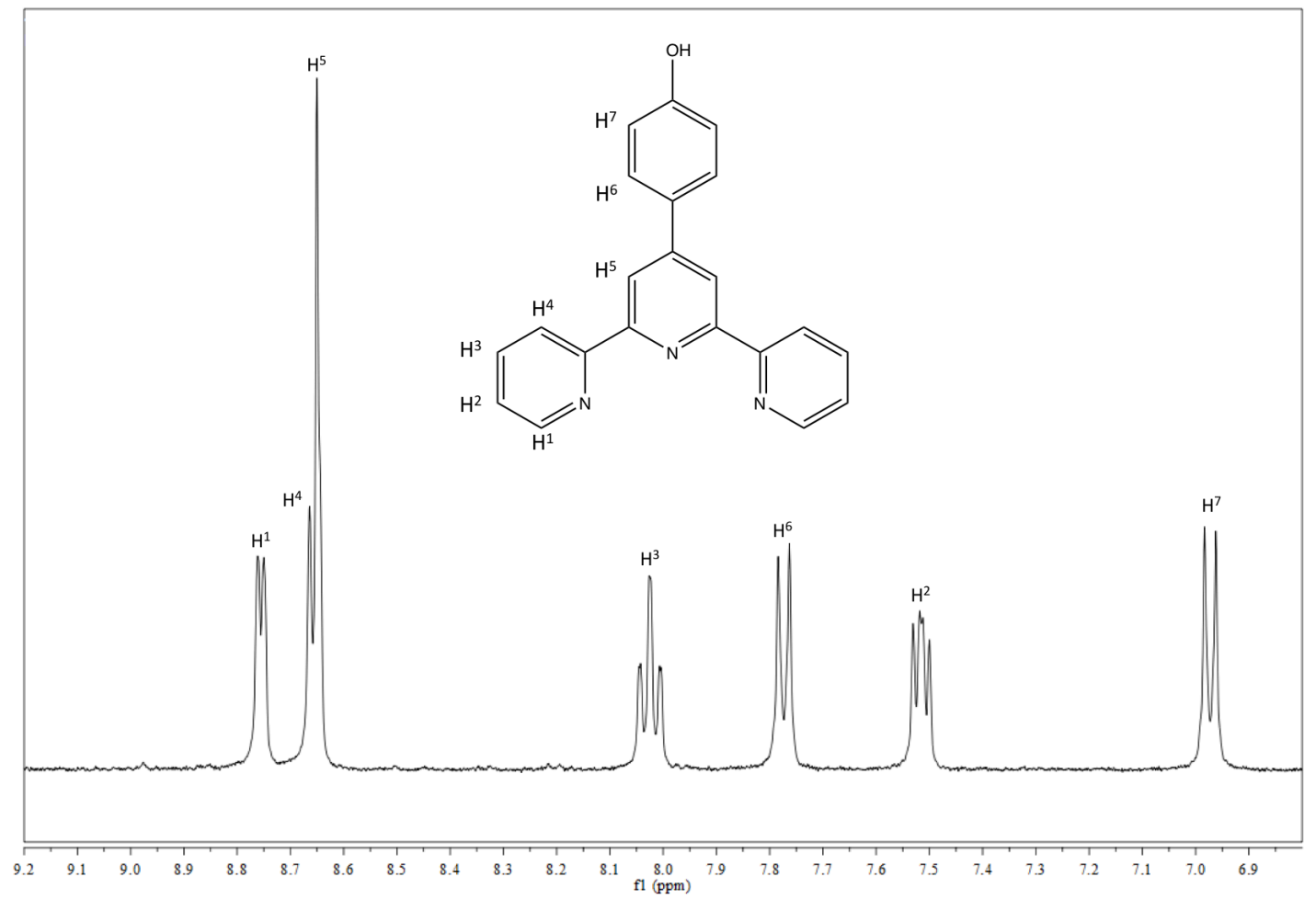

Figure 2.8. $400 \mathrm{MHz}{ }^{1} \mathrm{H}$ NMR spectrum of 4'-(4-hydroxyphenyl)-2,2':6',2"'-terpyridine ( $\left.\mathrm{L}^{2}\right)$ in DMSO-d 6

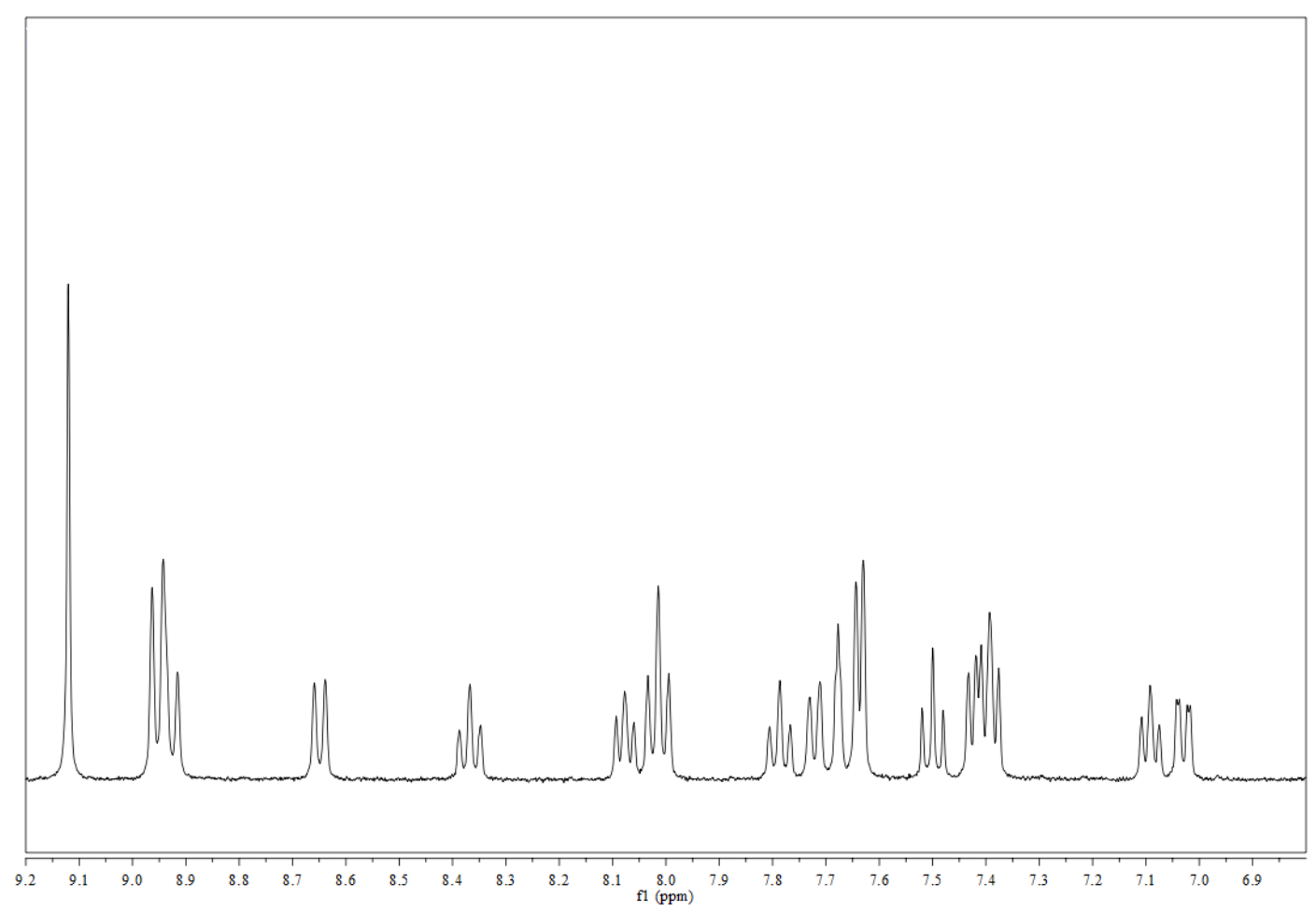

Figure 2.9. $400 \mathrm{MHz}{ }^{1} \mathrm{H}$ NMR spectrum of $\mathrm{Ru}\left(\mathrm{L}^{2}\right)(\mathrm{bpy}) \mathrm{Cl}$ in DMSO-d 6 


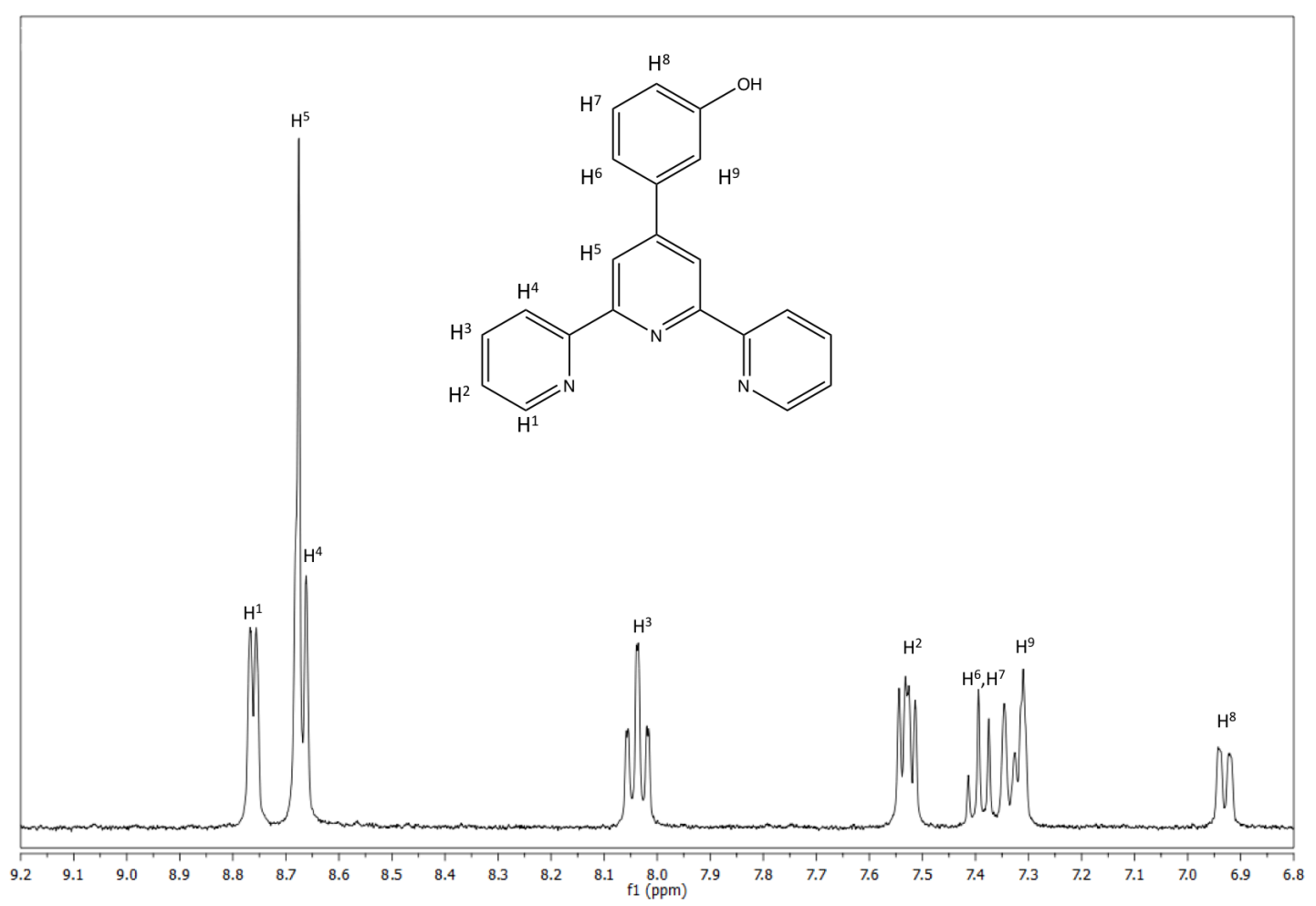

Figure 2.10. $400 \mathrm{MHz}{ }^{1} \mathrm{H}$ NMR spectrum of 4'-(3-hydroxyphenyl)-2,2':6',2'-terpyridine (L $\left.{ }^{3}\right)$ in DMSO-d 6

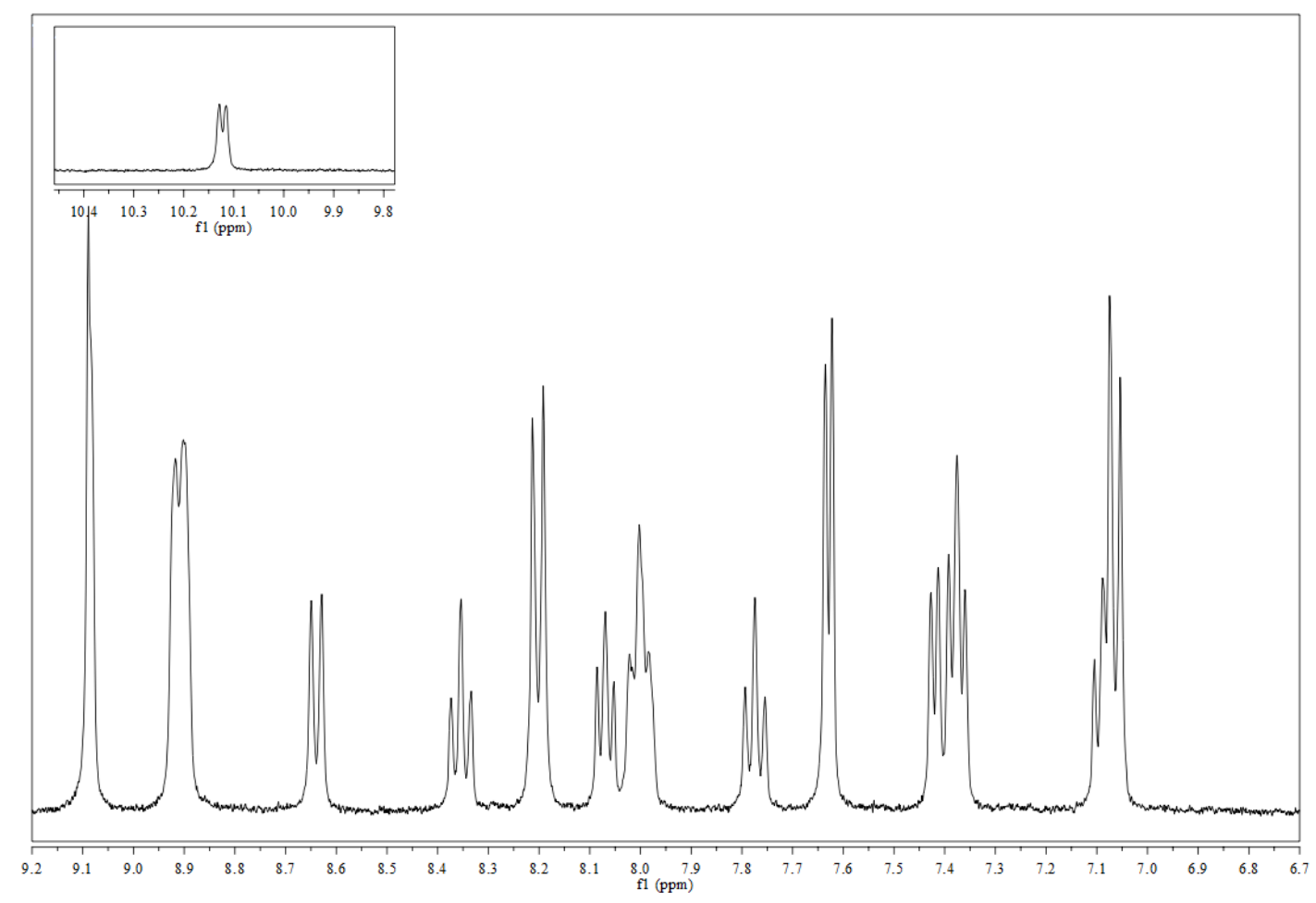

Figure 2.11. $400 \mathrm{MHz}{ }^{1} \mathrm{H}$ NMR spectrum of $\mathrm{Ru}\left(\mathrm{L}^{3}\right)(\mathrm{bpy}) \mathrm{Cl}$ in DMSO-d 6 


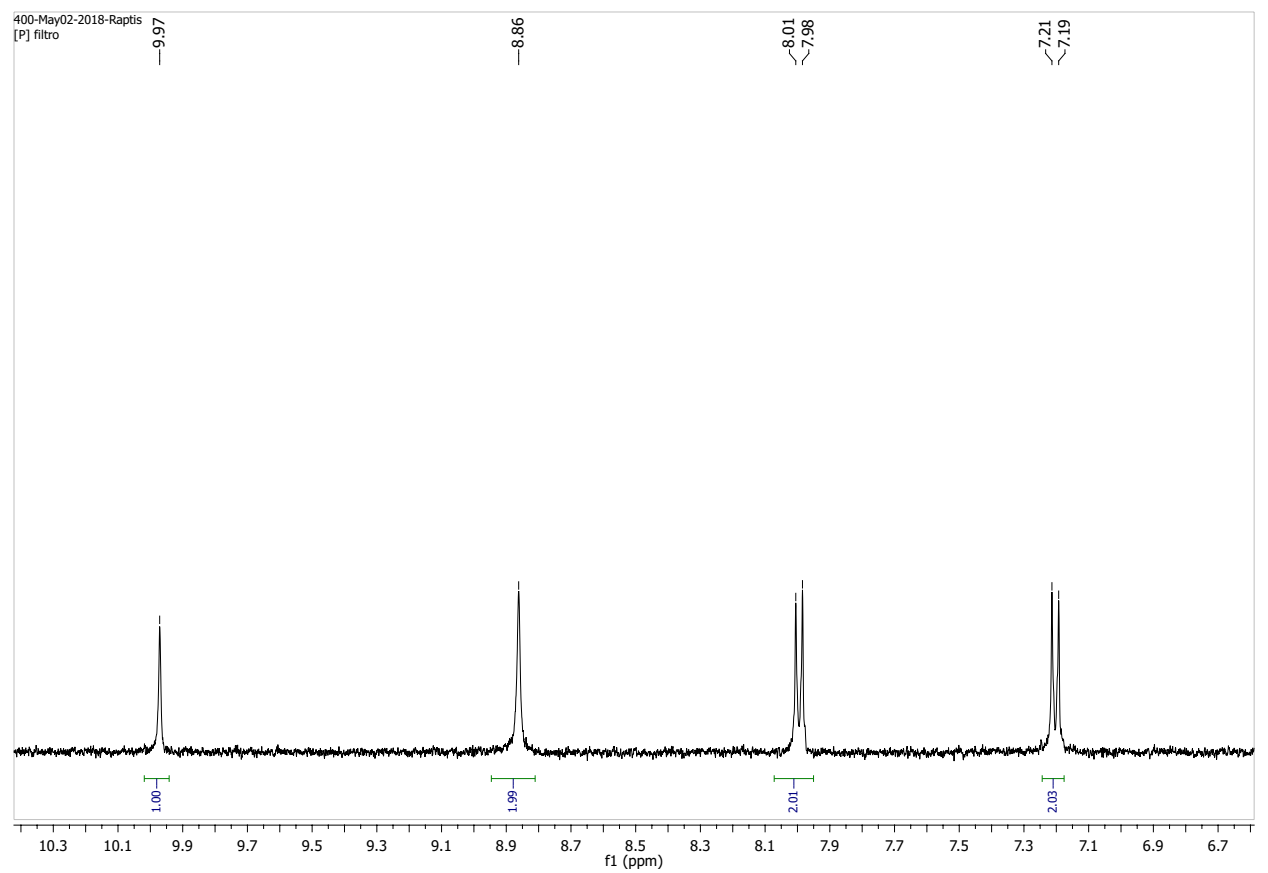

Figure 2.12. $400 \mathrm{MHz}{ }^{1} \mathrm{H}$ NMR spectrum of tetraphenolporphyrin in DMSO-d6

\subsection{Coordination attempts}

\subsection{1 $\mathrm{Fe}_{8}+\mathrm{L}^{1}$}

One of the first strategies used in the pursuit of a chemical dyad was the coordination of a phenol functionalized terpyridine ligand $\left(\mathrm{L}^{1}\right)$ to $\mathrm{Fe}$. The idea was to then introduce a metal complex that could be coordinated to the available tridentate ligand environment. Unexpectedly, when this strategy was attempted, an iron bis-terpyridine complex, $\mathrm{Fe}\left(\mathrm{L}^{1}\right)_{2}$, was obtained. The product's identity was confirmed by ESI-MS with peaks at $553 \mathrm{~m} / \mathrm{z}$ and a doubly charged peak at $277 \mathrm{~m} / \mathrm{z}$, and X-ray crystallography. 


\begin{tabular}{|c|c|}
\hline Empirical formula & $\mathrm{C}_{30} \mathrm{H}_{24} \mathrm{Cl}_{2} \mathrm{FeN}_{6} \mathrm{O}_{11}$ \\
\hline Formula weight & 771.3 \\
\hline Temperature/K & 300.89 \\
\hline Crystal system & monoclinic \\
\hline Space group & $P 2_{1} / c$ \\
\hline $\mathrm{a} / \AA$ & $16.9814(9)$ \\
\hline $\mathrm{b} / \AA$ & $19.9115(11)$ \\
\hline $\mathrm{c} / \AA$ & $9.1773(5)$ \\
\hline$\alpha /^{\circ}$ & 90 \\
\hline$\beta /{ }^{\circ}$ & $93.899(2)$ \\
\hline$\gamma /{ }^{\circ}$ & 90 \\
\hline Volume $/ \AA^{3}$ & $3095.9(3)$ \\
\hline Z & 4 \\
\hline$\rho_{\text {calc }} \mathrm{g} / \mathrm{cm}^{3}$ & 1.655 \\
\hline$\mu / \mathrm{mm}^{-1}$ & 0.734 \\
\hline $\mathrm{F}(000)$ & 1576 \\
\hline Crystal size $/ \mathrm{mm}^{3}$ & $0.356 \times 0.191 \times 0.103$ \\
\hline Radiation & $\operatorname{MoK} \alpha(\lambda=0.71073)$ \\
\hline $2 \Theta$ range for data collection $/{ }^{\circ}$ & 5.588 to 52.936 \\
\hline Reflections collected & 81422 \\
\hline Independent reflections & $\begin{array}{l}6373\left[\mathrm{R}_{\text {int }}=0.0821,\right. \\
\left.\mathrm{R}_{\text {sigma }}=0.0429\right]\end{array}$ \\
\hline Data/restraints/parameters & $6373 / 0 / 456$ \\
\hline Goodness-of-fit on $\mathrm{F}^{2}$ & 1.018 \\
\hline Final R indexes $[\mathrm{I}>=2 \sigma(\mathrm{I})]$ & $\mathrm{R}_{1}=0.0509, \mathrm{wR}_{2}=0.1115$ \\
\hline Final $\mathrm{R}$ indexes [all data] & $\mathrm{R}_{1}=0.0868, \mathrm{wR}_{2}=0.1278$ \\
\hline Largest diff. peak/hole / e $\AA^{-3}$ & $0.72 /-0.58$ \\
\hline
\end{tabular}

Table 2.2. Crystallographic details for $\mathrm{Fe}\left(\mathrm{L}^{1}\right)_{2}$.

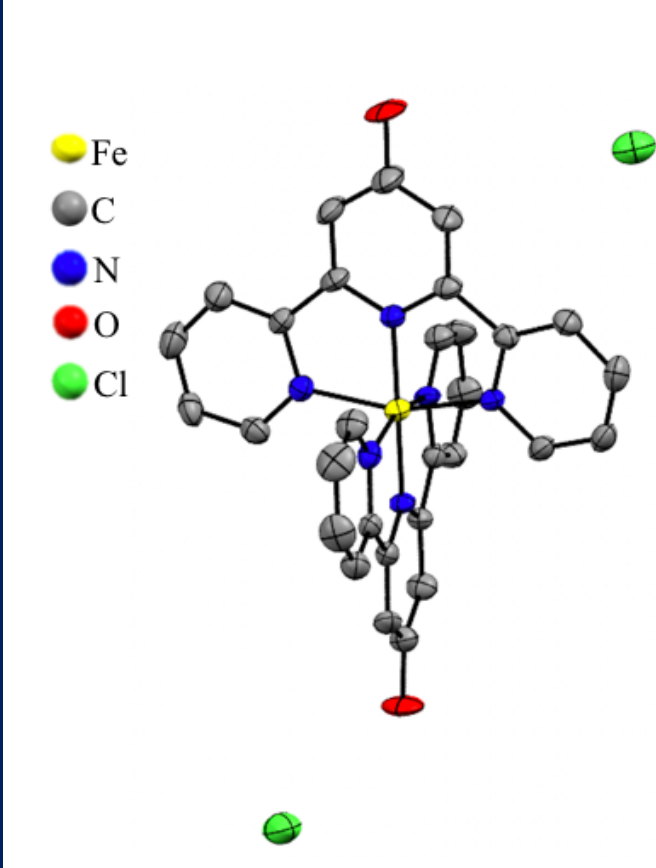

Figure 2.13. Ellipsoid model of $\mathrm{Fe}\left(\mathrm{L}^{1}\right)_{2}$

\subsection{2 $\mathrm{Fe}_{8}+\left[\mathrm{Ru}\left(\mathrm{L}^{1}\right)_{2}\right](\mathrm{Cl})_{2}$}

To avoid having the free ligand pulling iron out of the complex, a bis-terpyridine complex of ruthenium, $\left[\mathrm{Ru}\left(\mathrm{L}^{1}\right)_{2}\right]^{2+}$, was used to coordinate to the $\mathrm{Fe}_{8}$ cluster. For this reaction a 20 -fold excess of the ruthenium complex was used. The reaction was carried out in THF and after the addition of base, it was allowed to stir overnight. The reaction gave a brown precipitate poorly soluble in most solvent although the solution still exhibited a deep red color. The solution was filtered and set to recrystallize. Crystals of the initial ruthenium complex were obtained. 


\begin{tabular}{|c|c|}
\hline Empirical formula & $\mathrm{C}_{15.5} \mathrm{H}_{11} \mathrm{ClN}_{2.5} \mathrm{O}_{2} \mathrm{Ru}_{0.5}$ \\
\hline Formula weight & 350.25 \\
\hline Temperature/K & 298.34 \\
\hline Crystal system & triclinic \\
\hline Space group & P-1 \\
\hline $\mathrm{a} / \AA$ & $8.8887(15)$ \\
\hline $\mathrm{b} / \AA$ & $9.1219(14)$ \\
\hline $\mathrm{c} / \AA \AA$ & $19.108(3)$ \\
\hline$\alpha /{ }^{\circ}$ & $84.798(6)$ \\
\hline$\beta /{ }^{\circ}$ & $88.638(6)$ \\
\hline$\gamma /{ }^{\circ}$ & $87.807(5)$ \\
\hline Volume $/ \AA^{3}$ & $1541.5(4)$ \\
\hline Z & 4 \\
\hline$\rho_{\text {calc }} \mathrm{g} / \mathrm{cm}^{3}$ & 1.509 \\
\hline$\mu / \mathrm{mm}^{-1}$ & 0.726 \\
\hline $\mathrm{F}(000)$ & 706 \\
\hline Crystal size $/ \mathrm{mm}^{3}$ & $0.678 \times 0.48 \times 0.104$ \\
\hline Radiation & $\operatorname{MoK} \alpha(\lambda=0.71073)$ \\
\hline $2 \Theta$ range for data collection ${ }^{\circ}$ & 5.918 to 49.652 \\
\hline Reflections collected & 23938 \\
\hline Independent reflections & $\begin{array}{l}5311\left[\mathrm{R}_{\text {int }}=0.0904,\right. \\
\left.\mathrm{R}_{\text {sigma }}=0.0993\right]\end{array}$ \\
\hline Data/restraints/parameters & $5311 / 0 / 384$ \\
\hline Goodness-of-fit on $\mathrm{F}^{2}$ & 1.065 \\
\hline Final $\mathrm{R}$ indexes $[\mathrm{I}>=2 \sigma(\mathrm{I})]$ & $\mathrm{R}_{1}=0.0714, \mathrm{wR}_{2}=0.1509$ \\
\hline Final $\mathrm{R}$ indexes [all data] & $\mathrm{R}_{1}=0.1237, \mathrm{wR}_{2}=0.1724$ \\
\hline Largest diff. peak/hole / e $\AA^{-3}$ & $0.81 /-0.85$ \\
\hline
\end{tabular}

Table 2.3. Crystallographic details for $\mathrm{Ru}\left(\mathrm{L}^{1}\right)_{2}$

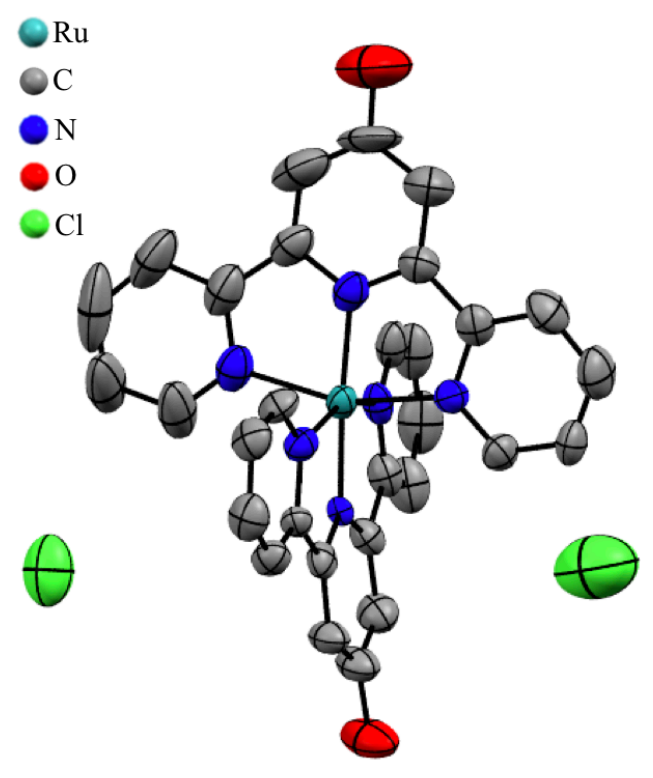

\subsection{Conclusions}

Ruthenium polypyridyls have been extensively studied as photo-active electron donors but there has been little done with phenol derivatives. In this project three new heteroleptic complexes of phenolic ruthenium polypyridyls have been prepared and characterized. Phenolporphyrins were also synthesized and their zinc metalated versions prepared. The meso-substituted porphyrins were characterized by UV-vis, NMR and Xray crystallography. Both phenolic electron donors were reacted with $\mathrm{Fe}_{8}$ to try to coordinate them into dyads. Unfortunately, the attempts so far have not yielded the 
expected results but there is reason to believe this strategy can bear fruits in the near future.

\subsection{Experimental}

This section describes the synthesis of two different types of electron donors: Ruthenium based polypyridyls and phenol functionalized porphyrins.

\subsubsection{Materials}

All commercially available reagents utilized in this work were of analytical grade and in most cases they were used as received. The following reagents were obtained from Acros Organics: 2-Acetylpyridine, 3-hydroxybenzaldehyde, 4-hydroxybenzaldehyde, sodium hydroxide, dichloro(p-cymene)ruthenium dimer, bipyridine, zinc acetate, aniline hydrochloride, ammonium hexafluorophosphate, pyrrole, propionic acid, dichloromethane, diethyl ether and tetrahydrofuran. Ammonium hydroxide and methanol were received from Fisher. 4-hydroxyterpyridine was purchased from HetCat. All solvents were distilled and degassed prior to use.

\subsubsection{Instrumentation}

The ${ }^{1} \mathrm{H}-\mathrm{NMR}$ spectra were recorded on a Bruker Avance $400 \mathrm{MHz}$ instrument. The UV-vis spectra were recorded on an Agilent Cary 5000 UV-vis-NIR spectrometer. Electrospray ionization mass spectra (ESI-MS) were recorded with a Bruker EvoQ LCTQ mass spectrometer using acetonitrile solutions. Single crystal X-ray crystallography data were obtained from crystals mounted atop glass fibers using a Bruker D8 Quest 
CMOS diffractometer fitted with a graphite-monochromated Mo-K $\alpha$ radiation $(\lambda=$ $0.71073 \AA$ ). Data were collected using the APEX3 software suite and corrected for Lorentz and polarization effects [46]. The structures were solved using SHELXT [47] and refined by full-matrix least squares on $\mathrm{F}^{2}$ using the SHELXL-direct methods and using OLEX2 [48] and ShelXle [49]. Multi-scan absorption correction was performed using SADABS [50]. All non-hydrogen atoms were anisotropically refined, and hydrogen atoms were placed at calculated positions and refined as riding atoms with isotropic displacement parameters.

\subsubsection{Synthesis}

\section{Synthesis of 4'-(4-hydroxyphenyl)-2,2':6',2'-terpyridine ( $\left.\mathrm{L}^{2}\right)$}

The 2-acetylpyridine (1.47 mL, $13.0 \mathrm{mmol})$, 4-hydroxybenzaldehyde $(0.757 \mathrm{~g}, 6.2$ mmol), $\mathrm{NH}_{4} \mathrm{OH}(4.00 \mathrm{~mL})$ and $36 \mathrm{~g}$ of a $15 \% \mathrm{NaOH}$ solution were added to a $250 \mathrm{~mL}$ RBF equipped with a stirring bar and a reflux condenser. The initial color of the reaction mixture was off-white. The solution was refluxed at for $48 \mathrm{~h}$ and a change in color was observed from off-white to pale maroon. After the $48 \mathrm{~h}$ reflux, the reaction mixture was allowed to cool to room temperature. Upon cooling, the reaction mixture became a thick slurry. At this point an extra $36 \mathrm{~g}$ of a $15 \% \mathrm{NaOH}$ solution were added to dissolve the slurry. The new suspension was transferred to a fritted funnel, filtered, and washed with copious amounts of water. The solid obtained was then suspended with stirring in a 5\% acetic acid solution for $24 \mathrm{~h}$ after which it was filtered, washed, and suspended again in $5 \%$ acetic acid for a further $3 \mathrm{~h}$. The solid was then filtered and washed with water and ether. The product was dried in vacuo and $1.37 \mathrm{~g}$ were obtained (67.8\% yield). Crystals 
were grown from a slow diethylether vapor diffusion into a methanolic solution of the compound. ${ }^{1} \mathrm{H}-\mathrm{NMR}(400 \mathrm{MHz}, \mathrm{DMSO}-\mathrm{d}), \delta(\mathrm{ppm}): 6.97\left(\mathrm{H}^{7}, \mathrm{~d},{ }^{3} \mathrm{~J}=8.4 \mathrm{~Hz}, 1 \mathrm{H}\right), 7.51$ $\left(\mathrm{H}^{2}, \mathrm{dd},{ }^{3} \mathrm{~J}=7.4 \mathrm{~Hz}\right.$ and $\left.{ }^{4} \mathrm{~J}=4.9 \mathrm{~Hz}, 1 \mathrm{H}\right), 7.77\left(\mathrm{H}^{6}, \mathrm{~d},{ }^{3} \mathrm{~J}=8.4 \mathrm{~Hz}, 1 \mathrm{H}\right), 8.02\left(\mathrm{H}^{3}, \mathrm{t},{ }^{3} \mathrm{~J}=\right.$ $7.6 \mathrm{~Hz}, 1 \mathrm{H}), 8.65\left(\mathrm{H}^{5}, \mathrm{~s}, 1 \mathrm{H}\right), 8.66\left(\mathrm{H}^{4}, \mathrm{~d},{ }^{3} \mathrm{~J}=5.2 \mathrm{~Hz}, 1 \mathrm{H}\right), 8.76\left(\mathrm{H}^{1}, \mathrm{~d},{ }^{3} \mathrm{~J}=4.5 \mathrm{~Hz}, 1 \mathrm{H}\right)$.

\section{Synthesis of 4'-(3-hydroxyphenyl)-2,2':6',2'-terpyridine $\left(\mathrm{L}^{3}\right)$}

The 2-acetylpyridine (1.47 mL, $13.0 \mathrm{mmol}), 3$-hydroxybenzaldehyde $(0.757 \mathrm{~g}, 6.2$ mmol), $\mathrm{NH}_{4} \mathrm{OH}(4.00 \mathrm{~mL})$ and $36 \mathrm{~g}$ of a $15 \% \mathrm{NaOH}$ solution were added to a $100 \mathrm{~mL}$ $\mathrm{RBF}$ equipped with a stirring bar and a reflux condenser. The initial color of the reaction mixture was off-white. This solution was refluxed for $24 \mathrm{~h}$ and a change in color was observed from off-white to pearly white. After the $24 \mathrm{~h}$ reflux, the reaction mixture was allowed to cool to room temperature. Upon cooling, a pearly white colored precipitate formed. The precipitate was transferred to a fritted funnel, filtered, and washed with copious amounts of water. The solid obtained was then suspended with stirring in a 5\% acetic acid solution for $3 \mathrm{~h}$ after which it was filtered, washed, and suspended again in $5 \%$ acetic acid for a further $3 \mathrm{~h}$. The solid was then filtered and washed with water and ether. The product was dried in vacuo and $1.62 \mathrm{~g}$ were obtained $(80.2 \%$ yield). Crystals were grown from an ether diffusion into methanol. ${ }^{1} \mathrm{H}-\mathrm{NMR}$ (400 MHz, DMSO-d), $\delta(\mathrm{ppm}): 6.93\left(\mathrm{H}^{8}, \mathrm{~d},{ }^{3} \mathrm{~J}=9.2 \mathrm{~Hz}, 1 \mathrm{H}\right), 7.31\left(\mathrm{H}^{9}, \mathrm{~s}, 1 \mathrm{H}\right), 7.33\left(\mathrm{H}^{6}, \mathrm{~d},{ }^{3} \mathrm{~J}=8.0 \mathrm{~Hz}, 1 \mathrm{H}\right), 7.38$ $\left(\mathrm{H}^{7}, \mathrm{t},{ }^{3} \mathrm{~J}=8.0 \mathrm{~Hz}, 1 \mathrm{H}\right), 7.53\left(\mathrm{H}^{2}, \mathrm{dd},{ }^{3} \mathrm{~J}=7.3 \mathrm{~Hz}\right.$ and $\left.{ }^{4} \mathrm{~J}=4.8 \mathrm{~Hz}, 1 \mathrm{H}\right), 8.03\left(\mathrm{H}^{3}, \mathrm{dt},{ }^{3} \mathrm{~J}=\right.$ $7.6 \mathrm{~Hz}$ and $\left.{ }^{4} \mathrm{~J}=4.0 \mathrm{~Hz}, 1 \mathrm{H}\right), 8.66\left(\mathrm{H}^{4}, \mathrm{~d},{ }^{3} \mathrm{~J}=5.2 \mathrm{~Hz}, 1 \mathrm{H}\right), 8.67\left(\mathrm{H}^{5}, \mathrm{~s}, 1 \mathrm{H}\right), 8.76\left(\mathrm{H}^{1}, \mathrm{~d},{ }^{3} \mathrm{~J}\right.$ $=4.4 \mathrm{~Hz}, 1 \mathrm{H})$. 


\section{Synthesis of $\left[\operatorname{Ru}\left(\mathbf{L}^{1}\right)(b p y) C l\right]\left[P_{6}\right]$}

A $30 \mathrm{~mL}$ DCM solution of Dichloro(p-cymene)ruthenium dimer $(0.2940 \mathrm{~g}, 0.48$ mmol) was added to a $100 \mathrm{~mL}$ three-necked flask equipped with a stirring bar, an addition funnel, a nitrogen gas inlet and an outlet. The addition funnel was charged with $30 \mathrm{~mL}$ of an $\mathrm{L}^{1}$ THF solution $(0.2393 \mathrm{~g}, 0.96 \mathrm{mmol})$. Under a flow of nitrogen, the $\mathrm{L}^{1}$ solution was added dropwise at a rate of $1 \mathrm{~mL} / \mathrm{min}$. After the addition of the ligand, the reaction mixture was stirred for $1 \mathrm{~h}$ and the formation of a precipitate was observed. The solid was filtered and washed with DCM, cold acetone and cold ether to yield a dark red material. The solid was dried overnight under high vacuum and used without any further purification. The dried solid $(0.3040 \mathrm{~g}, 0.36 \mathrm{mmol})$ was then dissolved in $60 \mathrm{~mL}$ of $\mathrm{H}_{2} \mathrm{O}$ :EtOH (1:1) and bpy $(0.1100 \mathrm{~g}, 0.704 \mathrm{mmol})$ was added to the solution. The reaction was refluxed for 18 hours, allowed to cool to room temperature and concentrated by removing approximately half its volume using a rotary evaporator. Ammonium hexafluorophosphate was added to the concentrated solution to precipitate the product. The solid was collected and washed with water and diethyl ether. The product was still not completely dry after $24 \mathrm{~h}$ in vacuum but it was dissolved in methanol and crystals were obtained from a diethylether diffusion. The pure material was collected with a $47 \%$ yield $(0.18 \mathrm{~g})$. 


\section{Synthesis of $\left[\mathrm{Ru}\left(\left(\mathrm{L}^{2}\right)(\mathrm{bpy}) \mathrm{Cl}\right]\left[\mathrm{PF}_{6}\right]\right.$}

A $30 \mathrm{~mL}$ DCM solution of Dichloro(p-cymene)ruthenium dimer $(0.2940 \mathrm{~g}, 0.48$ mmol) was added to a $100 \mathrm{~mL}$ three-necked flask equipped with a stirring bar, an addition funnel, a nitrogen gas inlet and an outlet. The addition funnel was charged with $30 \mathrm{~mL}$ of an $\mathrm{L}^{2} \mathrm{THF}$ solution $(0.3203 \mathrm{~g}, 0.9548 \mathrm{mmol})$. Under a flow of nitrogen, the $\mathrm{L}^{2}$ solution was added dropwise at a rate of $1 \mathrm{~mL} / \mathrm{min}$. After the addition of the ligand, the reaction mixture was stirred for $1 \mathrm{~h}$ and the formation of a precipitate was observed. The solid was filtered and washed with DCM, cold acetone and cold ether to yield a purple material. This solid was dried overnight under high vacuum and used without any further purification. The dried solid $(0.1080 \mathrm{~g}, 0.109 \mathrm{mmol})$ was then dissolved in $60 \mathrm{~mL}$ methanol and bpy $(0.0341 \mathrm{~g}, 0.218 \mathrm{mmol})$ was added to the solution. The reaction was refluxed for 48 hours, allowed to cool to room temperature. The methanol was removed with rotary evaporation under reduced pressure to dryness and the solids redissolved in 5 $\mathrm{mL}$ of water. Ammonium hexafluorophosphate was added to this concentrated solution and the precipitate was filtered and washed with ether. Crystals were obtained from methanol via ether diffusion. The pure material was collected with a $44 \%$ yield $(0.324 \mathrm{~g})$.

\section{Synthesis of $\left[\mathrm{Ru}\left(\left(\mathrm{L}^{3}\right)(\mathrm{bpy}) \mathrm{Cl}\right]\left[\mathrm{PF}_{6}\right]\right.$}

A $30 \mathrm{~mL}$ DCM solution of Dichloro(p-cymene)ruthenium dimer $(0.2940 \mathrm{~g}, 0.48$ mmol) was added to a $100 \mathrm{~mL}$ three-necked flask equipped with a stirring bar, an addition funnel, a nitrogen gas inlet and an outlet. The addition funnel was charged with $30 \mathrm{~mL}$ of an $\mathrm{L}^{3}$ THF solution $(0.3203 \mathrm{~g}, 0.9548 \mathrm{mmol})$. Under a flow of nitrogen, the $\mathrm{L}^{3}$ 
solution was added dropwise at a rate of $1 \mathrm{~mL} / \mathrm{min}$. After the addition of the ligand, the reaction mixture was stirred for $1 \mathrm{~h}$ and the formation of a precipitate was observed. The solid was filtered and washed with DCM, cold acetone and cold ether to yield a purple material. The solid was dried overnight under high vacuum and used without any further purification. The dried solid $(0.1080 \mathrm{~g}, 0.109 \mathrm{mmol})$ was then dissolved in $60 \mathrm{~mL}$ methanol and bpy $(0.0341 \mathrm{~g}, 0.218 \mathrm{mmol})$ was added to the solution. The reaction was refluxed for $48 \mathrm{~h}$, then allowed to cool to room temperature. The methanol was removed with rotary evaporation under reduced pressure to dryness and the solids redissolved in 5 $\mathrm{mL}$ of water. Ammonium hexafluorophosphate was added to this concentrated solution and the precipitate was filtered and washed with ether. Crystals were obtained from methanol via ether diffusion. The pure material was collected with a $61.4 \%$ yield $(0.450$ g).

\section{Synthesis of tetraphenolporphyrin (TPPOH)}

Strategy A:

In a two-necked $500 \mathrm{~mL}$ RBF equipped with stirring bar, an addition funnel and a reflux condenser, 4-hydroxybenzaldehyde $(9.75 \mathrm{~g}, 80 \mathrm{mmol})$ was added and dissolved in $200 \mathrm{~mL}$ of propionic acid. The addition funnel was charged with pyrrole $(5.5 \mathrm{~mL}, 80.7$ mmol) and when the propionic acid was heated to $145^{\circ} \mathrm{C}$ the pyrrole was added dropwise at a rate of 6 drops/min. Upon addition of pyrrole the solution changed from light yellow to black. The solution was refluxed for 30 mins, allowed to cool to room temperature and then it was further cooled in a refrigerator $\left(4^{\circ} \mathrm{C}\right)$ for $12 \mathrm{~h}$. The solution was filtered and a sticky paste-like product was obtained. This material was washed with $\mathrm{CH}_{2} \mathrm{Cl}_{2}$ and 
redissolved in methanol where it had good solubility. The solution was concentrated by means of rotary evaporation and filtered. A metallic blue microcrystalline solid was recovered. The amount recovered was $1.24 \mathrm{~g}$ for a $9.18 \%$ yield. Efforts to recrystallize for X-ray analysis gave a crystalline looking material that did not diffract. ${ }^{1} \mathrm{H}-\mathrm{NMR}$ (400 MHz, DMSO-d), $\delta\left(\right.$ ppm): $7.20\left(\mathrm{H}^{3}, \mathrm{~d},{ }^{3} \mathrm{~J}=8.4 \mathrm{~Hz}, 2 \mathrm{H}\right), 7.99\left(\mathrm{H}^{2}, \mathrm{~d},{ }^{3} \mathrm{~J}=8.4 \mathrm{~Hz}, 2 \mathrm{H}\right)$, $8.86\left(\mathrm{H}^{1}, \mathrm{~s}, 2 \mathrm{H}\right), 9.96\left(\mathrm{H}^{4}, \mathrm{~s}, 1 \mathrm{H}\right)$

\section{Strategy B:}

In a two-necked $500 \mathrm{~mL}$ RBF equipped with stirring bar, an addition funnel and a reflux condenser, 4-methoxybenzaldehyde (11 g, $80.7 \mathrm{mmol})$ was added and dissolved in $200 \mathrm{~mL}$ of propionic acid. The addition funnel was charged with pyrrole $(5.5 \mathrm{~mL}, 80.7$ mmol) and when the propionic acid was heated to $145^{\circ} \mathrm{C}$ the pyrrole was added dropwise at a rate of 6 drops/min. Upon addition of pyrrole the solution changed from light yellow to black. The solution was refluxed for 30 mins, allowed to cool to room temperature and then it was further cooled in a refrigerator $\left(4^{\circ} \mathrm{C}\right)$ for 12 hours. The solution was filtered and a metallic purple microcrystalline solid was recovered. It was washed with water and cold methanol and dried in high vacuum. The product was then added to a $50 \mathrm{~mL}$ RBF and $20 \mathrm{~g}$ of aniline hydrochloride were added. The RBM was equipped with a stirring bar and a reflux condenser and was placed in a sand bath were it was heated to $c a .200 \mathrm{C}$. At this temperature the aniline hydrochloride melted and refluxed slowly. The reflux was continued for $45 \mathrm{~min}$ and then it was stopped. When the solution became cool enough to handle, it was poured in $100 \mathrm{~mL}$ of hot water. A very fine precipitate resulted that proved difficult to filter with reduced pressure as it passes even through even fine filters. Liquid- 
liquid extraction and centrifugation were also tried but in the end, gravity filtration through a fine filter proved to be the most efficient way to collect the solid. The solid was then washed with water and redissolved in $100 \mathrm{~mL}$ of a $5 \% \mathrm{w} / \mathrm{v}$ solution of $\mathrm{NaOH}$. The solution was then brought to neutral $\mathrm{pH}$ by the addition of $\mathrm{HNO}_{3}$ and $\mathrm{NH}_{4} \mathrm{OH}$ as needed. At neutral or slightly acidic $\mathrm{pH}$ a precipitate formed, it was collected and washed with water to give a green material that turned purple after removing the solvent in high vacuum. Its NMR and UV-vis spectra confirmed that it was the desired porphyrin. The amount recovered was $1.91 \mathrm{~g}$ for a $14.16 \%$ yield. ${ }^{1} \mathrm{H}-\mathrm{NMR}$ (400 MHz, DMSO-d), $\delta(\mathrm{ppm}): 7.20\left(\mathrm{H}^{3}, \mathrm{~d},{ }^{3} \mathrm{~J}=8.4 \mathrm{~Hz}, 2 \mathrm{H}\right), 7.99\left(\mathrm{H}^{2}, \mathrm{~d},{ }^{3} \mathrm{~J}=8.4 \mathrm{~Hz}, 2 \mathrm{H}\right), 8.86\left(\mathrm{H}^{1}, \mathrm{~s}, 2 \mathrm{H}\right), 9.96$ $\left(\mathrm{H}^{4}, \mathrm{~s}, 1 \mathrm{H}\right)$

\section{Synthesis of Zn-tetraphenolporphyrin (Zn-TPPOH)}

The porphyrin $(1.0 \mathrm{~g}, 1.47 \mathrm{mmol})$ was added to a $50 \mathrm{~mL}$ RBF equipped with a stirring bar and a reflux condenser and dissolved in methanol. Zinc acetate in a 20-fold excess $(5.41 \mathrm{~g}, 29.5 \mathrm{mmol})$ was added and the mixture refluxed overnight. The initial color of the solution was burgundy but it change to a dark red-purple overnight. The reflux was stopped and allowed to reach room temperature. A suspension was observed and filtration yielded the product as a purple solid. It was washed with cold methanol and dried in vacuum. 


\title{
Chapter 3: Synthesis and characterization of transition metal polypyridyls with dihydroxybipyridine
}

\author{
This chapter has been published as an article: \\ Rodríguez-Santiago, A. J.; Cortés, N.; Pham, K.; Miksovska, J.; Raptis, R. G. \\ Polyhedron 150 (2018) 61-68
}

DOI: $10.1016 /$ j.poly.2018.04.039 


\subsection{Introduction}

This chapter details the study of four new complexes of earth-abundant cobalt, copper and zinc with 4,4'-dihydroxy-2,2'-bipyridine $\left(\mathrm{dhbpyH}_{2}\right)$ ligands with regard to their redox and photoexcitation properties as possible replacements for ruthenium bipyridine dyes and iodide-based redox shuttles in dye-sensitized solar cells (DSSC). Ruthenium is one of the least abundant elements in Earth's crust and consequently a costly metal. Iodide is a corrosive electrolyte with competing optical absorption and high overpotential $[51,52]$.

Molecule-based materials of metal polypyridyls have found a wide range of applications because of the versatility of these ligands $[53,54]$. Whereas the reported in the literature complexes encompass the common pyridine (py) and polypyridines - e.g. bipyridine (bpy) [55], terpyridine (tpy) [56, 57], and quaterpyridine (qpy) [58] -- the

more thoroughly explored group has been that of the bpy ligands. Ruthenium bpy complexes have been studied for applications in diverse fields, such as water splitting catalysis [59], solar fuel catalysis [60, 61], DNA studies [62], cancer therapy [63], oxygen sensing [64], and small molecule activation [65]. The peripheral substitution versatility of the bpy ligand, which can be functionalized in up to four positions per aromatic ring, enables these complexes to find a plethora of applications via judicious functionalization that allows tailoring to the targeted application. Typically, these derivatives include anchoring, dendrimeric, photosensitive and $\mathrm{pH}$-dependent groups, which confer new properties to bpy, often turning a spectator ligand into a non-innocent one. In particular, 
ruthenium complexes involving bpy and its 4,4'-dicarboxylic acid derivative exhibit remarkable light harvesting properties and long lived excited states [66]. For this reason, they have been studied as potential photo-excitable electron donors for solar fuel production and photovoltaic applications.

Given the urgency for the development of efficient alternative energy production technologies, several derivatives of these compounds, functionalized as to improve their light absorption, excited state lifetime and solubility, have also been studied [53-55]. Modification of these electron donor complexes has often incorporated linkers and anchoring groups that allow their attachment to an electron acceptor, such as $\mathrm{TiO}_{2}$ or $\mathrm{C}_{60}$ [67, 68]. Although there is extensive literature on the ruthenium bpy complexes [69-71], not much has been reported for the hydroxyl-bpy derivative. First reported in a metal complex in 1984 [38], only recently have hydroxyl derivatives been studied in detail. The hydroxyl functionality imparts useful properties, such as electron donation, hydrogen bonding (supramolecular organization), $\mathrm{pH}$ tunability, and reactivity (capability to be further derivatized). Electrochemical data reported by Paul et al. for $\left[\mathrm{Ru}(\mathrm{bpy})_{2}\left(\mathrm{dhbpyH}_{2}\right)\right]^{2+},\left[\mathrm{Ru}(\mathrm{bpy})\left(\mathrm{dhbpyH}_{2}\right)_{2}\right]^{2+}$ and $\left[\mathrm{Ru}\left(\mathrm{dhbpyH}_{2}\right)_{3}\right]^{2+}\left(\mathrm{dhbpyH}_{2}=4,4^{\prime}-\right.$ dihydroxy-2,2'-bipyridine), have revealed a predictable pattern, where the more hydroxyl groups present, the lower the $\mathrm{E}_{1 / 2}$ of the $\mathrm{Ru}^{(\mathrm{III} / \mathrm{II})}$ couple [39-41]. Deprotonation of the hydroxyl groups further decreased the $\mathrm{E}_{1 / 2}$ values. Because of the electron releasing effect of the hydroxyl groups, the oxidized form is stabilized, making it easier for these complexes to donate electrons, compared to the non-derivatized bipyridyl complex, $\left[\mathrm{Ru}(\mathrm{bpy})_{3}\right]^{2+}$. 
The $3 \mathrm{I}^{-} / \mathrm{I}_{3}^{-}$redox couple is up to date the most common electron shuttle in DSSC (Fig 3.1). Recent developments in the field of DSSCs are exploring the substitution of the $3 \mathrm{I}^{-} / \mathrm{I}_{3}^{-}$redox shuttle for $\mathrm{Co}^{\mathrm{II}} / \mathrm{Co}^{\mathrm{III}}$-bpy complexes. Cobalt offers the advantage of slow charge recombination kinetics from $\mathrm{TiO}_{2}$ due to $\mathrm{LS}-\mathrm{HS} \mathrm{Co}^{\mathrm{III}} / \mathrm{Co}^{\mathrm{II}}$ transition. The slow recombination minimizes the number of electrons lost directly from the $\mathrm{TiO}_{2}$ to the $\mathrm{Co}$, thus allowing for an improved charge collection efficiency, $\eta_{\mathrm{CC}}[72,73]$. Furthermore, functionalization of the bpy allows for the fine tuning of properties, such as bulkiness, reduction potential, dye regeneration and solubility, rendering these complexes an attractive substitute for the iodide-based electrolytes. The dihydroxybipyridine ligand has largely remained unexplored and its increased hydrophilicity aligns with the current trend of finding alternatives for aqueous DSSC.

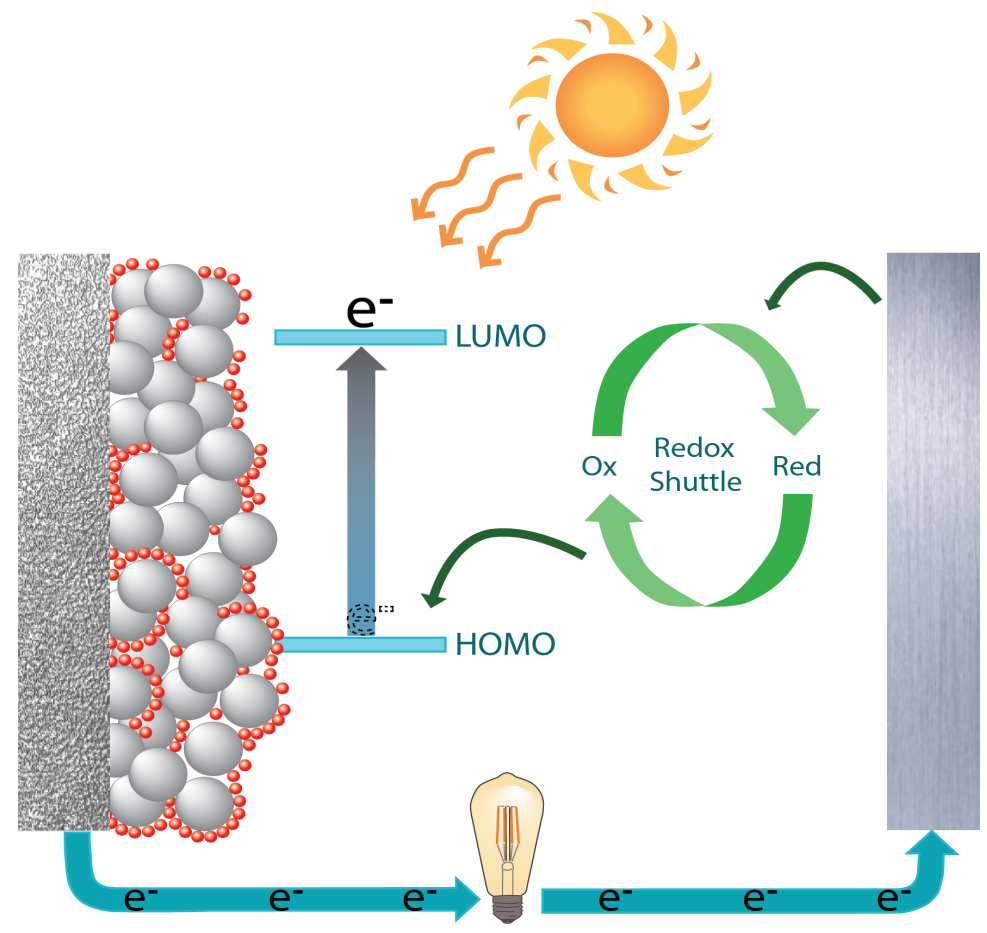

Figure 3.1. Architecture and mechanism of a DSSC. 
Copper and zinc are other first-row transition metals that have attracted renewed interest in the DSSC area. Copper bpy and zinc tpy complexes have been employed as photo-sensitive electron donors with moderate success, presenting an economic and environmental alternative for ruthenium [74, 75]. Additionally, copper phenanthroline complexes have also found applications as redox couples opening the door to all-copper DSSC. Initial reports on this type of DSSC have shown promising results, but there is still a long way to go before they can compete with the current state-of-the-art cells. Research on these complexes and synthesis of new derivatives is expected to advance the field, providing competitive alternatives to ruthenium-based dyes and iodide-based electrolytes [75].

\subsection{Synthesis of transition metal dhbpyH $\mathrm{H}_{2}$ complexes}

\subsubsection{Copper complex}

$\left[\mathrm{Cu}\left(\mathrm{dhbpyH}_{2}\right)_{2}\right]\left[\mathrm{ClO}_{4}\right]_{2}$ was prepared by addition of $\mathrm{dhbpyH}_{2}$ to a suspension of $\mathrm{Cu}\left(\mathrm{ClO}_{4}\right)_{2}$ in $10 \mathrm{~mL}$ of $\mathrm{THF}$ and stirred at ambient temperature for $24 \mathrm{~h}$. The resulting blue solution was filtered and the solvent was removed by rotary evaporation under reduced pressure. The collected solid was washed with $10 \mathrm{~mL}$ of cold methanol and ether. The solid was dried in vacuo and $0.0580 \mathrm{~g}(69 \%$ yield $)$ of the product $\left[\mathrm{Cu}\left(\mathrm{dhbpyH}_{2}\right)_{2}\right]\left[\mathrm{ClO}_{4}\right]_{2}$ were obtained. Blue crystals of X-ray quality were grown by layering a solution of $\mathbf{1}$ over toluene in a closed test tube. Compound $\mathbf{1}$ crystallized in the monoclinic space group $C 2 / c$ with one formula unit per asymmetric unit. The copper center is in a distorted square planar configuration (bpy-bpy dihedral angle, $38.98^{\circ}$ ) with

$\mathrm{Cu}-\mathrm{N}$ bond lengths between 1.963(2) $\AA$ and 1.986(2) $\AA$ and $\mathrm{N}-\mathrm{Cu}-\mathrm{N}$ bond angles 
between $82.30(8)^{\circ}$ and $156.43(9)^{\circ}$, in good agreement with related Cu-bpy complexes reported in the literature [76]. Viewed parallel to the c-axis, the crystal packing of the copper complex reveals alternating sheets of $\left[\mathrm{Cu}\left(\mathrm{dhbpyH}_{2}\right)_{2}\right]$-dications and perchlorate anions. A network of H-bonds between the hydroxyl groups of the ligand and perchlorate and interstitial water molecules, leaves a void large enough to accommodate an interstitial toluene molecule.

\subsubsection{Cobalt complex}

$\left[\mathrm{Co}\left(\mathrm{dhbpyH}_{2}\right)_{2}\left(\mathrm{dhbpyH}^{-}\right)\right]\left[\mathrm{ClO}_{4}\right]_{2}$ was prepared by addition of dhbpyH $\mathrm{H}_{2}$ to a suspension of $\mathrm{Co}\left(\mathrm{ClO}_{4}\right)_{3}$ in $10 \mathrm{~mL}$ of ethanol and stirred at ambient temperature for $24 \mathrm{~h}$. The resulting orange solution was filtered through Celite, and the filtrate reduced to dryness in vacuo, affording $0.0387 \mathrm{~g} \mathrm{(46 \%} \mathrm{yield)} \mathrm{of} \mathrm{the} \mathrm{product}\left[\mathrm{Co}\left(\mathrm{dhbpyH}_{2}\right)_{2}\left(\mathrm{dhbpyH}^{-}\right.\right.$ )$]\left[\mathrm{ClO}_{4}\right]_{2}$. Orange crystals suitable for X-ray analysis were grown by slow evaporation of an acetonitrile solution of the compound. Compound $\mathbf{2}$ crystallizes in the orthorhombic space group Pccn with one molecule per asymmetric unit. The Co(III) ion is in an octahedral geometry with Co-N bond lengths and N-Co-N angles in the ranges of $1.919(3) \AA$ to $1.943(3) \AA$ and $83.0(2)^{\circ}$ to $177.3(2)^{\circ}$, respectively. The crystal structure shows only two perchlorate counterions, raising the question about the valency of the cobalt center. The cobalt source and NMR hinted to a $\mathrm{Co}(\mathrm{III})$ center so to solve this discrepancy the Co-N bonds were considered. The Co-N bond lengths of 2 are consistent with those determined for $\left[\mathrm{Co}(\mathrm{bpy})_{3}\right]^{3+}(1.930 \AA$, average $)[77]$ and significantly shorter than those of $\left[\mathrm{Co}(\mathrm{bpy})_{3}\right]^{2+}(2.125 \AA$, average) [78], identifying unequivocally its Cocenter as a trivalent cation. A look at the packing of the cell help us resolve the seemingly 
conflicting crystallographic information. One of the three chelating ligands is singly deprotonated, as evident by one shorter C-O bond of 1.298(5) $\AA$ compared to the average of five $\mathrm{C}-\mathrm{OH}$ bonds of 1.331(5) $\AA$. In the supramolecular arrangement, significant intermolecular H-bonding between protonated and deprotonated ligands of neighboring complexes can be appreciated. This interaction results in shorter $\mathrm{C}-\mathrm{O}$ bonds for those protonated ligands involved as can be seen in table 3.1. Such monodeprotonated dhbpyH chelates have been previously reported in the crystal structures of $\mathrm{Co}(\mathrm{III})$ and $\mathrm{Ru}$ (II) complexes $[39,79]$ and explain the presence of only two counterions. A 3D network is created by the supramolecular arrangement where the voids are occupied by the perchlorates. One of the perchlorate counter ions is located on a special position and is crystallographically disordered, while the other ones are involved in H-bonding with the cationic complex.

\subsubsection{Zinc complexes}

The synthesis of $\left[\mathrm{Zn}\left(\mathrm{dhbpyH}_{2}\right)_{2}\right]\left(\mathrm{ClO}_{4}\right)_{2}$ was carried out in a fashion similar to the copper complex. $\mathrm{Zn}\left(\mathrm{ClO}_{4}\right)_{2}$ was added to a suspension of dhbpyH $\mathrm{H}_{2}$ in $10 \mathrm{~mL}$ of THF and stirred at ambient temperature for $24 \mathrm{~h}$. The resulting colorless solution was filtered through Celite, and the filtrate reduced to approximately one-half its original volume under reduced pressure. The concentrated solution was layered with toluene resulting in colorless crystals of $\left[\mathrm{Zn}\left(\mathrm{dhbpyH}_{2}\right)_{2}\right]\left[\mathrm{ClO}_{4}\right]_{2}(0.032 \mathrm{~g}, 38 \%$ yield $)$ as the major product and a few pink crystals of $\left[\mathrm{Zn}\left(\mathrm{dhbpyH}_{2}\right)_{3}\right]\left[\mathrm{ClO}_{4}\right]_{2}(0.008 \mathrm{~g}, 12 \%$ yield $)$ as the minor

product. Even though the reaction stoichiometry was varied as to favor the formation of 3, compound $\mathbf{4}$ always formed as the minor product. Similar results have been reported 
with related zinc bpy complexes $[80,81]$. A peculiarity of this complex is its pink color, visible in the solid phase, but only evident in solution as a very weak band at $540 \mathrm{~nm}$. It is relevant to point out that the other product, $\mathbf{3}$, crystallizes colorless from the same solution. The pink color has been observed for other zinc complexes that have aromatic guests intercalated in their crystal lattice and it has been attributed by other authors to $\mathrm{C}-$ $\mathrm{H} \bullet \bullet \pi$ and $\pi-\pi$ interactions between the zinc complex and the organic guest, which obviously cannot exist here $[80,81]$. Single crystal diffraction data were collected at room temperature. Compound 3 crystallizes in the triclinic space group P-1 with one molecule per asymmetric unit. The $\mathrm{Zn}(\mathrm{II})$ ion is in a quasi-trigonal bipyramidal geometry with perchlorate coordinating to the metal center. Compound $\mathbf{3}$ has $\mathrm{Zn}-\mathrm{N}$ bond lengths in the range of 2.032(6) $\AA$ to 2.081(6) $\AA$, a Zn-O distance of 2.230(6) $\AA$, N-Zn-N and N-Zn$\mathrm{O}$ angles in the range of $79.1(2)^{\circ}$ to $177.1(2)^{\circ}$ and $87.5(2)^{\circ}$ to $139.8(2)^{\circ}$, respectively. The packing reveals $\pi-\pi$ stacking, along with H-bonding among the hydroxyl group, the coordinated perchlorate anion and the interstitial THF molecule. In contrast with complexes 1 and 2, $\left[\mathrm{Zn}\left(\mathrm{dhbpyH}_{2}\right)_{2}\right]\left(\mathrm{ClO}_{4}\right)_{2}$ exhibit $\pi-\pi$ stacking with a centroid-centroid distance of 3.707(4) $\AA$ as the major determinant of its 3D packing.

Compound 4 crystallizes in the monoclinic space group P2/n with one-half complex and one interstitial THF molecule per asymmetric unit. The $\mathrm{Zn}(\mathrm{II})$ ion is in a distorted octahedral geometry with $\mathrm{Zn}-\mathrm{N}$ bond lengths and $\mathrm{N}-\mathrm{Zn}-\mathrm{N}$ angles in the ranges of $2.135(2) \AA$ to $2.173(2) \AA$ and $75.7(1)^{\circ}$ to $168.2(1)^{\circ}$, respectively. Both perchlorate anions are engaged in H-bonding to the hydroxyl groups of adjacent cations in bridging 
fashion. There was residual electron density corresponding to disorder solvent, which was removed using Platon squeeze function [82]. 


\subsection{Characterization of transition metal dhbpyH $\mathrm{H}_{2}$ complexes}

\subsubsection{X-ray crystallography}

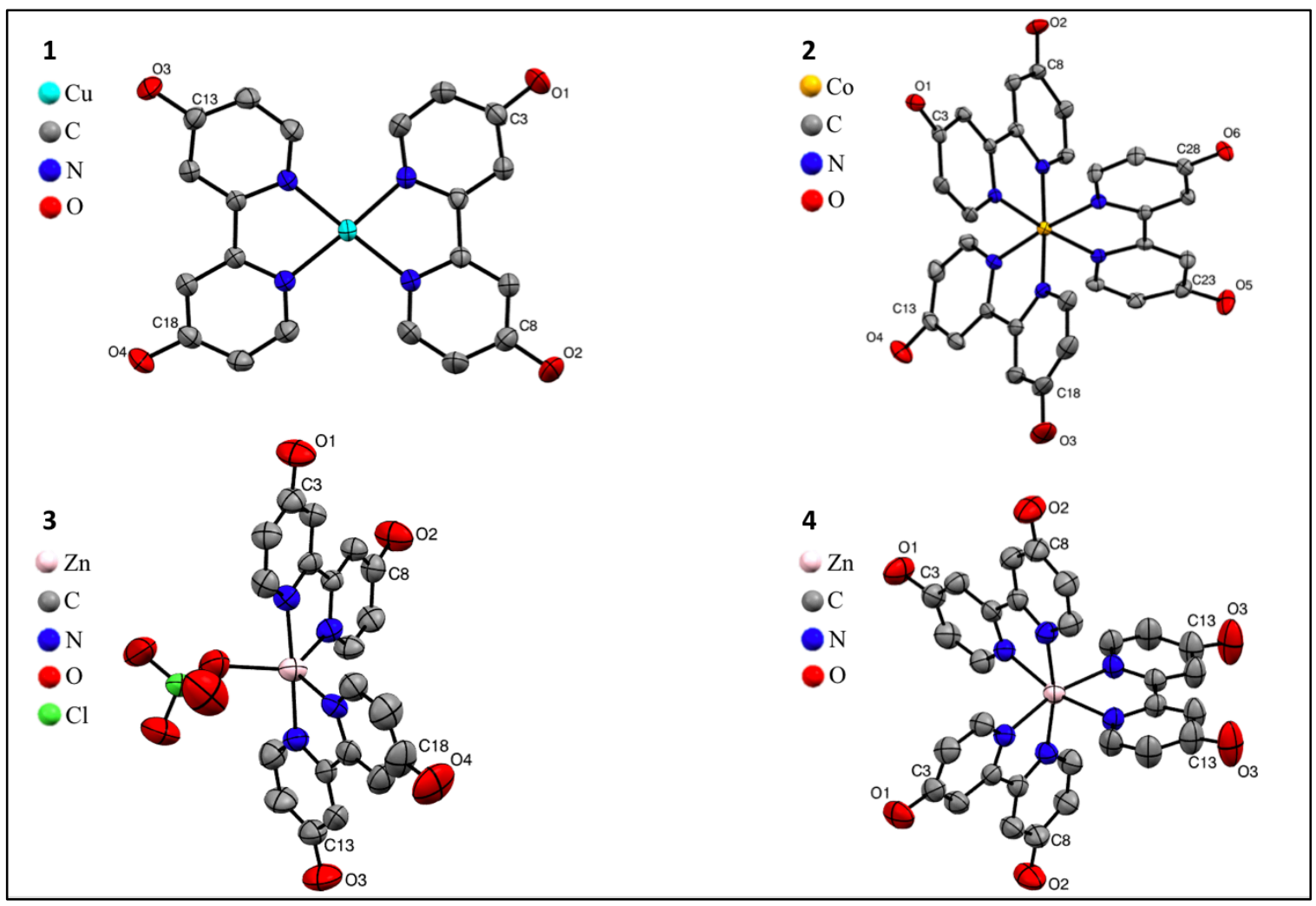

Figure 3.2. Ball and stick models of compounds 1-4.

\begin{tabular}{|c|c|c|c|c|c|c|c|}
\hline \multicolumn{2}{|c|}{$\mathrm{Cu}(\mathrm{dhbpyH})_{2}[1]$} & \multicolumn{2}{|c|}{$\mathrm{Co}\left(\mathrm{dhbpyH}_{2}\right)_{3}[2]$} & \multicolumn{2}{c|}{$\mathrm{Zn}(\mathrm{dhbpyH})_{2}[3]$} & \multicolumn{2}{|c|}{$\mathrm{Zn}(\mathrm{dhbpyH})_{3}[4]$} \\
\hline Bond & distance $(\AA)$ & Bond & distance $(\AA)$ & Bond & distance $(\AA)$ & Bond & distance $(\AA)$ \\
\hline C1-O1 & $\mathbf{1 . 3 3 9 ( 3 )}$ & C3-O1 & $\mathbf{1 . 3 2 1 ( 5 )}$ & C1-O1 & $\mathbf{1 . 3 2 8}(7)$ & C1-O1 & $\mathbf{1 . 3 3 7 ( 3 )}$ \\
\hline C2-O2 & $\mathbf{1 . 3 3 6 ( 3 )}$ & C8-O2 & $\mathbf{1 . 3 2 8 ( 5 )}$ & C2-O2 & $\mathbf{1 . 3 2 8 ( 8 )}$ & C2-O2 & $\mathbf{1 . 3 3 1 ( 3 )}$ \\
\hline C3-O3 & $\mathbf{1 . 3 3 7 ( 3 )}$ & C18-O3 & $\mathbf{1 . 3 3 6 ( 6 )}$ & C3-O3 & $\mathbf{1 . 3 3 4 ( 8 )}$ & C3-O3 & $\mathbf{1 . 3 3 5 ( 3 )}$ \\
\hline C4-O4 & $\mathbf{1 . 3 4 1 ( 3 )}$ & C13-O4 & $\mathbf{1 . 3 3 7 ( 5 )}$ & C4-O4 & $\mathbf{1 . 3 3 6 ( 8 )}$ & C4-O4 & $\mathbf{1 . 3 3 7 ( 3 )}$ \\
\hline & & C23-O5 & $\mathbf{1 . 3 3 3 ( 5 )}$ & & & C5-O5 & $\mathbf{1 . 3 3 1 ( 3 )}$ \\
\hline & & C28-O6 & $\mathbf{1 . 2 9 8 ( 5 )}$ & & & C6-O6 & $\mathbf{1 . 3 3 5 ( 3 )}$ \\
\hline
\end{tabular}

Table 3.1. Selected bond lengths for compounds 1-4 


\begin{tabular}{|c|c|c|c|c|}
\hline Compound & $\begin{array}{c}{\left[\mathrm{Cu}\left(\mathrm{dhbpyH}_{2}\right)_{2}\right]\left(\mathrm{ClO}_{4}\right)_{2}} \\
(\mathbf{1})\end{array}$ & $\begin{array}{c}{\left[\mathrm{Co}\left(\mathrm{dhbpyH}_{2}\right)_{3}\right]\left(\mathrm{ClO}_{4}\right)_{3}} \\
(\mathbf{2})\end{array}$ & $\begin{array}{c}{\left[\mathrm{Zn}\left(\mathrm{dhbpyH}_{2}\right)_{2}\right]\left(\mathrm{ClO}_{4}\right)_{2}} \\
(\mathbf{3})\end{array}$ & $\begin{array}{c}{\left[\mathrm{Zn}\left(\mathrm{dhbpyH}_{2}\right)_{3}\right]\left(\mathrm{ClO}_{4}\right)_{2}} \\
(\mathbf{4})\end{array}$ \\
\hline Empirical formula & $\mathrm{C}_{47} \mathrm{H}_{40} \mathrm{Cl}_{4} \mathrm{Cu} 2 \mathrm{~N}_{8} \mathrm{O}_{25}$ & $\mathrm{C}_{30} \mathrm{H}_{30} \mathrm{Cl}_{2} \mathrm{CoN}_{6} \mathrm{O}_{16}$ & $\mathrm{C}_{27} \mathrm{H}_{27} \mathrm{Cl}_{2} \mathrm{~N}_{4} \mathrm{O}_{13} \mathrm{Zn}$ & $\mathrm{C}_{38} \mathrm{H}_{40} \mathrm{Cl}_{2} \mathrm{~N}_{6} \mathrm{O}_{16} \mathrm{Zn}$ \\
\hline Formula weight & 1385.75 & 860.43 & 751.79 & 973.03 \\
\hline Temperature/K & 298 & 293 & 273 & 298 \\
\hline Crystal system & monoclinic & orthorhombic & triclinic & monoclinic \\
\hline Space group & $C 2 / c$ & Pccn & $P-1$ & $P 2 / n$ \\
\hline $\mathrm{a} / \AA$ & $25.1020(9)$ & $32.190(2)$ & $8.1593(9)$ & $12.223(2)$ \\
\hline $\mathrm{b} / \AA$ & $14.6838(5)$ & $14.8240(8)$ & $14.147(2)$ & $14.838(2)$ \\
\hline $\mathrm{c} / \AA$ & $15.8194(5)$ & $15.0524(8)$ & $15.248(2)$ & $13.547(2)$ \\
\hline$\alpha /^{\circ}$ & 90 & 90 & $111.678(3)$ & 90 \\
\hline$\beta /{ }^{\circ}$ & $112.626(1)$ & 90 & $104.854(3)$ & $95.669(3)$ \\
\hline$\gamma /{ }^{\circ}$ & 90 & 90 & $94.404(3)$ & 90 \\
\hline Volume $/ \AA^{3}$ & $5382.1(3)$ & $7182.8(7)$ & $1551.8(3)$ & $2445.0(5)$ \\
\hline $\mathrm{Z}$ & 4 & 8 & 2 & 2 \\
\hline$\rho_{\text {calc }} \mathrm{g} / \mathrm{cm}^{3}$ & 1.710 & 1.591 & 1.609 & 1.322 \\
\hline$\mu / \mathrm{mm}^{-1}$ & 1.086 & 0.709 & 1.04 & 0.680 \\
\hline $\mathrm{F}(000)$ & 2816 & 3528 & 770 & 1004 \\
\hline Reflections collected & 35601 & 87416 & 27026 & 28884 \\
\hline Independent reflections & 5737 & 7420 & 6396 & 4940 \\
\hline Data/restraints/parameters & $5737 / 123 / 425$ & $7420 / 94 / 554$ & $6396 / 20 / 431$ & $4940 / 203 / 352$ \\
\hline Goodness-of-fit on $\mathrm{F}^{2}$ & 1.026 & 1.079 & 1.005 & 1.043 \\
\hline Final $\mathrm{R}$ indexes $[\mathrm{I}>=2 \sigma(\mathrm{I})]$ & $\mathrm{R}_{1}=0.0379, \mathrm{wR}_{2}=0.0876$ & $\mathrm{R}_{1}=0.0687, \mathrm{wR}_{2}=0.1760$ & $\mathrm{R}_{1}=0.0815, \mathrm{wR}_{2}=0.1814$ & $\mathrm{R}_{1}=0.524, \mathrm{wR}_{2}=0.1390$ \\
\hline Final $\mathrm{R}$ indexes [all data] & $\mathrm{R}_{1}=0.0563, \mathrm{wR}_{2}=0.0956$ & $\mathrm{R}_{1}=0.0838, \mathrm{wR}_{2}=0.1866$ & $\mathrm{R}_{1}=0.2120, \mathrm{wR}_{2}=0.2335$ & $\mathrm{R}_{1}=0.0733, \mathrm{wR}_{2}=0.1517$ \\
\hline Largest diff. peak/hole / e $\AA^{-3}$ & $0.348 /-0.45$ & $2.10 /-0.68$ & $0.67 /-0.46$ & $0.62 /-0.32$ \\
\hline
\end{tabular}

Table 3.2. Crystallographic details for compounds 1-4 


\subsubsection{Luminescence}

Absorbance and emission spectra were collected for all the samples in degassed DMF. All the complexes exhibited a $\lambda_{\max } 290 \mathrm{~nm}$ attributed to the $\pi-\pi *$ transition. Steady-state emission spectra were measured using $305 \mathrm{~nm}$ excitation wavelength with bandwidth and slit width for emission set at $2 \mathrm{~nm}$. Luminescence studies revealed fluorescence for both zinc complexes with complex $\mathbf{3}$ exhibiting the highest response.
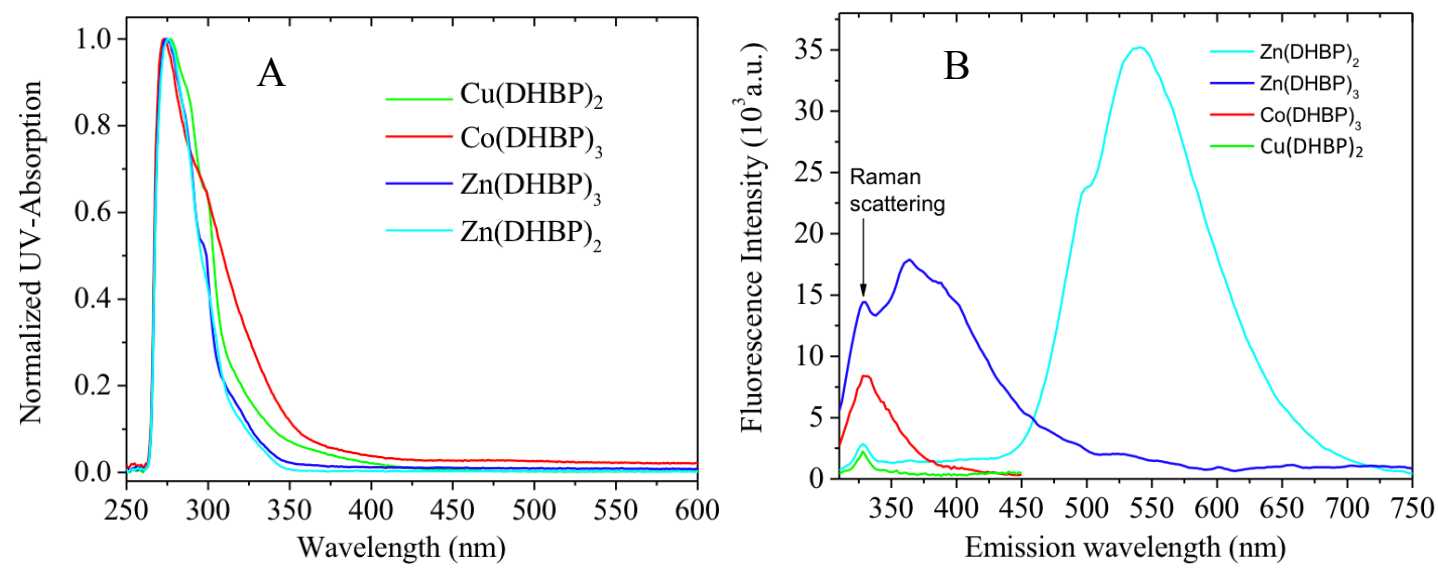

Figure 3.3. A) Absorption spectra and B) Emission spectra for compounds 1-4 in DMF

Normalized absorption and emission spectra for $\left[\mathrm{Zn}\left(\mathrm{dhbpyH}_{2}\right)_{2}\right]^{2+}(3)$ in DMF is shown in Fig. 3.3. The emission spectrum of $\mathbf{3}$ occurs at $\lambda_{\max }=537 \mathrm{~nm}$ with a Stokes shift of $15,860 \mathrm{~cm}^{-1}$ and a quantum yield of $6 \times 10^{-4}$.

Fluorescence lifetimes were determined using multi-frequency phase/modulation fluorometry. The plot of phase shift and modulation ratio as a function of modulation frequency is shown in Fig. 3.4 for $\left[\mathrm{Zn}\left(\mathrm{dhbpyH}_{2}\right)_{2}\right]^{2+}$. Phase delay is shown as squares and modulation ratio as circles and the solid line represents the data fitting using two exponential decay models. The data analysis using a sum of two exponential models 
reveal a major component with a lifetime of $4.95 \mathrm{~ns}$ and fractional intensity of 0.98 and a minor component with a sub nanosecond lifetime of $0.16 \mathrm{~ns}$ and fraction intensity of 0.02 .

The emission decay of $\left[\mathrm{Zn}\left(\mathrm{dhbpyH}_{2}\right)_{3}\right]^{2+}$ is more complex as a satisfactory fit was only obtained using a three exponential decay model, according to which the major component (fractional contribution of 0.23 ) has the shorter lifetime of $0.15 \mathrm{~ns}$, followed by two slower processes with lifetimes of $1.85 \mathrm{~ns}$ and $7.95 \mathrm{~ns}$ (and fractional contributions of 0.13 and 0.11 ), respectively.

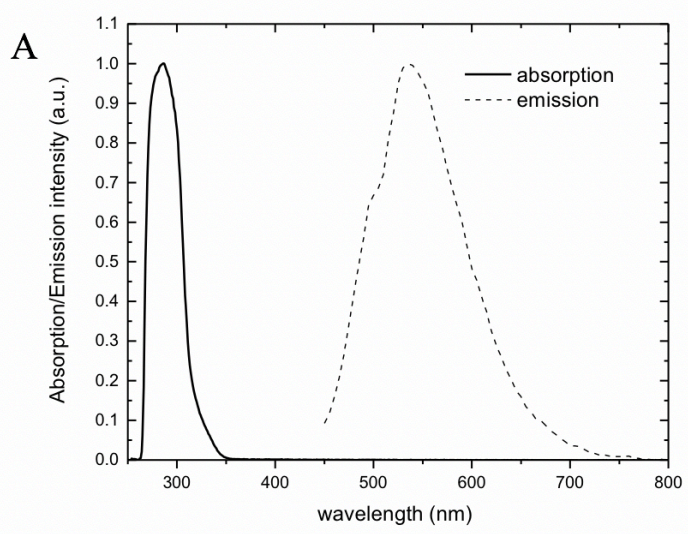

Figure 3.4. Absorption (solid) and emission spectra (broken) of $\mathbf{3}$ in DMF.

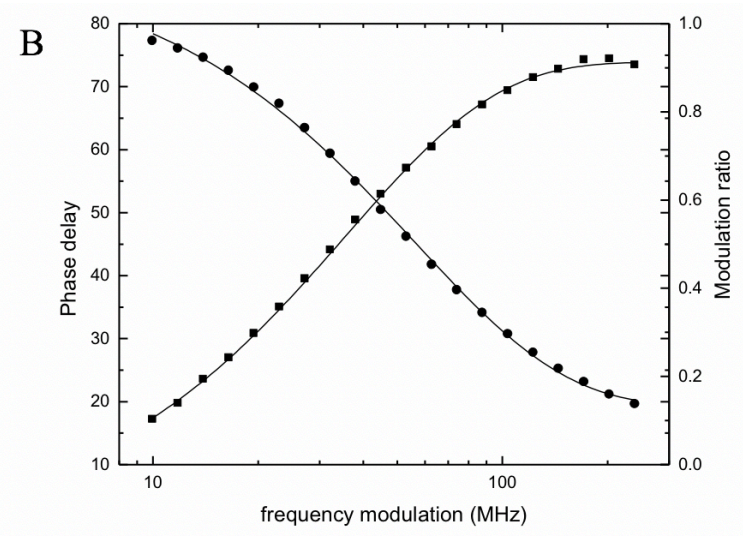

Figure 3.5. Frequency intensity decay of $\mathbf{3}$ in DMF. 


\subsubsection{Electrochemistry}

Complexes 1 and 2 exhibited reversible redox process at a $-0.429 \mathrm{~V}$ and $-0.328 \mathrm{~V}$ (vs. $\mathrm{Fc} / \mathrm{Fc}^{+}$) attributed to the $\mathrm{Cu}^{2+/+}$ and $\mathrm{Co}^{3+/ 2+}$ couples, respectively (Fig. 3.5). The reduction of 2 occurs at a more anodic $\mathrm{E}_{1 / 2}$ than that of $\left[\mathrm{Co}(\mathrm{bpy})_{3}\right]^{3+}(-0.07 \mathrm{~V})[73]$, in agreement with the trend observed by Nolan et al., namely, the better electron releasing properties of the dihydroxylated bipyridine ligand destabilize the reduced species [83]. As expected, no reversible process was observed for the zinc complexes $\mathbf{3}$ and $\mathbf{4}$ within the potential window of our study.

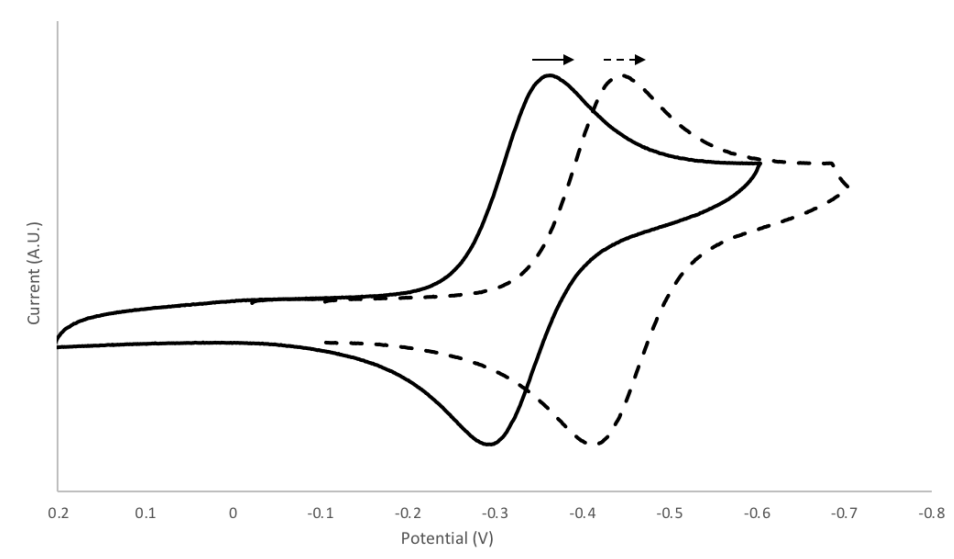

Figure 3.6. Cyclic voltammogram of $\mathbf{1}$ (solid) and $\mathbf{2}$ (dashed).

\subsubsection{NMR}

The NMR spectra were collected for all complexes, as expected the paramagnetic copper complex did not show signals for the ligand protons. Compound $\mathbf{3}$ gave a very straightforward spectrum with three signals accounting for the protons in one pyridine ring (scheme 3.1). Compound 4 also shows three signals but there is a shift when compared to 3 , attributed to the proximity of proton 6 in an octahedral environment. 


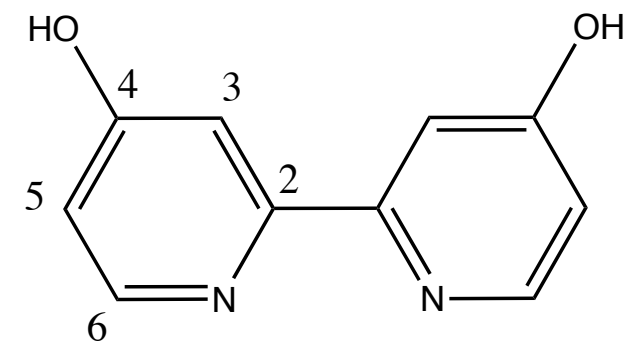

Scheme 3.1. Atom labeling scheme for the dhbpyH $\mathrm{H}_{2}$ ligand.

The case of $\left[\mathrm{Co}\left(\mathrm{dhbpyH}_{2}\right)_{3}\right]^{3+}$ cation of complex 2 is quite unusual as the ${ }^{1} \mathrm{H}-$ NMR spectra in both $\mathrm{CD}_{3} \mathrm{OD}(400$ and $600 \mathrm{MHz})$ (Fig 3.6) and $\left(\mathrm{CD}_{3}\right)_{2} \mathrm{NC}(\mathrm{O}) \mathrm{D}(400$ $\mathrm{MHz}$ ) show only two resonances at 7.14 and $8.01 \mathrm{ppm}$ with integration 2:1, instead of the expected three, with 1:1:1 ratio. Furthermore, no proton-proton coupling was observed. In contrast, the ${ }^{13} \mathrm{C}-\mathrm{NMR}$ spectrum shows the expected five distinct resonances for the pyridyl rings (Fig. 3.7). The above observations are attributed to accidental isochronism of $\mathrm{H}^{5}$ and $\mathrm{H}^{6}$, a rare phenomenon, which has been reported mainly in organic compounds and, to the best of our knowledge, for only two inorganic complexes, $\left[\mathrm{Co}(\text { tpy })_{2}\right]^{3+}$ and dibenzylphenylsilyllithium $[84,85]$. 


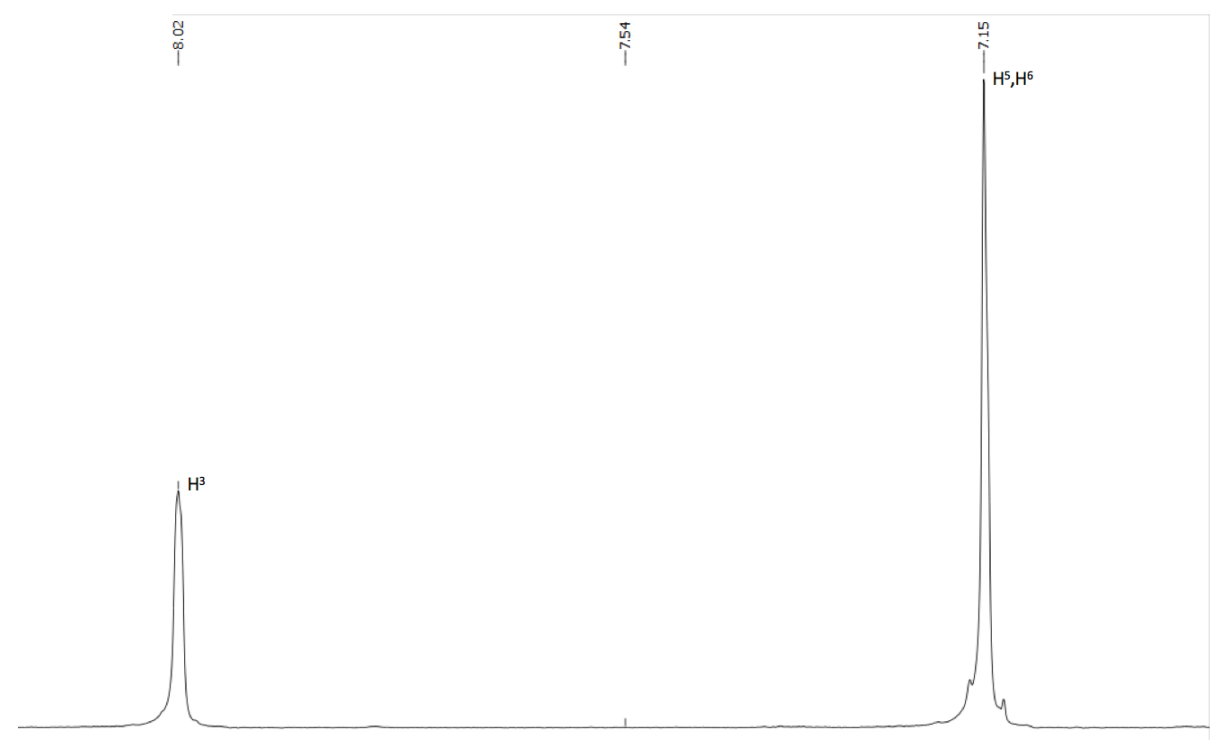

$\begin{array}{lllllllllllllllllllllllllllll}20 & 8.15 & 8.10 & 8.05 & 8.00 & 7.95 & 7.90 & 7.85 & 7.80 & 7.75 & 7.70 & 7.65 & 7.60 & 7.75 & 7.50 & 7.45 & 7.40 & 7.35 & 7.30 & 7.25 & 7.20 & 7.15 & 7.10 & 7.05 & 7.00 & 6.95 & 6 .\end{array}$

Figure 3.7. $400 \mathrm{MHz}{ }^{1} \mathrm{H}-\mathrm{NMR}$ of $\left[\mathrm{Co}\left(\mathrm{dhbpyH}_{2}\right)_{3}\right]\left(\mathrm{ClO}_{4}\right)_{3}$ in $\mathrm{CD}_{3} \mathrm{OD}$.

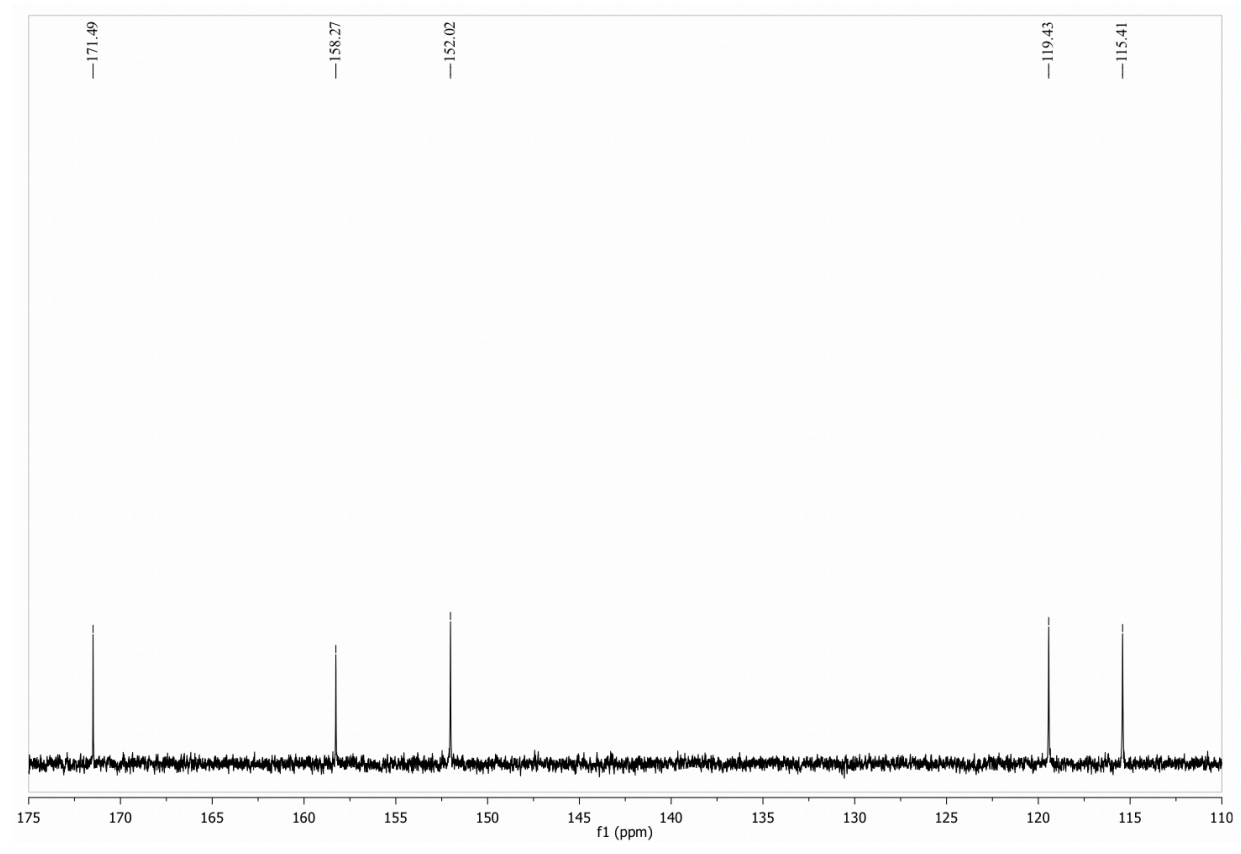

Figure 3.8. $100 \mathrm{MHz}{ }^{13} \mathrm{C}-\mathrm{NMR}$ of $\left[\mathrm{Co}\left(\mathrm{dhbpyH}_{2}\right)_{3}\right]\left[\mathrm{ClO}_{4}\right]_{3}$ in $\mathrm{CD}_{3} \mathrm{OD}$ 


\subsection{Conclusions:}

Four first-row transition metal homoleptic dhbpyH $\mathrm{H}_{2}$ complexes have been prepared and characterized structurally, electrochemically and photophysically. The sterically unhindered peripheral hydroxyl groups should allow in future work the attachment of these complexes to solid supports, or further chemical functionalization. The hydroxyl functionality also imparts the complexes with a $\mathrm{pH}$ responsiveness that can be used to tailor their properties for specific applications such as imaging and sensors.

One of the original objectives of this particular part of the project was to compare and contrast the properties of first-row transition metal complexes of dhbpyH $\mathrm{H}_{2}$ to the properties of the ruthenium version. In particular how the redox and luminescence compared. The table below compares the results obtained on this part of the project.

\begin{tabular}{|c|c|c|c|c|c|}
\hline & $\mathbb{E}_{1 / 2}$ & Abs $(\mathbf{n m})$ & Emission (nm) & Lifetime (ns) & Quantum yield \\
\hline $\mathbf{1}$ & -0.429 & 274 & - & - & - \\
\hline $\mathbf{2}$ & -0.328 & 274 & - & - & - \\
\hline $\mathbf{3}$ & - & 274 & 537 & 5.1 & 0.0006 \\
\hline $\mathbf{4}$ & - & 274 & 415 & $0.15,1.85$, & - \\
\hline$\left[\mathbf{R u}(\mathbf{d h b p y H})_{3}\right]^{2+}$ & $0.88(\mathrm{SCE})$ & 273 & 650 & $?$ & 0.0066 \\
\hline
\end{tabular}

Table 3.3. Comparison of electrochemical and photophysical properties of 1-4 vs $\mathrm{Ru}\left(\mathrm{dhbpyH}_{2}\right)_{3}$.

Electrochemically, compounds $\mathbf{1}$ and $\mathbf{2}$ contrast with the ruthenium complex in that they undergo a metal based reduction as opposed to the metal based oxidation observed for ruthenium. Their electrochemistry as well as the fact that they exhibit no luminescence indicate that compounds $\mathbf{1}$ and $\mathbf{2}$ could not function as photo-excitable 
electron donors. Compounds $\mathbf{3}$ and $\mathbf{4}$ do exhibit some luminescence but do not undergo any metal based redox process. Out of those two, compound $\mathbf{3}$ exhibits the best photophysical properties but even so it does not compare positively to ruthenium. Compound $\mathbf{3}$ has a much lower quantum yield than its ruthenium analogue which is in turn another order of magnitude lower than the Ru(bpy $)_{3}$ standard. The lack or redox processes, low quantum yield and the short lifetimes of their photoexcited states, much shorter than the $50 \mathrm{~ns}$ and $1100 \mathrm{~ns}$ lifetime of the best Ru-bpy-based devices [65, 66], show compounds $\mathbf{3}$ and $\mathbf{4}$ to be poor candidates for applications in solar energy conversion. However, the high redox stability and luminescence render complex 3 potentially useful in biomedical applications. For such applications, the hydroxyl groups represent an advantage in terms of solubility and biocompatibility, as well as serving as a functionalizable group to attach targeting motifs.

These complexes provide an alternative to the ruthenium counterpart and although the properties of these abundant metals are not as good as those for the ruthenium complex, they represent a first step in the understanding the chemistry of this ligand with first row transition metals and provide a starting point to work on the development of more efficient alternatives.

Furthermore, compounds $\mathbf{1}$ and $\mathbf{2}$ exhibit comparable electrochemical properties to other cobalt based redox couples used in DSSC, opening the possibility that these complexes could be use in photovoltaic cells as electron shuttles. These complexes undergo reversible one electron reduction with the added benefit of an increased hydrophilicity due to the hydroxylated ligand, making them appealing alternatives for the emerging water-based systems. 


\subsection{Experimental:}

This chapter describes the synthesis and characterization of four first-row transition metal complexes with the dihydroxybipyridine ligand.

\subsubsection{Materials:}

All commercially available reagents utilized in this work were of analytical grade and in most cases they were used as received. 4,4'-dihydroxy-2,2'-bipyridine was synthesized using previously reported procedures [86]. The following reagents were obtained from Acros Organics: $\mathrm{Cu}\left(\mathrm{ClO}_{4}\right)_{2}, \mathrm{Co}\left(\mathrm{ClO}_{4}\right)_{3}, \mathrm{Zn}\left(\mathrm{ClO}_{4}\right)_{2}, \mathrm{THF}$, toluene and acetonitrile. Ethanol was received from Fisher. All solvents were distilled and degassed prior to use.

\subsubsection{Instrumentation:}

Single crystal X-ray crystallography data were obtained from crystals mounted atop glass fibers using a Bruker D8 Quest CMOS diffractometer fitted with a graphitemonochromated Mo-K $\mathrm{K}_{\alpha}$ radiation $(\lambda=0.71073 \AA)$. Data were collected using the APEX3 software suite and corrected for Lorentz and polarization effects [46]. The structures were solved using SHELXT [47] and refined by full-matrix least squares on $\mathrm{F}^{2}$ using the SHELXL-direct methods and using OLEX2 [48] and ShelXle [49]. Multi-scan absorption correction was performed using SADABS [50]. All non-hydrogen atoms were anisotropically refined, and hydrogen atoms were placed at calculated positions and refined as riding atoms with isotropic displacement parameters. Crystallographic details pertaining to data collection and structure refinement for $\mathbf{1}-\mathbf{4}$ are collected in Table 1 . 
Electrochemical measurements were carried out with a Bioanalytical Systems (BASi) Epsilon potentiostat. Cyclic voltammetry (CV) was performed with a standard three-electrode setup with an $\mathrm{Ag} / \mathrm{AgNO}_{3}$ reference electrode, platinum wire auxiliary electrode, and glassy carbon working electrode. All measurements were conducted in 0.1 $\mathrm{M}$ tetrabutylammonium hexafluorophosphate $\left(\mathrm{TBAPF}_{6}\right)$ in acetonitrile. The solutions were degassed for approximately $10 \mathrm{~min}$ with argon before running the experiments. All experimental data are calibrated with reference to the ferricinium/ferrocene $\left(\mathrm{Fc}^{+/ 0}\right)$ couple measured using an internal Fc standard.

Steady-state emission spectra were measured on a PC1 spectrofluorometer using $305 \mathrm{~nm}$ excitation wavelength with bandwidth and slit width for emission set at 2 $\mathrm{nm}$. Frequency-domain fluorescence lifetime measurements were performed using a ChronosFD spectrofluorometer. Samples were excited with a frequency modulated 305 nm LED and emission was collected using a $400 \mathrm{~nm}$ long pass filters (Andover); 1, 4bis(5-phenyloxazole-2-yl)benzene (POPOP) in ethanol was used as a lifetime reference ( $\tau$ $=1.35 \mathrm{~ns})$. Modulation-phase data were fitted by a multiple-exponential decay model using GlobalsWE software and the $\chi^{2}$ parameters was used as criterion for goodness of fit. ${ }^{1} \mathrm{H}-\mathrm{NMR}$ and ${ }^{13} \mathrm{C}-\mathrm{NMR}$ were collected in a Bruker Avance $400 \mathrm{MHz}$ NMR. Elemental analyses were carried out by Galbraith Labs Inc., Knoxville, TN.

\subsubsection{Synthesis:}

\section{$\left[\mathrm{Cu}\left(\mathrm{dhbpyH}_{2}\right)_{2}\right]\left[\mathrm{ClO}_{4}\right]_{2} \cdot 0.5 \mathrm{H}_{2} \mathrm{O} \cdot 0.5$ toluene (1)}

In a $25 \mathrm{~mL}$ Erlenmeyer flask $0.0500 \mathrm{~g}$ of dhbpyH $\mathrm{H}_{2}(0.235 \mathrm{mmol})$ were added to a suspension of $\mathrm{Cu}\left(\mathrm{ClO}_{4}\right)_{2}(0.050 \mathrm{~g} ; 0.134 \mathrm{mmol})$ in $10 \mathrm{~mL}$ of tetrahydrofuran (THF) and 
stirred at ambient temperature for $24 \mathrm{~h}$. The resulting blue solution was filtered through Celite. The filtrate was then brought to dryness by means of rotary evaporation to afford $0.0580 \mathrm{~g}(69 \%$ yield $)$ of the product $\left[\mathrm{Cu}\left(\mathrm{dhbpyH}_{2}\right)_{2}\right]\left[\mathrm{ClO}_{4}\right]_{2}$. X-ray quality blue crystals were grown by layering a solution of $\mathbf{1}$ over toluene in a closed test tube. For 1.0.5 $\mathrm{H}_{2} \mathrm{O} \cdot 0.5 \mathrm{C}_{7} \mathrm{H}_{8} \mathrm{O}, \mathrm{C}_{23.5} \mathrm{H}_{21} \mathrm{~N}_{4} \mathrm{Cl}_{2} \mathrm{CuO}_{12.5}$, found (calculated)\%: $\mathrm{C}, 40.84$ (40.68); $\mathrm{H}$, 3.07 (3.05); N, 8.09 (8.07).

\section{$\left[\mathrm{Co}\left(\mathrm{dhbpyH}_{2}\right)_{2}\left(\mathrm{dhbpyH}^{-}\right)\right]\left[\mathrm{ClO}_{4}\right]_{3} \cdot 2 \mathrm{H}_{2} \mathrm{O}$ (2).}

In a $25 \mathrm{~mL}$ Erlenmeyer flask $0.0500 \mathrm{~g}$ of dhbpyH $\mathrm{H}_{2}(0.235 \mathrm{mmol})$ were added to a suspension of $\mathrm{Co}\left(\mathrm{ClO}_{4}\right)_{3}(0.033 \mathrm{~g} ; 0.089 \mathrm{mmol})$ in $10 \mathrm{~mL}$ of ethanol and stirred at ambient temperature for $24 \mathrm{~h}$. The resulting blue solution was filtered through Celite. The filtrate was then brought to dryness by means of rotary evaporation to afford $0.0387 \mathrm{~g}$ ( $46 \%$ yield) of the product $\left[\mathrm{Co}\left(\mathrm{dhbpyH}_{2}\right)_{3}\right]\left[\mathrm{ClO}_{4}\right]_{2}$. X-ray quality orange crystals were grown by slow evaporation of an acetonitrile solution of the compound over several weeks. For $2 \cdot 2 \mathrm{H}_{2} \mathrm{O}, \mathrm{C}_{30} \mathrm{H}_{27} \mathrm{~N}_{6} \mathrm{Cl}_{2} \mathrm{CoO}_{16}$ found (calculated)\%: C, 40.60 (42.03); $\mathrm{H}, 3.09$ (3.17); N, 9.37 (9.80). ${ }^{1} \mathrm{H}-\mathrm{NMR}\left(400 \mathrm{MHz}\right.$ and $\left.600 \mathrm{MHz}, \mathrm{CD}_{3} \mathrm{OD}\right), \delta(\mathrm{ppm}): 8.01\left(\mathrm{H}^{3}, \mathrm{~s}, 1 \mathrm{H}\right), 7.14$ $\left(\mathrm{H}^{5,6}, \mathrm{~s}, 2 \mathrm{H}\right) .{ }^{1} \mathrm{H}-\mathrm{NMR}\left(400 \mathrm{MHz}, \mathrm{DMF}-\mathrm{d}^{7}\right), \delta(\mathrm{ppm}): 8.01\left(\mathrm{H}^{3}, \mathrm{~s}, 1 \mathrm{H}\right), 7.14\left(\mathrm{H}^{5,6}, \mathrm{~s}, 2 \mathrm{H}\right)$, $8.06(\mathrm{OH}, \mathrm{s}, 1 \mathrm{H}) .{ }^{13} \mathrm{C}-\mathrm{NMR}\left(100 \mathrm{MHz}, \mathrm{CD}_{3} \mathrm{OD}\right), \delta(\mathrm{ppm}): 115.41\left(\mathrm{C}^{5}\right), 119.43\left(\mathrm{C}^{3}\right)$, $152.02\left(\mathrm{C}^{6}\right), 158.27\left(\mathrm{C}^{4}\right), 171.49\left(\mathrm{C}^{2}\right)$.

\section{$\left[\mathrm{Zn}\left(\mathrm{dhbpyH}_{2}\right)_{2}\right]\left[\mathrm{ClO}_{4}\right]_{2} \cdot 2 \mathrm{H}_{2} \mathrm{O}(3)$ and $\left.\left[\mathrm{Zn}\left(\mathrm{dhbpyH}_{2}\right)_{3}\right][\mathrm{ClO}]_{4}\right]_{2} \cdot \mathrm{THF}(4)$.}

In a $25 \mathrm{~mL}$ Erlenmeyer flask $0.0500 \mathrm{~g}$ of dhbpyH $\mathrm{H}_{2}(0.235 \mathrm{mmol})$ were added to a suspension of $\mathrm{Zn}\left(\mathrm{ClO}_{4}\right)_{2}(0.050 \mathrm{~g} ; 0.133 \mathrm{mmol})$ in $10 \mathrm{~mL}$ of tetrahydrofuran (THF) and 
stirred at ambient temperature for $24 \mathrm{~h}$. At this point a faint pink tint could be observed. The solution was filtered through Celite and its volume reduced to a few $\mathrm{mL}$ by means of rotary evaporation. The pink concentrated solution was set to recrystallize by layering it over toluene in a closed test tube. After a few days colorless crystals as well as pink crystals could be observed in the test tube. Crystals had to be harvested manually under a microscope and $0.0320 \mathrm{~g}$ of $\mathbf{3}$ ( $38 \%$ yield, colorless) and $0.0080 \mathrm{~g}$ of 4 (12\% yield, pink) were obtained. For $32 \mathrm{H}_{2} \mathrm{O}, \mathrm{C}_{22} \mathrm{H}_{22} \mathrm{~N}_{4} \mathrm{Cl}_{2} \mathrm{ZnO}_{14.5}$ found (calculated)\%: C, 36.29(36.92); $\mathrm{H}$, 4.11 (3.35); N, 8.29 (7.90). ${ }^{1} \mathrm{H}-\mathrm{NMR}\left(400 \mathrm{MHz}, \mathrm{CD}_{3} \mathrm{OD}\right), \delta(\mathrm{ppm}): 7.70\left(\mathrm{H}^{3}, \mathrm{~s}, 1 \mathrm{H}\right), 7.16$ $\left(\mathrm{H}^{5}, \mathrm{dd},{ }^{3} \mathrm{~J}=6.24 \mathrm{~Hz}\right.$ and $\left.{ }^{4} \mathrm{~J}=2.12 \mathrm{~Hz}, 1 \mathrm{H}\right), 8.51\left(\mathrm{H}^{6}, \mathrm{~d},{ }^{3} \mathrm{~J}=6.24 \mathrm{~Hz}, 1 \mathrm{H}\right)$. For $4 \mathrm{THF}$, $\mathrm{C}_{38} \mathrm{H}_{40} \mathrm{~N}_{6} \mathrm{Cl}_{2} \mathrm{ZnO}_{16}$ found (calculated)\%: C, 45.86 (45.33); $\mathrm{H}, 3.87$ (3.58); N, 10.57 (9.33). ${ }^{1} \mathrm{H}-\mathrm{NMR}\left(400 \mathrm{MHz}, \mathrm{CD}_{3} \mathrm{OD}\right), \delta(\mathrm{ppm}): 7.75\left(\mathrm{H}^{3}, \mathrm{~s}, 1 \mathrm{H}\right), 6.93\left(\mathrm{H}^{5}, \mathrm{~d},{ }^{3} \mathrm{~J}=6.24\right.$ $\mathrm{Hz}, 1 \mathrm{H}), 7.70\left(\mathrm{H}^{6}, \mathrm{~d},{ }^{3} \mathrm{~J}=6.24 \mathrm{~Hz}, 1 \mathrm{H}\right)$.

Warning: Perchlorate salts are potentially explosive and should be handled with extreme caution in the minimum quantities required. 


\section{Chapter 4: Preparation and characterization of hybrid materials for solar polymer cell applications}

The results of this chapter were obtained in collaboration with:

Dr. Yiannis Sanakis, NCSR Demokritos, Athens, Greece

Dr. Hyeon Suk Shin, UNIST, Ulsan, Korea

Dr. Arturo Hernandez-Maldonado, UPR-M, Mayaguez, Puerto Rico 


\subsection{Introduction:}

Bulk heterojunction cells typically use $\mathrm{C}_{60}$ derivatives, phenyl- $\mathrm{C}_{61}$-butyric acid methyl ester (PCBM) being the most common, as electron acceptors [87]. While the solubility of these molecules in common polymer donors is not optimal, so far they are have mostly been used directly. As detailed above $\mathrm{Fe}_{8}$ has lower reduction potentials than $\mathrm{C}_{60}$, making it an attractive alternative for the electron acceptor role. Previous attempts to prepare cells using $\mathrm{Fe}_{8}$ resulted in aggregation of the material and dephasing, so a new strategy was devised, to imbed $\mathrm{Fe}_{8}$ in a compatible polymer. This new material that combines $\mathrm{Fe}_{8}$ and an organic polymer, falls under the category of hybrid materials.

The combinations of organic and inorganic motifs into single products have afforded an interesting array of new composites classified under the broad term of hybrid materials [88]. These new materials include sol-gel matrices, metal organic frameworks, coordination polymers, nanoparticles coated or decorated with organic molecules and polymers embedded or decorated with inorganic clusters. The advantages of hybrid materials over their basic components have opened up new avenues to address challenges in the emerging material field. An interesting area of research on the hybrid materials subject is the organic polymer-inorganic cluster hybrids. The combinations of these building blocks yield new products that do not conform to the traditional structural demarcations of conventional polymers. In these hybrid materials the electronic, thermal and optical properties of metal clusters are combined synergistically with the mechanical flexibility and low cost properties of organic polymers. The resulting composites exhibit the desirable properties of the basic components, minus some of the disadvantages of the starting materials. Some of the properties that can be improved in the resulting composite 
are: thermal stability, conductivity, magnetics, catalytic activity, reduced flammability, reduced viscosity, dielectric constant, and oxidation resistance. These properties have been exploited in diverse fields including: flexible electronics, sensors, catalysis, electrochemical devices, and biomedical or bioactive materials [89].

Some of the initial problems associated with these new materials were nonhomogeneous distribution, leaching, demixing, and phase agglomeration due to the intermolecular forces involved. Simple mechanical mixing of the components led to Van der Waals and H-bonding interactions that were not strong enough to guarantee an even and fixed distribution of the inorganic clusters in the organic polymer host [90]. Recent advances have led to the development of new synthetic strategies that incorporate functionalities on the surface of the inorganic motif that allow for covalent bonding to the polymer thus overcoming the initial problems that prevented practical applications for the composites [91].

This project will examine the composite produced by the combination of poly(4vinylphenol) (PVPOH) (Scheme 4.1a) or poly(4-vinylphenol-co-methyl methacrylate) (PVPOH-co-MMA) (organic hosts) and member of the $\left[\mathrm{Fe}_{8}\left(\mu_{4}-\mathrm{O}\right)_{4}(\mu-4-\mathrm{R}-\mathrm{pz})_{12} \mathrm{Cl}_{4}\right]\left(\mathrm{Fe}_{8}\right)$ family (inorganic guest). Polyvinylphenol is an inexpensive polymer similar in structure to polystyrene, but with a hydroxyl group on the para position. It is a weakly acidic polymer that can be deprotonated and will cross-link when exposed to deep UV light. Upon deprotonation the electrostatic repulsion of the phenoxide groups induces swelling of the polymer. The polyvinylphenol polymer can be used for the fabrication of films with large area, making it very useful in diverse applications such as photoresist materials in semiconductor industries and dielectric material. 

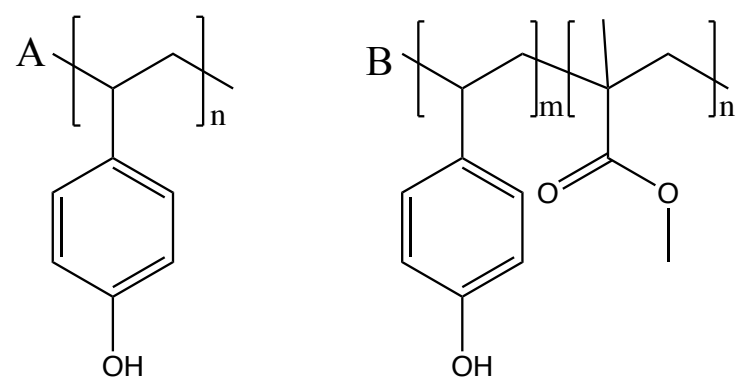

Scheme 4.1. Monomers of a) PVPOH and b) PVPOH-co-MMA

Unpublished results from our research group have shown that a wide variety of phenols can be coordinated to the $\mathrm{Fe}_{8}$ cluster by substitution of the terminal chlorides. Isolated products of such substitutions have enabled us to characterize them and establish patterns that can now be used to easily and clearly assess the success of phenol coordination. The ability to deprotonate the polymers chosen will be used to coordinate the corresponding phenoxides to $\mathrm{Fe}_{8}$ by ligand substitution of the capping chlorides (Scheme 4.2).

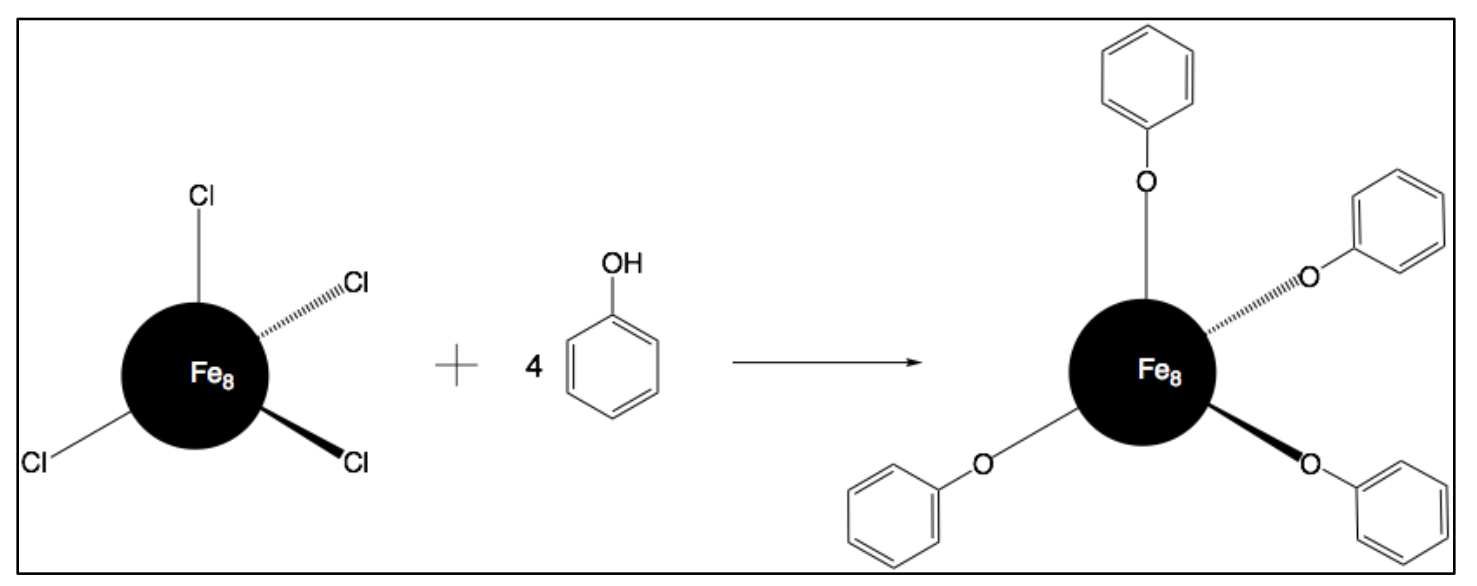

Scheme 4.2. Substitution of $\mathrm{Fe}_{8}$ chlorides by phenol. 


\subsection{Preparation of $\mathrm{Fe}_{8}$-PVPOH hybrids for BHJ}

Three hybrid materials were prepared by changing either the inorganic motif or the polymer matrix. The first hybrid material prepared was the parent cluster, Fe $8-(4-\mathrm{H}-$ pz), with the phenolic PVPOH polymer to yield hybrid 1 (H1). To study the effects of the $\mathrm{Fe}_{8}$ derivatives, a samples of the methyl functionalized $\mathrm{Fe}_{8}-(4-\mathrm{Me}-\mathrm{pz})$ was reacted with PVPOH to yield hybrid 2 (H2). To understand the effects of the polymer matrix, a hybrid was also prepared with a different phenolic polymer (PVPOH-co-MMA) with the parent cluster. To simplify the nomenclature of these hybrids, below is a table with the composition, ratio and codification for the hybrids.

\begin{tabular}{|l|l|c|c|}
\multicolumn{1}{|c|}{ Polymer } & \multicolumn{1}{c|}{$\mathrm{Fe}_{8}$} & $\mathrm{Fe}_{8}$ :Phenol ratio & Code \\
\hline PVPOH & $\mathrm{Fe}_{8}-(4-\mathrm{H}-\mathrm{pz})$ & $1: 43.4$ & H1 \\
\hline PVPOH & $\mathrm{Fe}_{8}-(4-\mathrm{Me}-\mathrm{pz})$ & $1: 43.4$ & H2 \\
\hline PVPOH-co-MMA & $\mathrm{Fe}_{8}-(4-\mathrm{H}-\mathrm{pz})$ & $1: 43.4$ & H3 \\
\hline
\end{tabular}

Table 4.1. Composition of the $\mathrm{Fe}_{8}-\mathrm{PVPOH}$ hybrids.

\subsubsection{Changing the inorganic cluster}

The hybrid composites can be prepared with various derivatives of the parent $\mathrm{Fe}_{8}$. For this project the $\mathrm{Fe}_{8}(4-\mathrm{H}-\mathrm{pz})$ and $\mathrm{Fe}_{8}(4-\mathrm{Me}-\mathrm{pz})$ motifs were prepared.

\subsubsection{Fes-(4-H-pz) [H1]}

An $\mathrm{Fe}_{8}(4-\mathrm{H}-\mathrm{pz})$ solution was added to a polyvinylphenol solution in THF and excess triethylamine was added. The reaction mixture was stirred overnight although a clear change in color (from brick red to dark green) was observed a few minutes after the 
addition of the base. The solution was used for most analysis, solids were obtained by rotary evaporation of the solution to afford a plastic like dark green material.

\subsubsection{2 $\mathrm{Fe}_{8}(4-\mathrm{Me}-\mathrm{pz})[\mathrm{H} 2]$}

Polyvinylphenol and $\mathrm{Fe}_{8}(4-\mathrm{Me}-\mathrm{pz})$ were dissolved in THF and triethylamine was added in excess. The reaction mixture was stirred overnight although a clear change in color (from brick red to dark green) was observed a few minutes after the addition of the base. The reaction was then added dropwise into water and the product precipitated out of the solution. The solid was collected by filtration, washed with DCM and THF, and dried in vacuum.

\subsubsection{Changing the organic host}

The versatility of these hybrids allows for the organic matrix to be changed, for this project PVPOH-co-MMA was also used. The synthesis was carried out in a similar fashion to the PVPOH polymer.

\subsubsection{1 $\mathrm{Fe}_{8}(4-\mathrm{H}-\mathrm{pz})[\mathrm{H} 3]$}

Polyvinylphenol-co-methylmethacrylate and $\mathrm{Fe}_{8}(\mathrm{pz})$ were dissolved in THF and triethylamine was added in excess. The reaction mixture was stirred overnight although a clear change in color (from brick red to dark green) was observed a few minutes after the addition of the base. The reaction was then rotoevaporated and redissolved in THF and added dropwise into stirred water. The product precipitated out of the solution and was collected by filtration, washed with DCM and THF, and dried in vacuum. 


\subsection{Characterization of hybrids}

\subsubsection{UV-vis}

Both polymers employed in this project gave colorless solutions when dissolved in THF and the $\mathrm{Fe}_{8}$ derivatives are shades of brown-red. When mixed and upon the addition of base, a drastic change in color from red to green occurs for the hybrids with $\mathrm{Fe}_{8}(4-\mathrm{H}-\mathrm{pz})$, but for the $\mathrm{Fe}_{8}(4-\mathrm{Me}-\mathrm{pz})$ and $\mathrm{Fe}_{8}(4-\mathrm{Cl}-\mathrm{pz})$ no obvious change was observed. A charge-transfer band in the visible region is characteristic of $\mathrm{Fe}_{8}$-phenol coordination and is the responsible for the observed change in color [92]. The UV-vis spectra were collected for all hybrids and as expected, the $\mathrm{Fe}_{8}(4-\mathrm{H}-\mathrm{pz})$ exhibited a marked at $\sim 17000$ $\mathrm{cm}^{-1}$ that is not observed on the spectra of the $\mathrm{Fe}_{8}$ or PVPOH (Fig 4.1). For the hybrids of the other $\mathrm{Fe}_{8}$ derivatives, there was a very weak absorption in this region raising questions about the nature of the polymer $\mathrm{Fe}_{8}$-interaction (Fig 4.2).

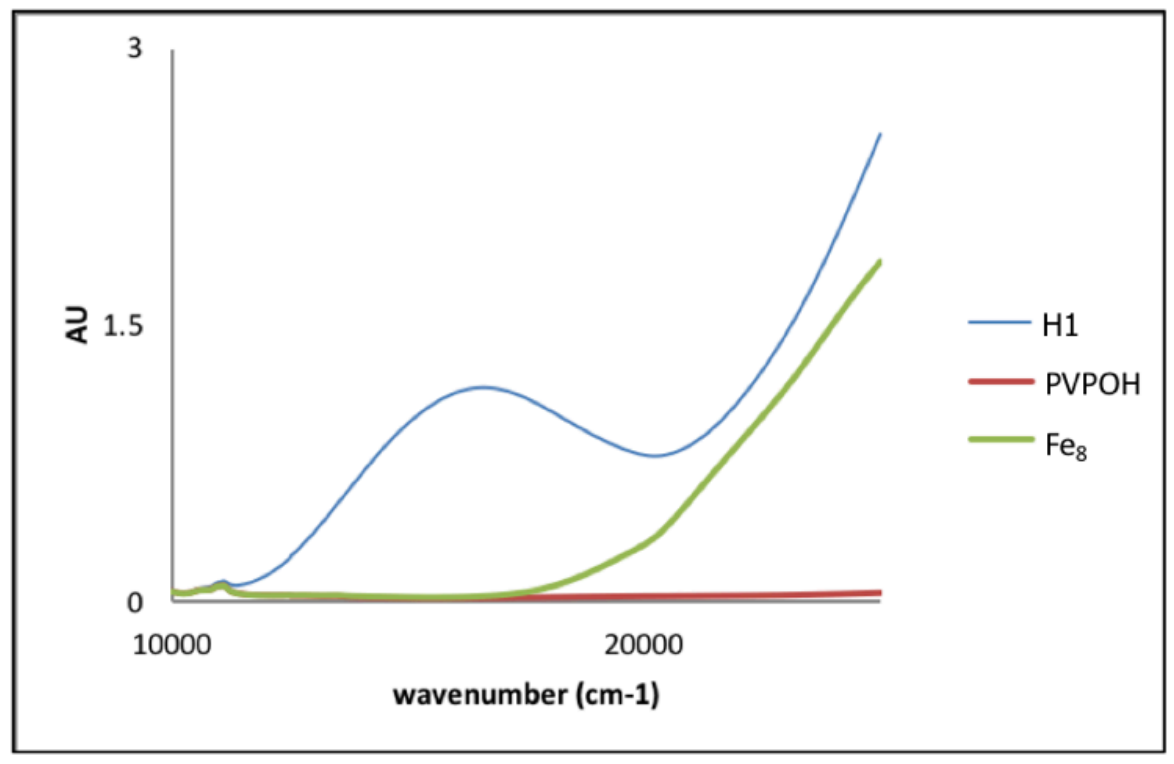

Figure 4.1. UV-vis spectra of $\mathbf{H 1}$ and precursors 


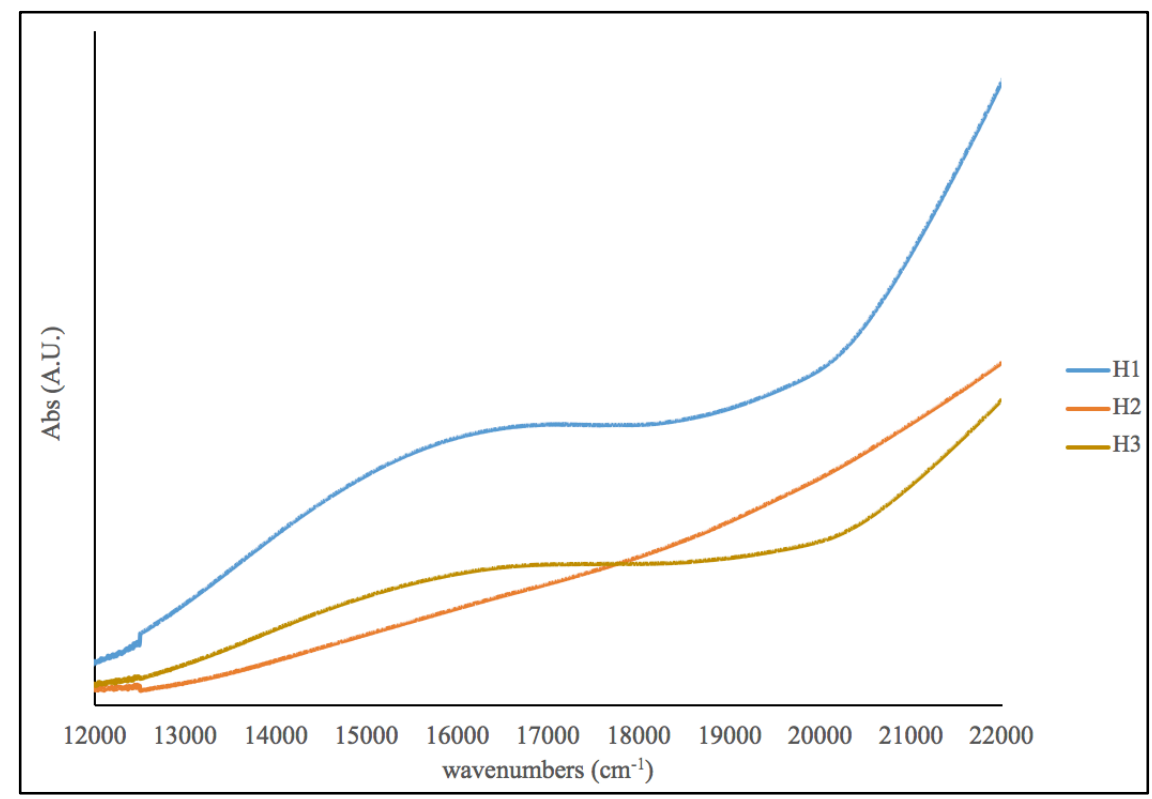

Figure 4.2. UV-vis spectra of hybrids

\subsubsection{Mössbauer spectroscopy}

To probe the coordination of phenols and the structural integrity of the $\mathrm{Fe}_{8}$ in the hybrid material Mössbauer spectroscopy was used. The ${ }^{57} \mathrm{Fe}$ Mössbauer spectroscopic technique is sensitive to oxidation state, coordination number, coordination geometry and chemical environment. The octanuclear iron cluster has to distinct iron centers, those on the cubane core and those on the periphery. The cubane iron atoms are in an octahedral environment whereas the peripheral iron atoms reside in a trigonal bipyramidal geometry. The difference in geometries give raise to two distinct doublets in the Mössbauer spectrum. Experimental evidence and theoretical calculations have demonstrated that the outer doublet corresponds to the outer iron atoms and the inner doublet corresponds to the cubane iron atoms (Fig 4.3). Previous unpublished results from our lab demonstrate that the quadrupole splitting of the outer doublet increases significantly upon phenolic 
coordination. A methyl-4-hydroxybenzoate complex was prepared and structurally characterized by x-ray crystallography and Mössbauer spectroscopy (Fig 4.4)
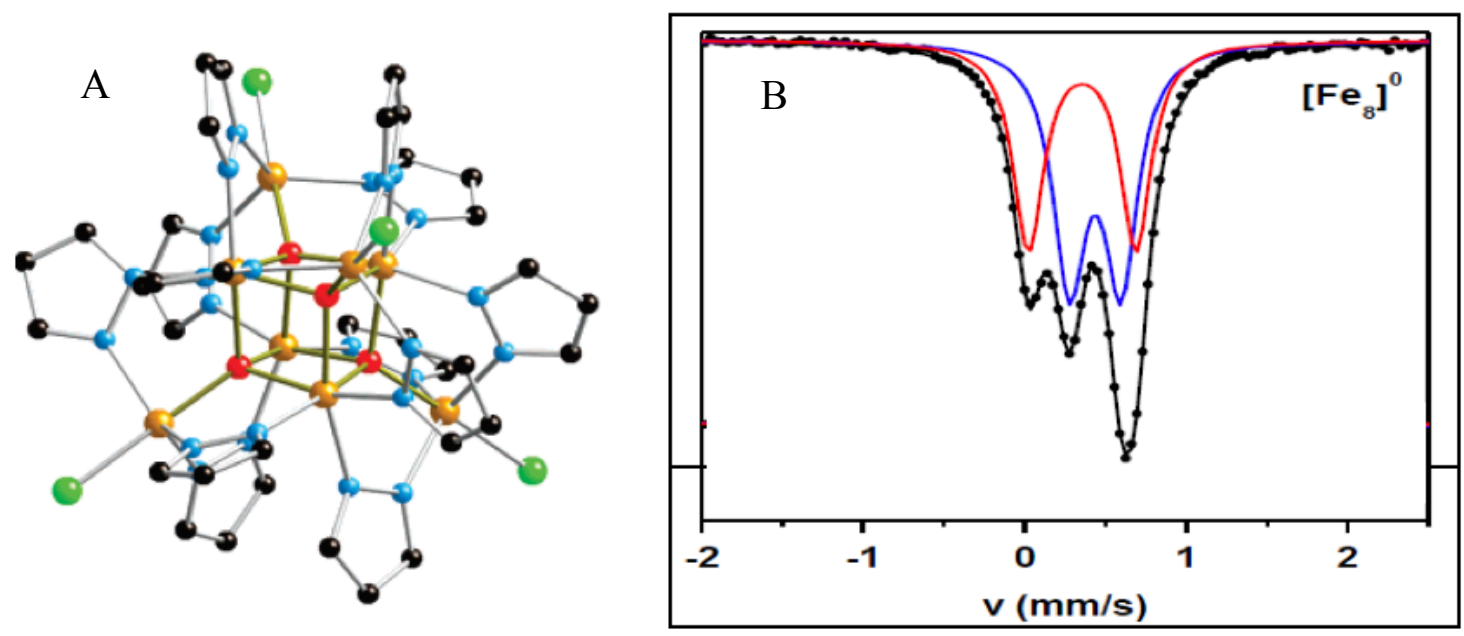

Figure 4.3. A) Ball and stick model of $\left.\left[\mathrm{Fe}^{\mathrm{III}} 8(\mu-4-\mathrm{H}-\mathrm{pz}){ }_{12} \mathrm{Cl}_{4}\right] \mathrm{B}\right)$ Mössbauer spectrum of $\left[\mathrm{Fe}^{\mathrm{III}} 8(\mu-4-\mathrm{H}-\right.$ pz) $\left.{ }_{12} \mathrm{Cl}_{4}\right]$ [ 32]
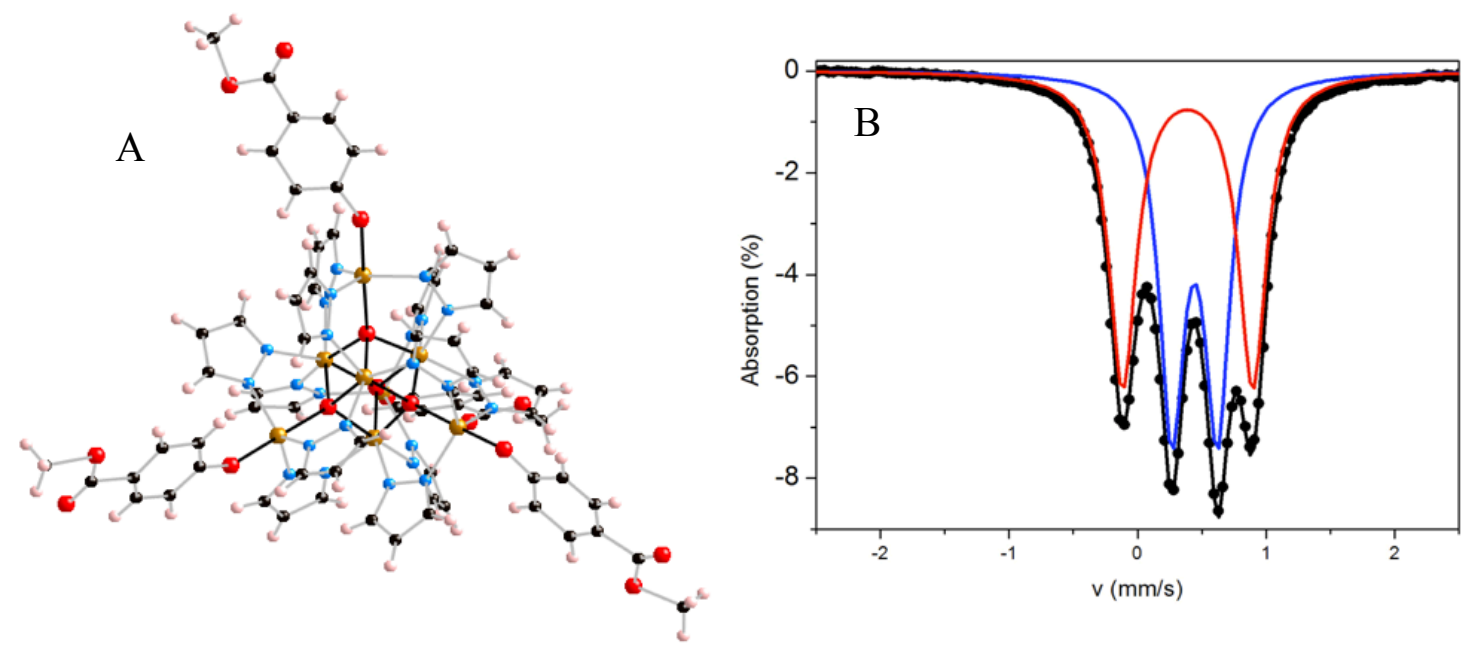

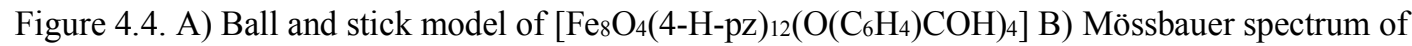
$\left[\mathrm{Fe}_{8} \mathrm{O}_{4}(4-\mathrm{H}-\mathrm{pz})_{12}\left(\mathrm{O}\left(\mathrm{C}_{6} \mathrm{H}_{4}\right) \mathrm{COH}\right)_{4}\right]$ 
The room temperature spectrum of $\mathbf{H 2}$ (Fig. 4.5) shows two doublets (black line) that when mathematically deconvoluted become three doublets (blue, red, and green traces). Comparison of these results to unpublished spectra from our research group indicates that the inner doublet represented by the blue line corresponds to the octahedral ferric ions in the core of the $\mathrm{Fe}_{8}$ cubane. The red line and the green line overlap to give the outer doublet and correspond to the outer penta-coordinated phenoxide-capped ferric ions. The lower intensity green doublet is due to chloride-capped iron ions; which is indicative that phenol substitution was not complete. From the ratio of the outer iron doublets an estimate of the remaining chloride can be made and for every case a $\sim 20-25 \%$ retention of the chlorides is observed. Below is a comparison of the parent cluster, the methyl-4-hydroxybenzoate complex and hybrid H2 (Table 4.3).

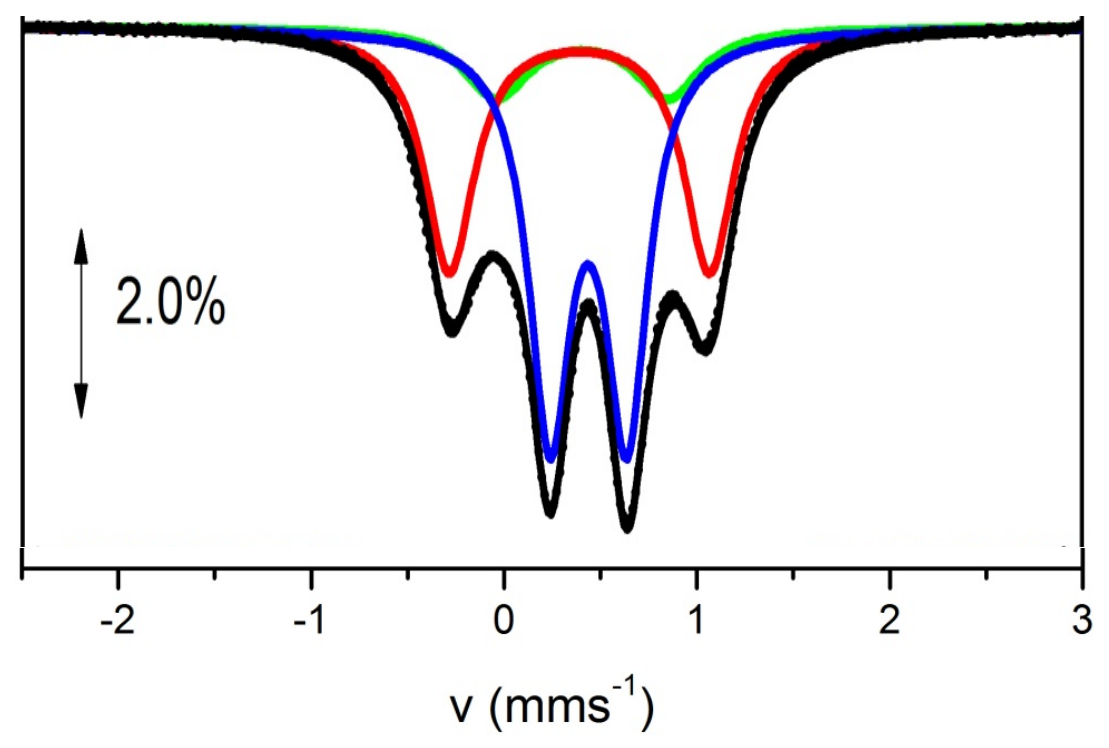

Figure 4.5. Mössbauer spectrum of $\mathbf{H 1}$ at room temperature. 


\begin{tabular}{|c|c|c|c|c|}
\hline Sample & Site & $\delta\left(\mathrm{mm} \mathrm{s}^{-1}\right)$ & $\Delta \mathrm{E}_{\mathrm{Q}}\left(\mathrm{mm} \mathrm{s}^{-1}\right)$ & Area (\%) \\
\hline \multirow{2}{*}[\mathrm{Fe}_{8}\mathrm{O}_{4}(\mu-4-\mathrm{H}-\mathrm{pz})_{12}\mathrm{Cl}_{4}]{} & I & 0.44 & 0.31 & 50 \\
\hline & II & 0.36 & 0.65 & 50 \\
\hline \multirow[t]{2}{*}{$\mathrm{Fe}_{8} \mathrm{O}_{4}(4-\mathrm{H}-\mathrm{pz})_{12}\left(\mathrm{O}\left(\mathrm{C}_{6} \mathrm{H}_{4}\right) \mathrm{COH}\right)_{4}$} & I & 0.45 & 0.39 & 48 \\
\hline & II & 0.4 & 1.31 & 48 \\
\hline \multirow[t]{3}{*}{ H2 } & I & 0.44 & 0.4 & 50 \\
\hline & II & 0.39 & 1.35 & 36.5 \\
\hline & III & 0.41 & 0.89 & 13.5 \\
\hline
\end{tabular}

Table 4.3. Mössbauer parameters for the parent Fe8, a phenol substituted $\mathrm{Fe} 8$ and $\mathbf{H 1}$.

An additional Mössbauer experiment was performed at liquid Helium temperatures and no obvious change was observed except for an expected minor displacement in the isomer shift (Fig 4.6). These results indicate that there are no strong cluster to cluster interactions as this behavior is expected of magnetically isolated clusters.

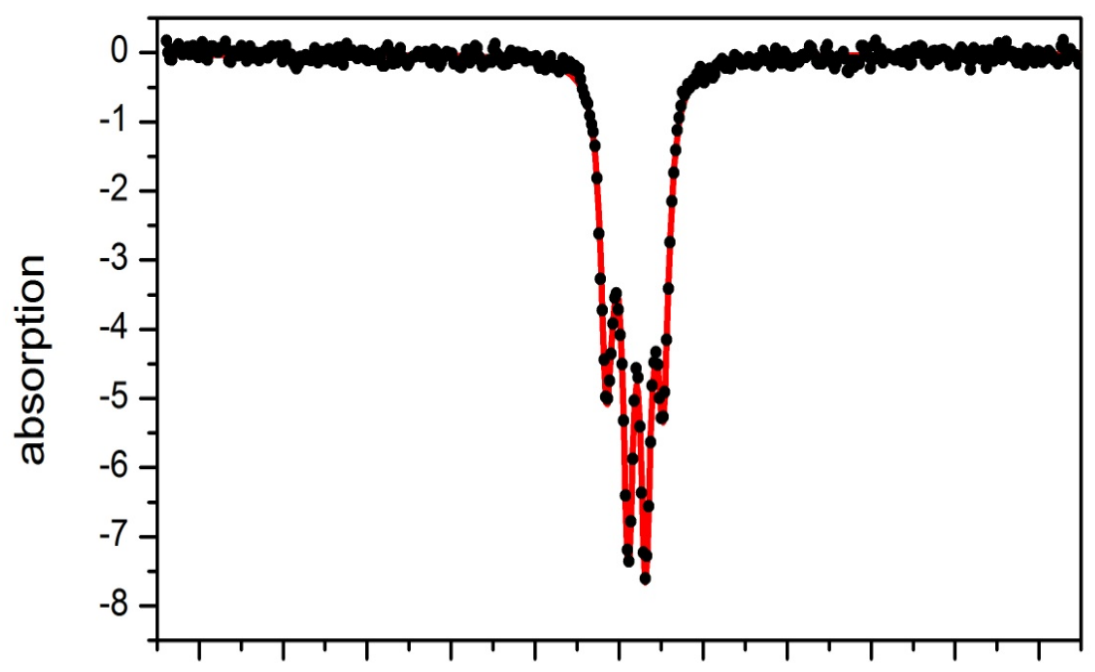

Figure 4.6. Mössbauer spectrum of $\mathbf{H 1}$ at $4.2 \mathrm{~K}$. 


\subsubsection{Electrochemistry}

A prominent feature of the $\mathrm{Fe}_{8}$ cluster that is expected to carry on to the composite is its electrochemical properties. $\mathrm{The}_{\mathrm{Fe}}$ has four reversible redox processes whereas the polymer shows no electrochemical processes in the range from $1.5 \mathrm{~V}$ to $-2 \mathrm{~V}$. Due to solubility issues with the purified polymer, the electrochemical characterization was carried out using the reaction crude. The reaction was carried out in dry THF, so after the electrochemical cell had been prepared, drops of the composite solution were deposited on the working electrode and allowed to evaporate. A film was grown to be thick enough not to see the glassy part of the electrode and the cyclic voltammetry and differential pulsed voltammetry were collected. The cyclic voltammetry hinted to the expected fourth reduction process but this was not clear enough (Fig. 4.7). The values obtained are listed and compared to other $\mathrm{Fe}_{8}$ based materials in the table below (Table 4.4). The polymer coating on the surface of the electrode did not survive after two cycles and efforts to reproduce this result have faced the same problem. To address the situation, electrochemistry in solution has been measured for the other hybrids. Due to the limited concentration that can be achieved in the typical setup, the more sensitive differential pulsed voltammetry (DPV) technique has been used (Fig. 4.8). The values for the solution electrochemistry are given in table 4.5. 


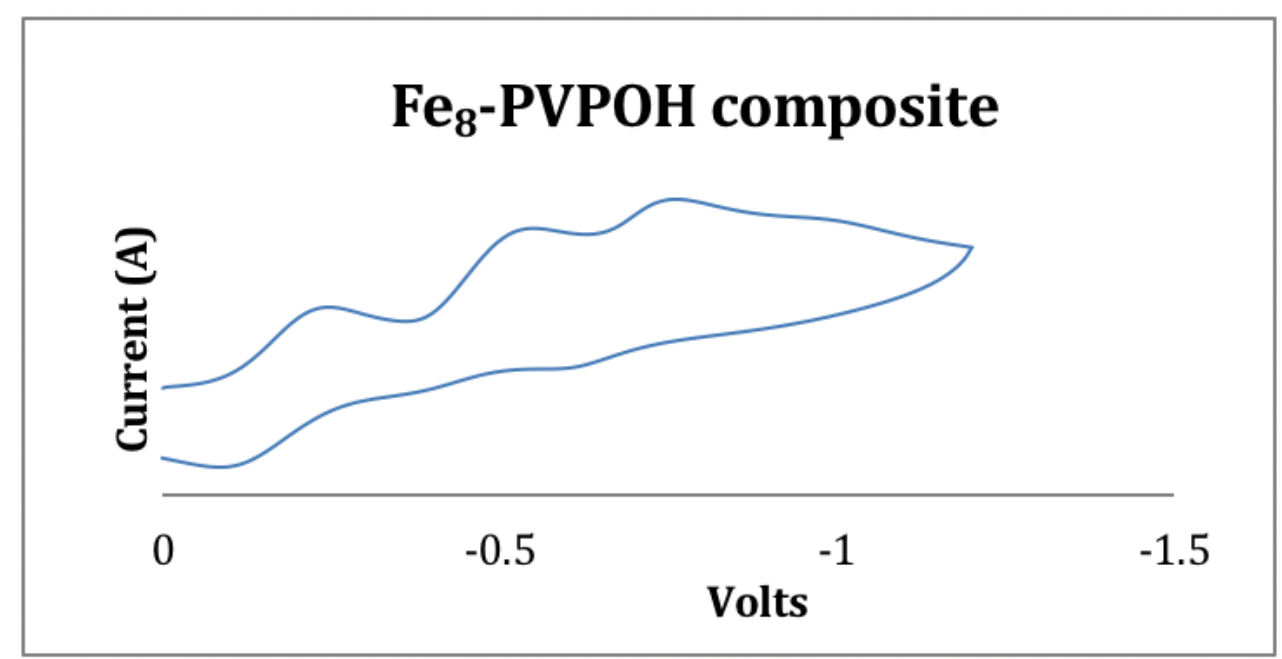

Figure 4.7. Cyclic voltammogram of $\mathbf{H 1}$ in the solid state.

\begin{tabular}{|l|c|c|c|c|}
\hline \multicolumn{1}{|c|}{ Compound } & $\mathrm{E}_{1 / 2}{ }^{0 / 1-}(\mathbf{V})$ & $\mathrm{E}_{1 / 2}{ }^{1-2-}(\mathbf{V})$ & $\mathrm{E}_{1 / 2}{ }^{2-/ 3-}(\mathbf{V})$ & $\mathrm{E}_{1 / 2}{ }^{3-14-}(\mathbf{V})$ \\
\hline $\mathrm{Fe}_{8} \mathrm{O}_{4}(\mathrm{pz})_{12} \mathrm{Cl}_{4}$ & -0.43 & -0.78 & -1.07 & -1.38 \\
\hline $\mathrm{Fe}_{8} \mathrm{O}_{4}(\mathrm{pz})_{12}-(\mathrm{PhO})_{4}$ & -0.73 & -1.27 & -1.65 & - \\
\hline $\mathrm{Fe}_{8} \mathrm{O}_{4}(\mathrm{pz})_{12} \mathrm{Cl}_{4}-\mathrm{PVPOH}^{*}(\mathbf{H 2})$ & -0.37 & -0.65 & -0.88 & -1.15 \\
\hline
\end{tabular}

Table 4.4. $\mathrm{E}_{1 / 2}$ values for $\mathrm{Fe}_{8}$ and phenol substituted $\mathrm{Fe}_{8}, 0.5 \mathrm{M} \mathrm{Bu} 4 \mathrm{NPF}_{6} / \mathrm{CH}_{2} \mathrm{Cl}_{2}$. *This sample was measured in the solid state

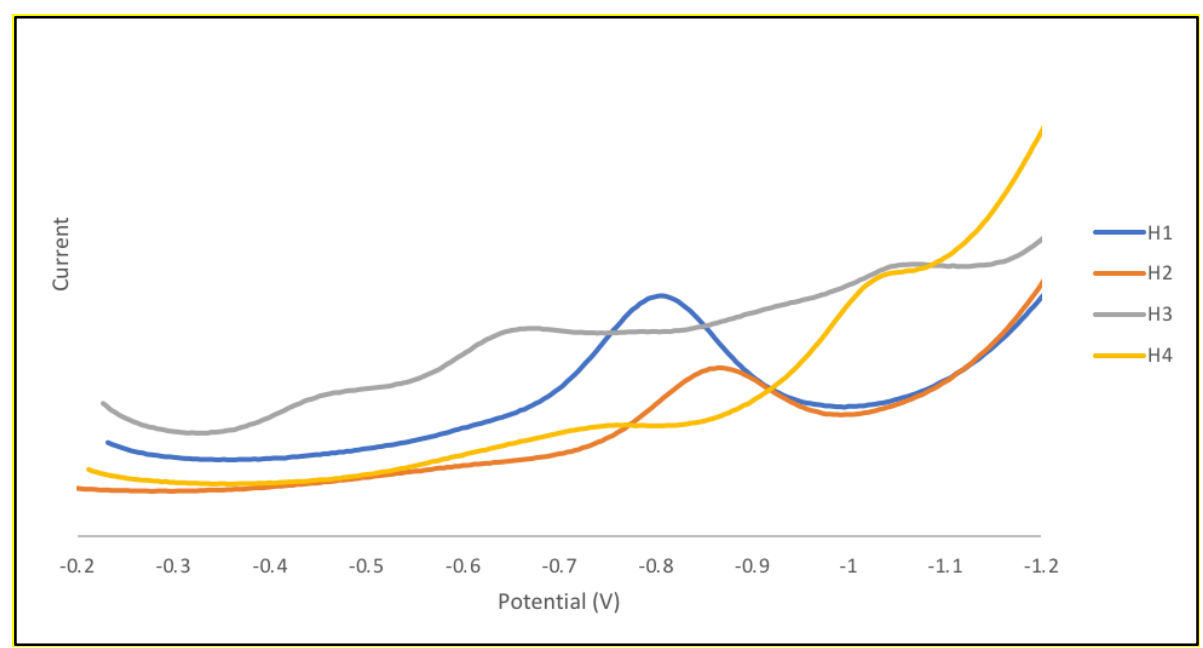

Figure 4.8. Differential pulsed voltammetry of selected hybrids, 0.5 M Bu4NPF 6 /THF, $298 \mathrm{~K}$ 


\begin{tabular}{|c|c|c|c|}
\hline Hybrid & $\mathrm{E}_{1 / 2}{ }^{0 / 1-}(\mathbf{V})$ & $\mathrm{E}_{1 / 2}{ }^{1-2-}(\mathbf{V})$ & $\mathrm{E}_{1 / 2}{ }^{2-3-}(\mathbf{V})$ \\
\hline $\mathbf{H 2}$ & -0.82 & - & - \\
\hline $\mathbf{H 4}$ & -0.88 & - & - \\
\hline $\mathbf{H 5}$ & -0.46 & -0.66 & -1.06 \\
\hline $\mathbf{H 8}$ & - & -0.75 & -1.04 \\
\hline
\end{tabular}

Table 4.5. E1/2 values for selected hybrids, $0.5 \mathrm{M} \mathrm{Bu}_{4} \mathrm{NPF}_{6} / \mathrm{THF}$.

\subsubsection{Conductivity}

Polyvinylphenol is a well-known dielectric material so conductivity measurements were carried out to see if that property had change. A $1 / 2$ " pellet was prepared and the measurements were carried out at room temperature and pressure but no detectable conductivity was detected. The pellet was then subjected to high pressure and measurements were recorded again but no significant conductivity was found.

\subsubsection{Transmission electron microscopy}

The parent materials for $\mathbf{H} 2$ were observed by TEM and their morphologies compared to that of the hybrid. The PVPOH is a globular irregular solid (Fig. 4.9) and the $\mathrm{Fe}_{8}$ are rod-shaped nanoparticles (Fig. 4.10). In contrast the hybrid is an amorphous mass that does not resemble either precursor but suggests the formation of a new material by coordination of the PVPOH to the $\mathrm{Fe}_{8}$ (Fig. 4.11). 

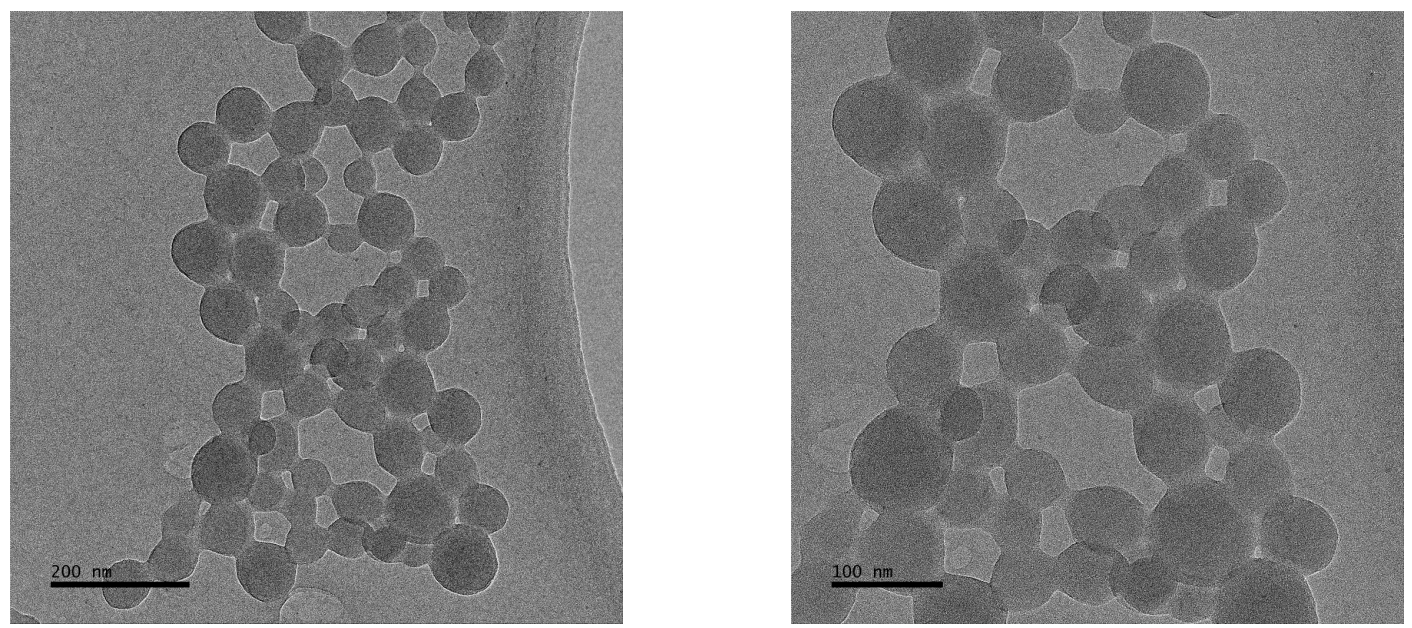

Figure 4.9. TEM images of the neat PVPOH
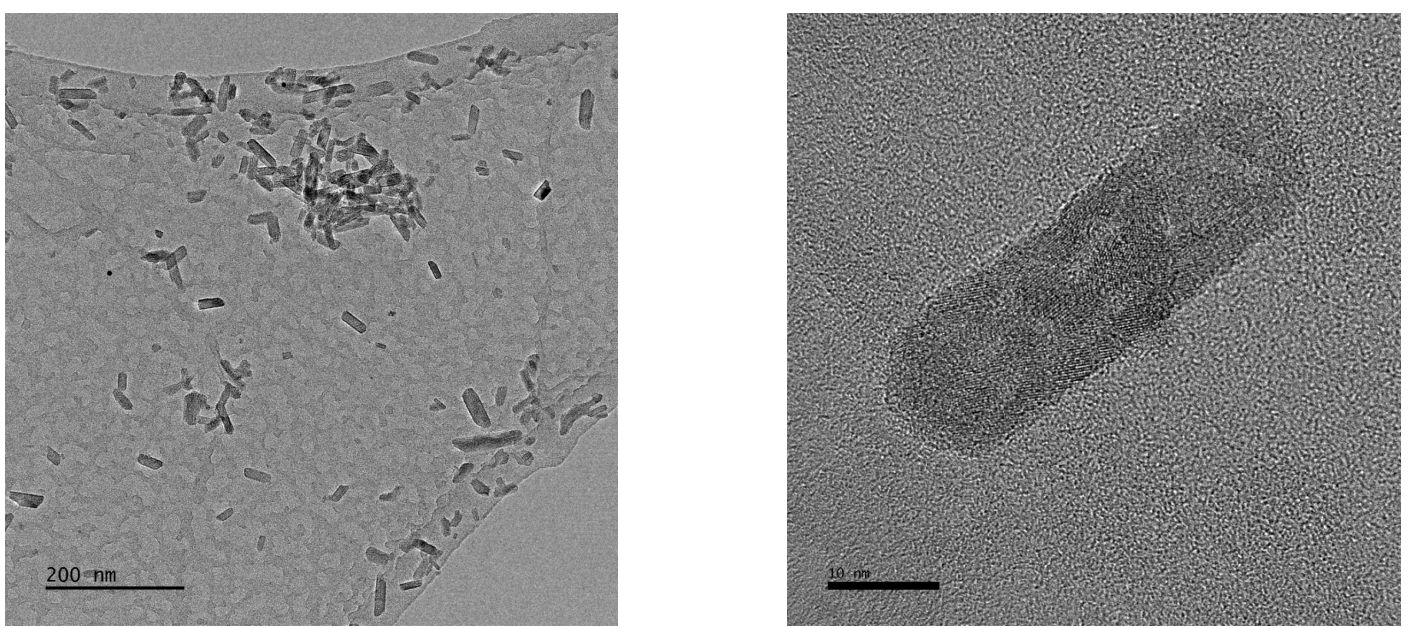

Figure 4.10. TEM images of the neat $\mathrm{Fe}_{8}$
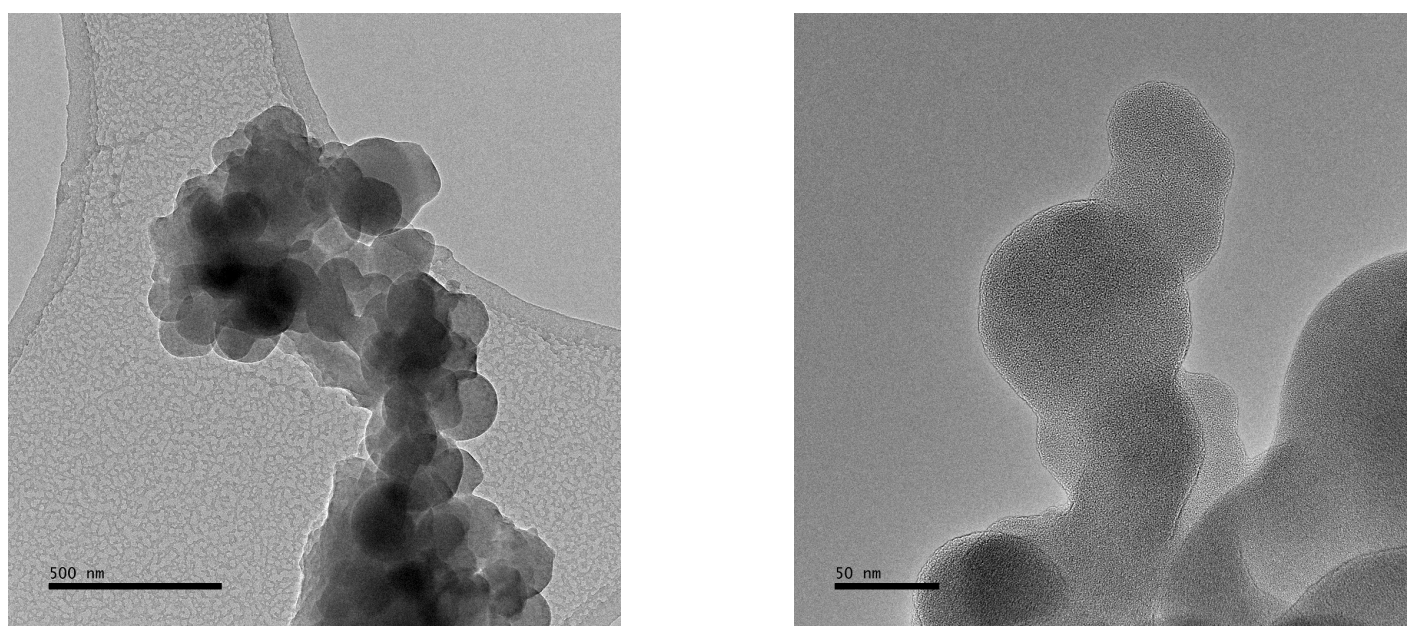

Figure 4.11. TEM images of the $\mathbf{H 1}$ hybrid 


\subsubsection{Scanning transmission electron microscopy with energy dispersive spectroscopy}

Besides TEM, scanning microscopy was also used to study the hybrids. In this case, STEM in High-Angle Annular Dark Field (HAADF) as well as in Bright Field (BF) modalities were used. HAADF detectors are Z-sensitive allowing in some cases to provide atomically precise images of solids. The Bright Field detector provides complementary information to that obtained by HAADF. In this project, HAADF and BF were also used to study the morphology of the hybrids (Fig 4.14) and of the precursors (Figs. 4.12 and 4.13). Furthermore, this technique was also coupled with EDS. Using EDS allowed to map the areas where $\mathrm{C}$, $\mathrm{O}$ and Fe were found (Figs $4.15-4.17$ ). Both $\mathrm{C}$ and $\mathrm{O}$ form part of both precursor materials but $\mathrm{Fe}$ is exclusive of the inorganic component. By contrasting the presence of Fe vs $\mathrm{C}$ and $\mathrm{O}$, a good picture of the "mixing" of these materials in the hybrids is obtained. It is relevant to point out that although the neat PVPOH presents some indication of Fe present, the intensity and density of those signals is quite low (Fig 4.16). 

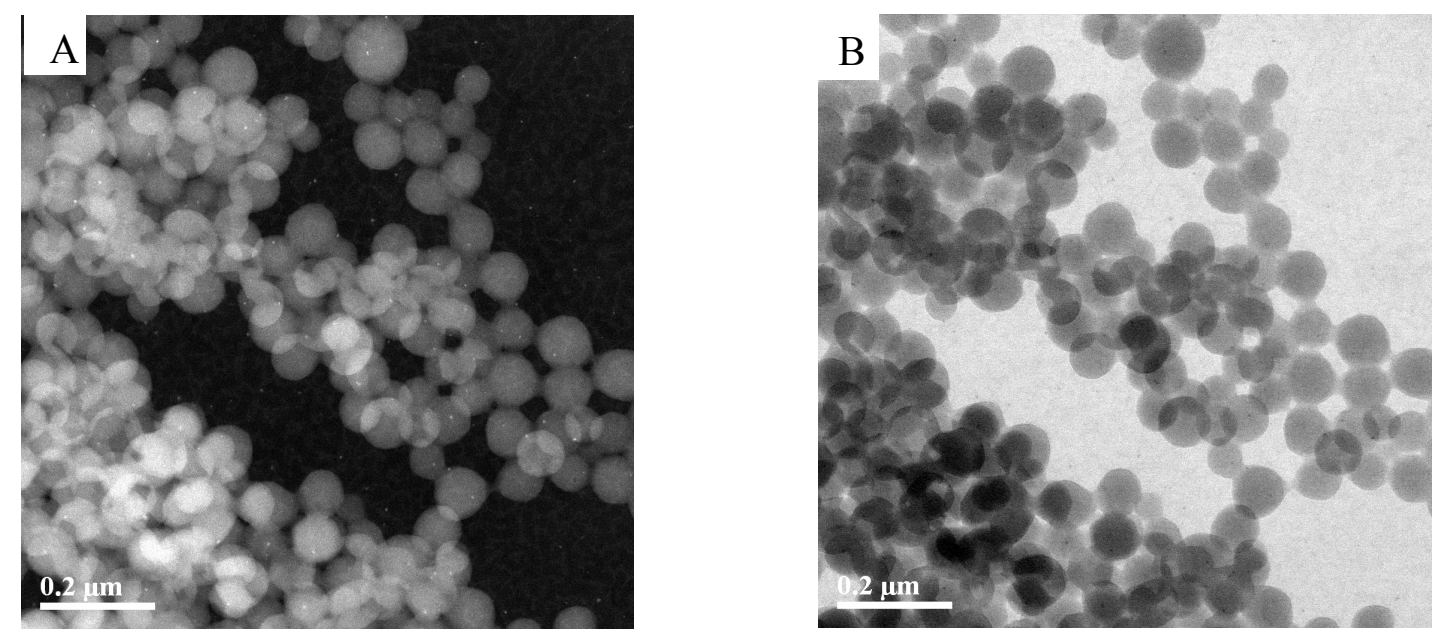

Figure 4.12. STEM images of PVPOH using: a) HAADF and b) BF detectors
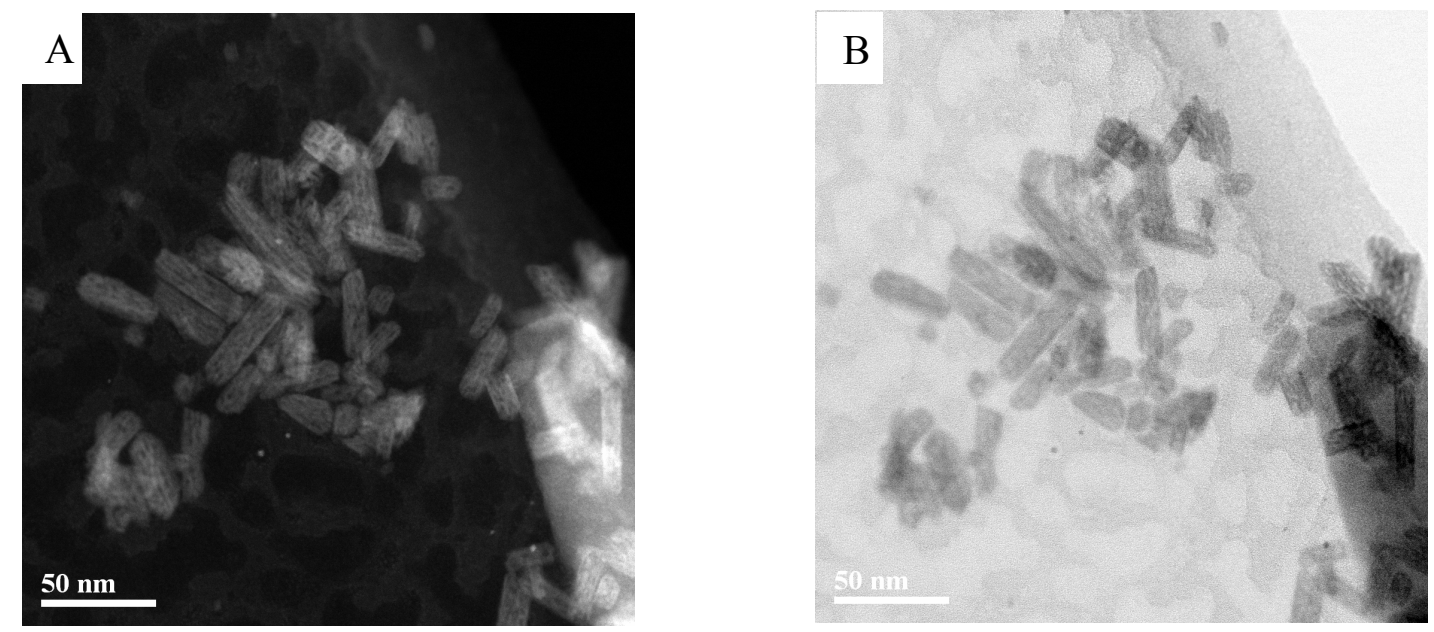

Figure 4.13. STEM images of $\mathrm{Fe}_{8}$ using: a) HAADF and b) BF detectors
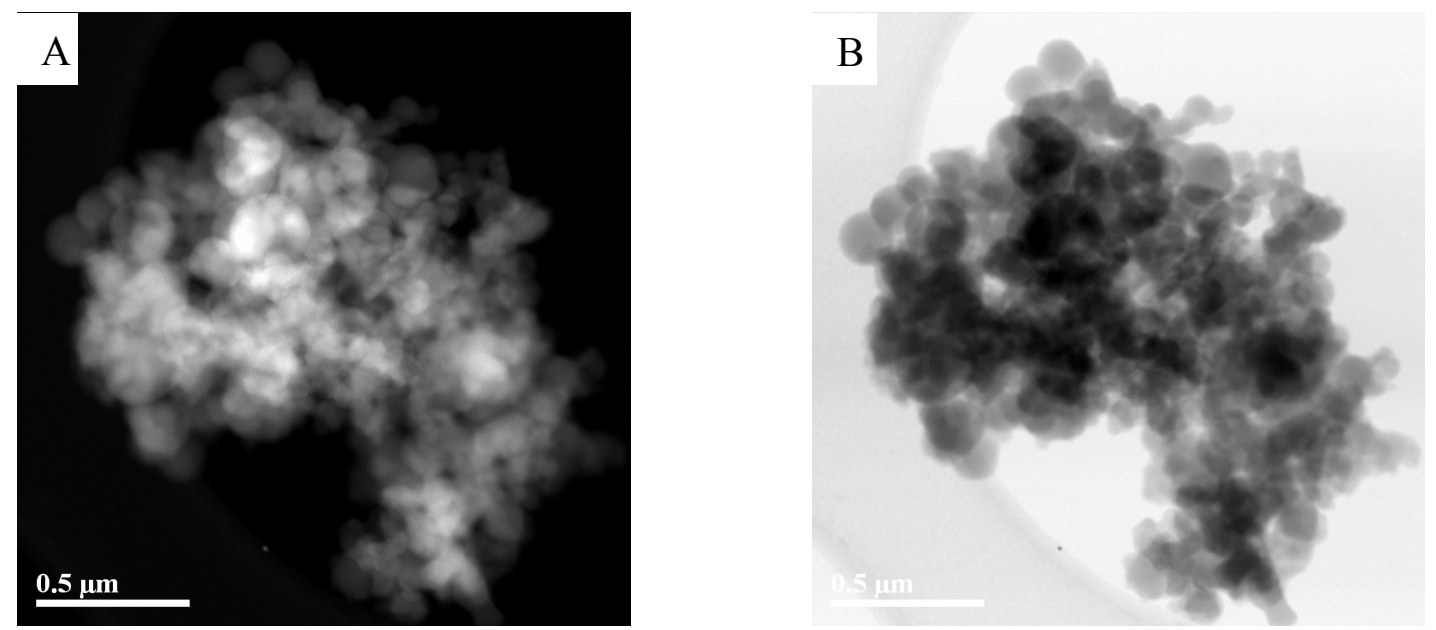

Figure 4.14. STEM images of H1 using: a) HAADF and b) BF detectors 

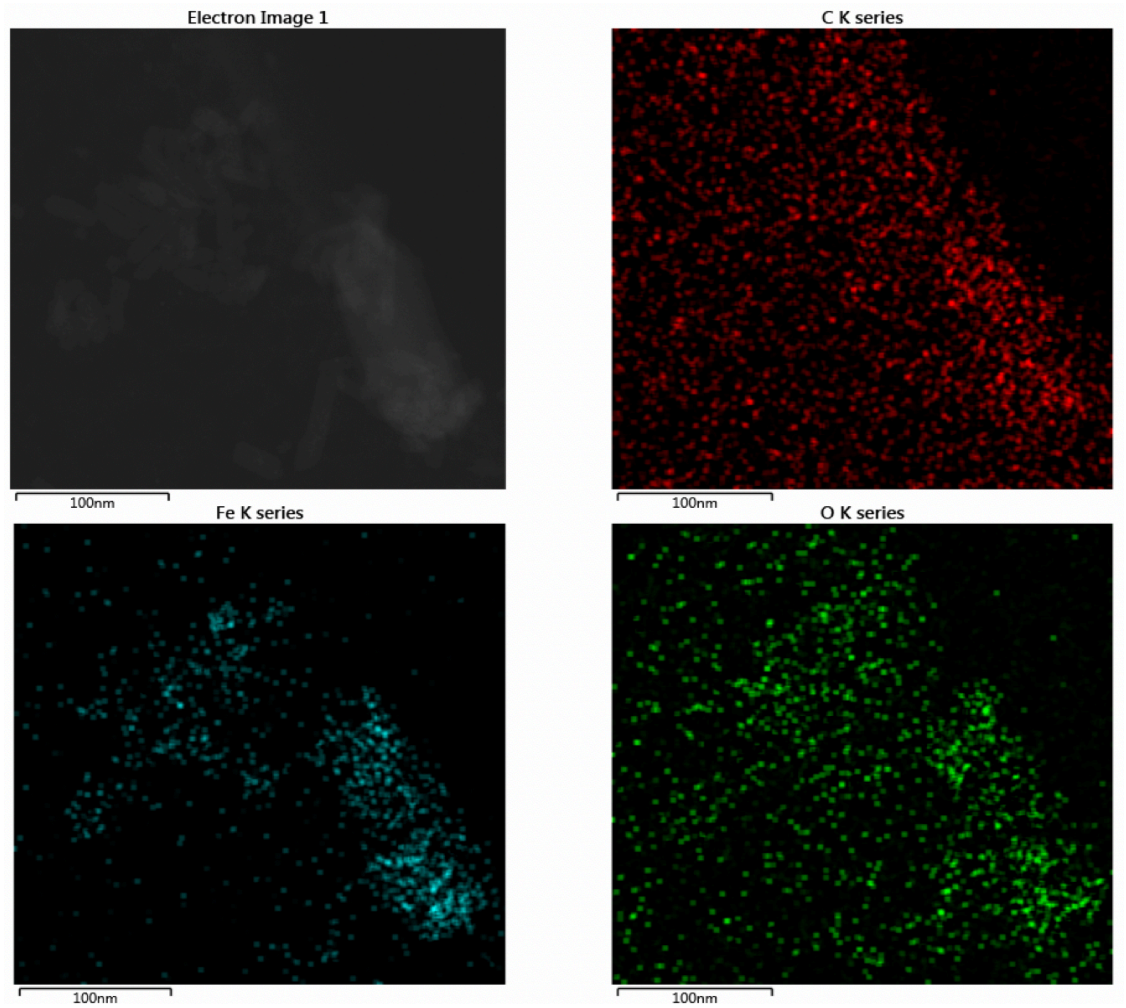

Figure 4.15. EDS mapping of $\mathrm{Fe}_{8}$
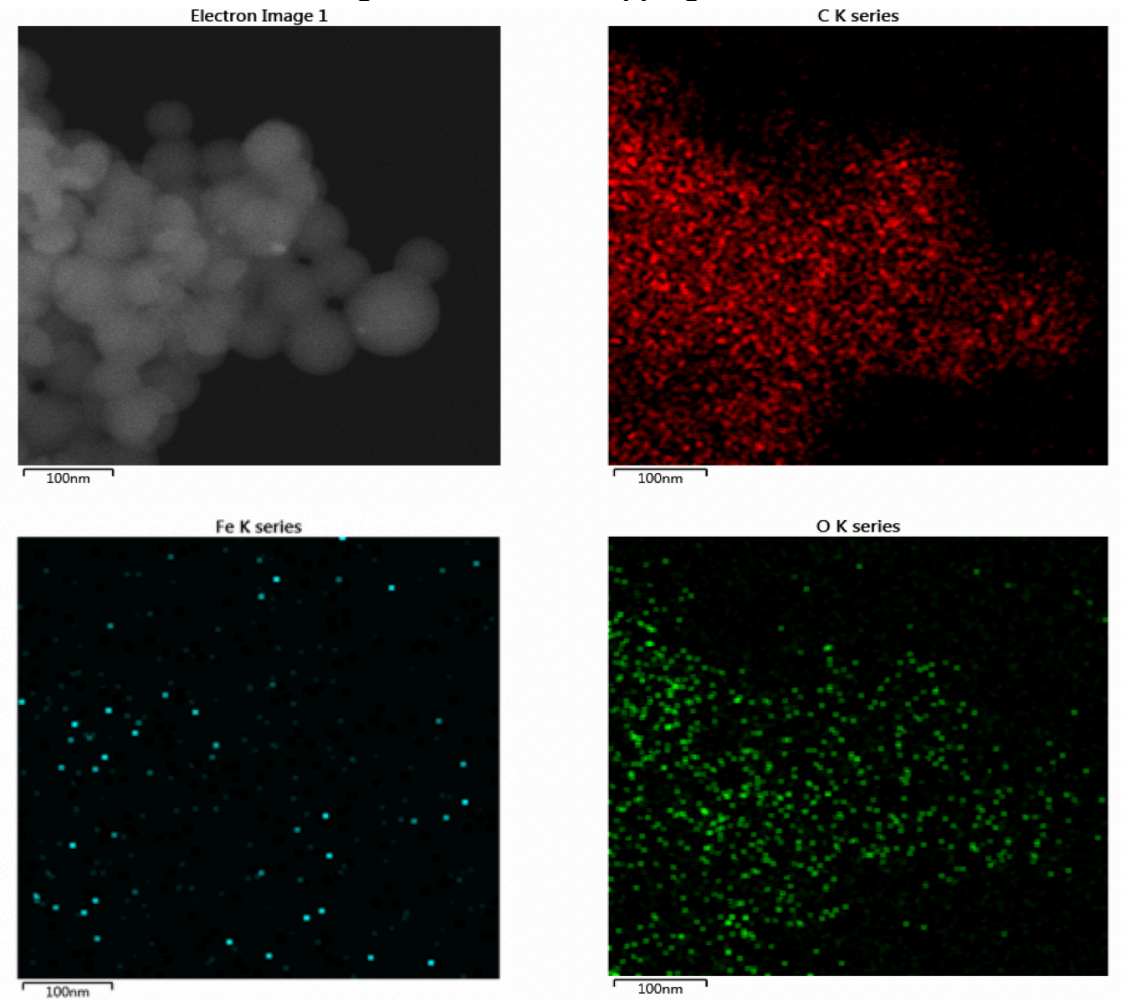

Figure 4.16. EDS mapping of PVPOH. 

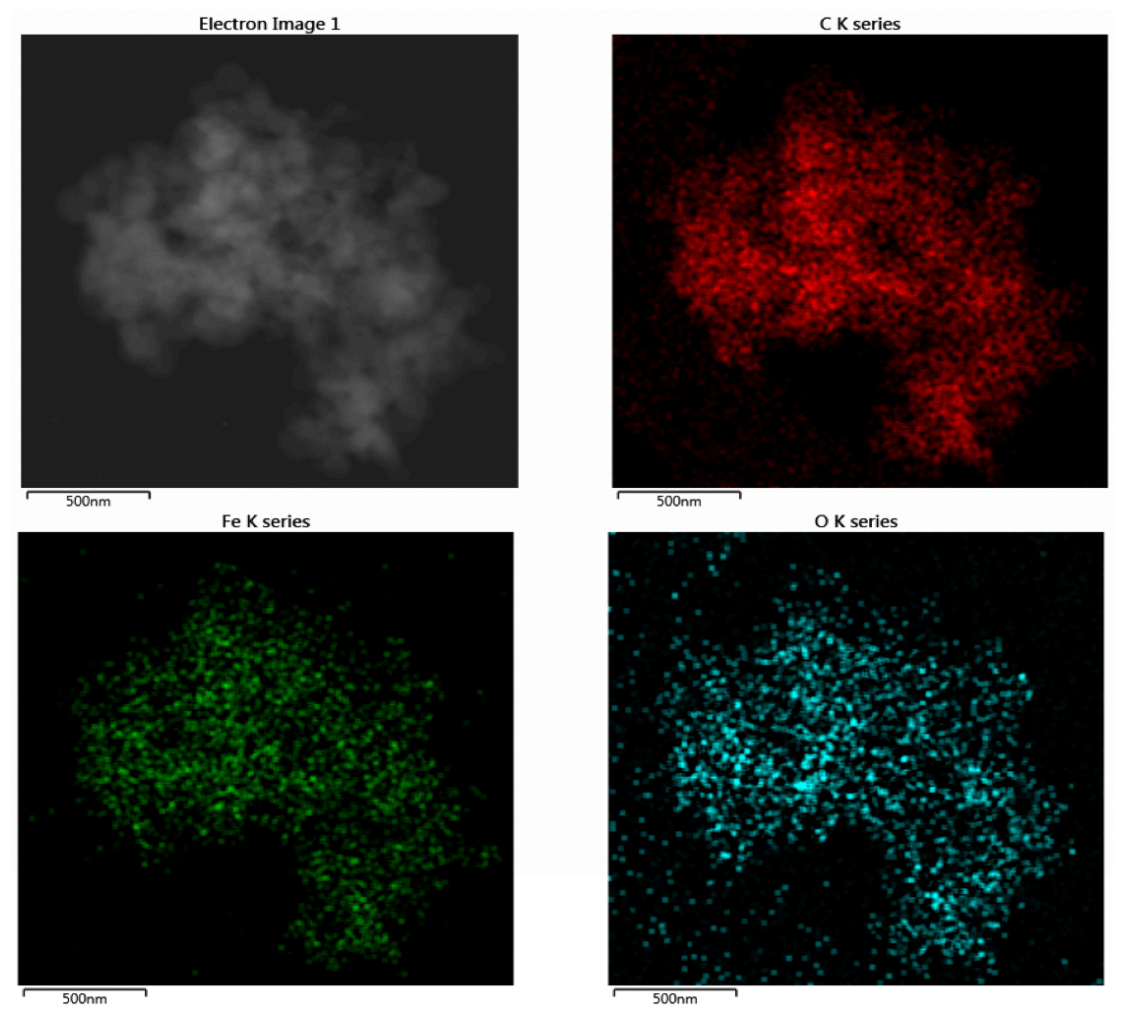

Figure 4.17. EDS mapping of $\mathbf{H 1}$

\subsubsection{Gas adsorption}

The PVPOH and PVPOH-co-MMA polymers exhibit intrinsic porosity that leads to the adsorption of $\mathrm{CO}_{2}$ as can be seen in figures 4.18 and 4.19 , but upon coordination of $\mathrm{Fe}_{8}$ this adsorption property is enhanced. All the samples analyzed show hysteresis on their isotherms and when the curves are compared a $16 \%$ increase in adsorption is observed for H1 over neat PVPOH and a 46\% increase is observed for H3 over PVPOHco-MMA. Another interesting feature of these hybrids is their selectivity for $\mathrm{CO}_{2}$ adsorption over $\mathrm{N}_{2}$ or $\mathrm{CH}_{4}$. 


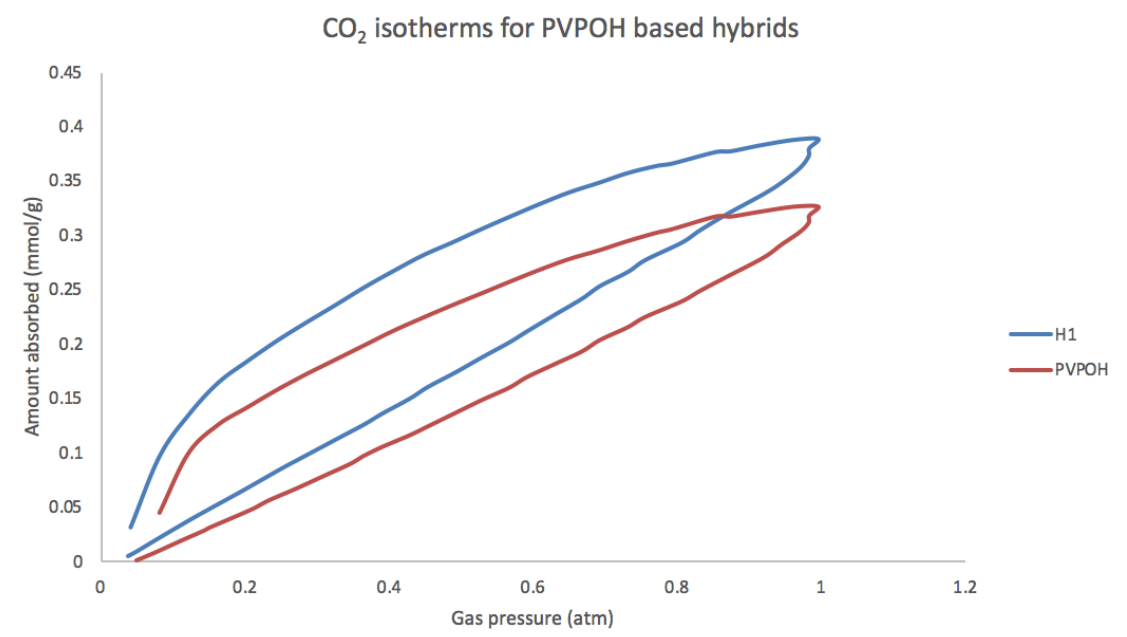

Figure 4.18. $\mathrm{CO}_{2}$ adsorption isotherms for PVPOH and $\mathbf{H 1}$

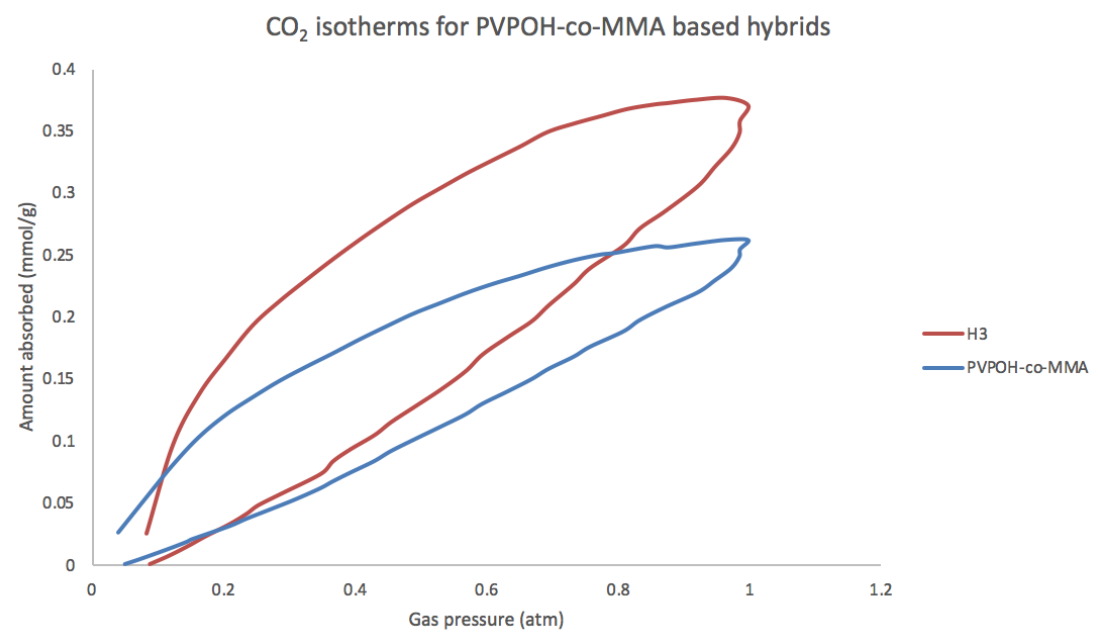

Figure 4.19. $\mathrm{CO}_{2}$ adsorption isotherms for PVPOH-co-MMA and $\mathbf{H 3}$

\subsection{Conclusions}

The preparation of $\mathrm{Fe}_{8}$ based hybrid materials has been confirmed by various methods including spectroscopic, optical and analytical techniques. These demonstrate the formation of phenol-coordination to the $\mathrm{Fe}_{8}$ cluster and a good stability of the hybrid as evidenced by the lack of dephasing in the STEM and TEM analysis. Preliminary studies on the properties of these hybrids demonstrate that they remain electrochemically 
active like the inorganic precursor but unlike the precursor, the hybrids can now be casted into films. Although conductivity measurements on the hybrids showed no conductivity, a detrimental feature for polymer cell applications, it is a proof of concept that the tunable and inexpensive $\mathrm{Fe}_{8}$ electron acceptor can now be included in a formulation that would allow it to be casted into films and still retain its properties. Other analysis performed demonstrate a degree of selectivity towards the adsorption of $\mathrm{CO}_{2}$ over other gases and an increase in this capacity for the hybrid over the polymer.

Future experiments involve the chemical reduction of the clusters and the study of the properties of the reduced hybrids. Another direction into which this project will move is the use of conductive polymers to prepare the hybrids and to study their conductivity. These hybrids are expected to be adequate electron acceptors in polymer solar cells. Last, the coordination of $\mathrm{Fe}_{8}$ to biocompatible polymers might open a door to safely introduce $\mathrm{Fe}_{8}$ into the body where its paramagnetic properties can be used for contrasting applications in MRI.

\subsection{Experimental}

This chapter describes the synthesis and characterization of hybrid materials based on $\mathrm{Fe}_{8}$ derivatives embedded in organic polymers.

\subsubsection{Materials}

All commercially available reagents utilized in this work were of analytical grade and in most cases they were used as received. The following reagents were obtained from Acros Organics: Triethylamine, tetrahydrofuran and dichloromethane. The PVPOH and 
PVPOH-co-MMA polymers were obtained from Sigma. All solvents were distilled and degassed prior to use.

\subsubsection{Instrumentation}

Electrochemical measurements were carried out with a Bioanalytical Systems (BASi) Epsilon potentiostat. Cyclic voltammetry (CV) was performed with a standard three-electrode setup with an $\mathrm{Ag} / \mathrm{AgNO}_{3}$ reference electrode, platinum wire auxiliary electrode, and glassy carbon working electrode. All measurements were conducted in 0.1 $\mathrm{M}$ tetrabutylammonium hexafluorophosphate $\left(\mathrm{TBAPF}_{6}\right)$ in acetonitrile. The solutions were degassed for approximately 10 min with argon before running the experiments. All experimental data are calibrated with reference to the ferricinium/ferrocene $\left(\mathrm{Fc}^{+/ 0}\right)$ couple measured using an internal $\mathrm{Fc}$ standard.

\subsubsection{Synthesis}

\section{$\mathrm{Fe}_{8}-(4-\mathrm{H}-\mathrm{pz})[\mathrm{H1}]$}

Polyvinylphenol (0.5000 g, $4.2 \mathrm{mmol}$ of phenol) was added to an Erlenmeyer flask and dissolved in $10 \mathrm{~mL}$ of THF, when all the polymer was dissolved, $0.2 \mathrm{~mL}$ of triethylamine was added. A 5mL THF solution of $\mathrm{Fe}_{8}(4-\mathrm{H}-\mathrm{pz})(0.1400 \mathrm{~g}, 0.096 \mathrm{mmol})$ was added dropwise at a rate of $0.5 \mathrm{~mL} /$ minute. The initially colorless solution turned red upon the first additions of $\mathrm{Fe}_{8}$ but after a minute a dark green color was observed. The reaction mixture was stirred overnight. A solid was obtained by removing the solvent by means of rotary evaporation. To make sure that there was no leeching of the $\mathrm{Fe}_{8}$, the solid 
was washed with DCM and no color was observed in the wash. The solid was soluble in THF but slow addition into water yielded a dark green insoluble material.

\section{Fe8-(4-Me-pz) [H2]}

Polyvinylphenol (0.2500 g, $2.1 \mathrm{mmol}$ of phenol) was added to an Erlenmeyer flask and dissolved in $10 \mathrm{~mL}$ of $\mathrm{THF}$, when all the polymer was dissolved, $0.2 \mathrm{~mL}$ of triethylamine was added. A 5mL THF solution of $\mathrm{Fe}_{8}(4-\mathrm{Me}-\mathrm{pz})(0.1560 \mathrm{~g}, 0.096 \mathrm{mmol})$ was added dropwise at a rate of $0.5 \mathrm{~mL} / \mathrm{min}$. The initially colorless solution turned brownish red upon the addition of $\mathrm{Fe}_{8}$. The reaction mixture was stirred overnight. A solid was obtained by removing the solvent by means of rotary evaporation. To make sure that there was no leeching of the $\mathrm{Fe}_{8}$, the solid was washed with DCM and no color was observed in the wash.

\section{$\mathrm{Fe}_{8}(4-\mathrm{H}-\mathrm{pz})[\mathrm{H} 3]$}

Poly(4-vinylphenol-co-methyl methacrylate) (0.2500 g, $1.1 \mathrm{mmol}$ of phenol) was added to an Erlenmeyer flask and dissolved in $10 \mathrm{~mL}$ of THF, when all the polymer was dissolved, $0.2 \mathrm{~mL}$ of triethylamine was added. A $5 \mathrm{~mL}$ THF solution of $\mathrm{Fe}_{8}(4-\mathrm{H}-\mathrm{pz})$ $(0.1400 \mathrm{~g}, 0.096 \mathrm{mmol})$ was added dropwise at a rate of $0.5 \mathrm{~mL} / \mathrm{min}$. The initially colorless solution turned red upon the first additions of $\mathrm{Fe}_{8}$ but after a minute a dark green color was observed. The reaction mixture was stirred overnight. A solid was obtained by removing the solvent by means of rotary evaporation. To make sure that there was no leeching of the $\mathrm{Fe}_{8}$, the solid was washed with DCM and no color was 
observed in the wash. The solid was soluble in THF but slow addition into water yielded a dark green insoluble material. 
Chapter 5: General conclusions 


\subsection{General conclusions and future work}

This research project intended to test the hypothesis that an octanuclear iron-oxo cluster could be used as an electron acceptor for solar energy applications. Considering the diverse strategies used, we focused on two: photo-catalysis and photovoltaics. The photo-catalysis strategies requires the generation of a charge separated state that can be used as redox equivalents to carry out reactions. In this scenario the $\mathrm{Fe}_{8}$ cluster would serve as the electron acceptor, but a suitable electron donor is still needed. Based on the extensive literature on photo-active ruthenium polypyridyl this project embarked on the synthesis of a derivative that contain a phenol group. Considering the outstanding properties of the $\left[\mathrm{Ru}(\mathrm{bpy})_{3}\right]^{2+}$ monomer and the commercial availability of the dihydroxybipyridine ligand, the first strategy was to synthesize the $\left[\mathrm{Ru}\left(\mathrm{dhbpyH}_{2}\right)_{3}\right]^{2+}$ analogue complex. This compound was successfully synthesized but coordination efforts consistently yielded insoluble materials. After careful consideration, it was decided that a donor with less coordinative phenols should be tried. To that purpose the project turned to 4-hydroxyterpyridine as the ligand of choice. With this ligand, two approaches were tried, to coordinate first the ligand to the $\mathrm{Fe}_{8}$ and add a ruthenium salt afterwards or to prepare the homoleptic complex of ruthenium (which would bear to phenol groups) and try to coordinate it to $\mathrm{Fe}_{8}$. The first strategy, coordination of the ligand first, proved to be inadequate since the terpyridine would pull out iron from the cluster yielding the homoleptic $\left[\mathrm{Fe}\left(\mathrm{L}^{1}\right)\right](\mathrm{Cl})_{2}$ complex. The second approach was also unsuccessful yielding more insoluble material as well as some unreacted ruthenium monomer. At this point it was decided that a ruthenium donor with only one phenol group was needed and thus the 
synthesis of a heteroleptic complex bearing a single phenol on a terpyridine ligand was pursued. In the process two ligand were synthesized $\left(\mathrm{L}^{2}\right.$ and $\left.\mathrm{L}^{3}\right)$ and a third ligand was found out to be commercially available $\left(\mathrm{L}^{1}\right)$. The use of this ligands led to the preparation and characterization of three unreported ruthenium complexes. The coordination of these complexes to $\mathrm{Fe}_{8}$ have not been confirmed yet.

From the perspective of the photocatalysis approach, research is still going on to assess if the $\mathrm{Fe}_{8}$ can be used as an electron acceptor in molecular dyads. Regardless of the results, the future steps on this front should be to investigate if the $\mathrm{Fe}_{8}$ can be used as an electron acceptor in systems that do not require an actual bond between the donor and acceptor moieties but simple outer sphere electron transfer would prove the point.

When the photocatalysis project started, several metals were tried for the preparation of the dihydroxybipyridine complexes. Motivated by the need to find more abundant alternatives to ruthenium, first row transmission metals, copper, cobalt and zinc were used. The complexes of these metals were characterized and found not good enough to be an alternative to ruthenium. As the project began studying $\mathrm{Fe}_{8}$ for photovoltaic applications, an interesting fact came up, mononuclear first row transition metal complexes of bipyridine and derivatives were beginning to be used as substitutes for $\mathrm{I}^{-} / \mathrm{I}_{3}{ }^{-}$in DSSC. The complexes of cobalt, copper and zinc with dihydroxybipyridine were fully characterized and the results were published in the journal Polyhedron [93] (DOI: $10.1016 /$ j.poly.2018.04.039)

While DSSC is not the best system to study $\mathrm{Fe}_{8}$ in a photovoltaic scenario, BHJ cells seemed like the perfect setting. In BHJ fullerene is commonly used as the electron acceptor. Although fullerene and its derivatives exhibit striking redox chemistry with up 
to 6 reversible reductions the $\mathrm{Fe}_{8}$ family can be reduced at lower potentials. Unfortunately, the $\mathrm{Fe}_{8}$ as synthesized does not lend itself to the formulation of $\mathrm{BHJ}$, so an alternative method of casting it was needed. PVPOH is a commercially available polymer with available phenol groups that can be used to coordinate the polymer to Fes. This polymer has very good miscibility with many other polymers making it an interesting host for an $\mathrm{Fe}_{8}$-based hybrid that can be employed in BHJ cells. Several hybrid materials were prepared with this polymer and with a related polymer, PVPOH-co-MMA, and their properties were studied. Unfortunately, these polymers exhibit no detectable conductivity even under high pressure, precluding them from any practical application in BHJ cells. Nonetheless, they serve as a proof of concept that $\mathrm{Fe}_{8}$ can be embedded into a polymer host to form class II hybrid materials that keep the redox chemistry of the $\mathrm{Fe}_{8}$ with the processability of the polymer host. Other properties such as gas adsorption of the hybrids were studied and some interesting results were obtained. The next step for this project is to find a conductive polymer that can bind to the $\mathrm{Fe}_{8}$ and prepare hybrids to be used in the preparation of BHJ cells. These cells would test the feasibility of substituting fullerene with the less expensive $\mathrm{Fe}_{8}$. 


\section{References}

1. Lewis, N. S.; Nocera, D. G. Proc. Natl. Acad. Sci. 2006, 103, 15729-15735.

2. Jelley, N.; Smith, T. Proc. Inst. Mech. Eng. A 2015, 229, 693-713.

3. Hambourger, M.; Moore, G. F.; Kramer, D. M.; Gust, D.; Moore, A. L.; Moore, T. A. Chem. Soc. Rev. 2009, 38, 25-35.

4. Gust, D.; Moore, T. A.; Moore, A. L. Acc. Chem. Res. 2009, 42, 1890-1898.

5. Rakowski Dubois, M.; Dubois, D. L. Acc. Chem. Res. 2009, 42, 1974-1982.

6. Grätzel, M. Acc. Chem. Res. 2009, 42, 1788-1798.

7. Scholes, G. D.; Fleming, G. R.; Olaya-Castro, A.; Van Grondelle, R. J. Phys. Chem. 2009, 113, 6290-6297.

8. Bredas, J.-L.; Norton, J. E.; Cornil, J.; Coropceanu, V. Acc. Chem. Res. 2009, 42, 1691-1699.

9. Le-Quang, L.; Farran, R.; Lattach, Y.; Bonnet, H.; Jamet, H.; Guérente, L.; Maisonhaute, E.; Chauvin, J. Langmuir 2018, 34, 5193-5203.

10. Hosseini, M.; Rivera-Nazario, D. M.; Echegoyen, L. ACS Appl. Mater. Interfaces 2014, 6, 3712-3720.

11. Miles, R.; Zoppi, G.; Forbes, I. Materials Today 2007, 10, 20-27.

12. Che, X.; Li, Y.; Qu, Y.; Forrest, S. R. Nat. Energy 2018, 3, 422-427.

13. Hagfeldt, A.; Boschloo, G.; Sin, L.; Kloo, L.; Pettersson, H. Chem. Rev. 2010, 110, 6595-6663.

14. Wu, J.; Lan, Z.; Lin, J.; Huang, M.; Huang, Y.; Fan, L.; Luo, G. Chem. Rev. 2015, $115,2136-2173$.

15. Kumavat, P. P.; Sonar, P.; Dalal, D. Renew. Sust. Energ. Rev. 2017, 78, $1262-$ 1287.

16. Nazeeruddin, M. K.; Klein, C.; Liska, P.; Grätzel, M. Coord. Chem. Rev. 2005, 249, 1460-1467.

17. Ozawa, H.; Sugiura, T.; Kuroda, T.; Nozawa, K.; Arakawa, H. J. Mater. Chem. A 
2016, 4, 1762-1770.

18. Birel, Ö.; Nadeem, S.; Duman, H. J Fluoresc 2017, 27, 1075-1085.

19. Higashino, T.; Imahori, H. Dalton Trans. 2015, 44, 448-463.

20. O'Regan, B.; Grätzel, M. Nature 1991, 353, 737-740.

21. Rho, W.-Y.; Jeon, H.; Kim, H.-S.; Chung, W.-J.; Suh, J. S.; Jun, B.-H. J Nanomater 2015, 2015, 17.

22. Abd-Ellah, M.; Bazargan, S.; Thomas, J. P.; Rahman, A.; Srivastava, S.; Wang, X.; Hienig, N. F.; Leung, K. T. Adv. Electron. Mater. 2015, 1, 1500032.

23. Kumar, R.; Umar, A.; Kumar, G.; Nalwa, H. S.; Kumar, A.; Akhtar, M. S. J. Mater. Sci. 2017, 52, 4743-4795.

24. Hamann, T. W.; Ondersma, J. W. Energy Environ. Sci. 2011, 4, 370-381.

25. Li, T.; Spokoyny, A.; She, C. J. Am. Chem. Soc. 2010, 132, 4580-4582.

26. Huang, Y.; Kramer, E. J.; Heeger, A. J.; Bazan, G. C. Chem. Rev. 2014, 114, 7006-7043.

27. Mazzio, K. A.; Luscombe, C. K. Chem. Soc. Rev. 2015, 44, 78-90.

28. Tamai, Y.; Ohkita, H.; Benten, H.; Ito, S. J. Phys. Chem. Lett. 2015, 6, 3417-3428.

29. Frost, J. M.; Cheynis, F.; Tuladhar, S. M.; Nelson, J. Nano Lett. 2006, 6, 16741681.

30. Watkins, P. K.; Walker, A. B.; Verschoor, G. L. B. Nano Lett 2005, 5, 1814-1818.

31. Raptis, R. G.; Georgakaki, I. P.; Hockless, D. C. R. Angew. Chem. Int. Ed. 1999, $38,1623-1634$.

32. Baran, P.; Boča, R.; Chakraborty, I.; Giapintzakis, J.; Herchel, R.; Huang, Q.; McGrady, J. E.; Raptis, R. G.; Sanakis, Y.; Simopoulos, A. Inorg. Chem. 2008, $47,645-655$.

33. Tributsch, H. Electrochim. Acta 2007, 52, 2302-2316.

34. Das, S.; Chakraborty, I.; Skachkov, D.; Ahmadi, M.; Ishikawa, Y.; Baran, P.; Raptis, R. G. Eur. J. Inorg. Chem. 2012, 3704-3711. 
35. Piñero, D. UPR-RP Thesis. 2009.

36. Govor, E. V.; Al-Ameed, K.; Chakraborty, I.; Coste, C. S.; Govor, O.; Sanakis, Y.; McGrady, J. E.; Raptis, R. G. Angew. Chem. Int. Ed. 2017, 56, 582-586.

37. Diao, G.; Li, L.; Zhang, Z. Talanta 1996, 43, 1633-1637.

38. Constable, E. C. Inorg. Chim. Acta 1984, 82, 53-57.

39. Charboneau, D. J.; Piro, N. A.; Kassel, W. S.; Dudley, T. J.; Paul, J. J. Polyhedron 2015, $91,18-27$.

40. Klein, S.; Dougherty, W. G.; Kassel, W. S.; Dudley, T. J.; Paul, J. J. Inorg. Chem. 2011, 50, 2754-2763.

41. Fuentes, M. J.; Bognanno, R. J.; Dougherty, W. G.; Boyko, W. J.; Kassel, W. S.; Dudley, T. J.; Paul, J. J. Dalton Trans. 2012, 41, 12514-12523.

42. Gupta, N.; Sharma, C.; Kumar, M.; Kumar, R. New J. Chem. 2017, 41, 1327613286.

43. Adler, A. D.; Longo, F. R.; Finarelli, J. D.; Goldmacher, J.; Assour, J.; Korsakoff, L. J. Org. Chem. 1967, 32, 476-476.

44. Dares, C.; Manivannan, T.; Potvin, P. G.; Lever, A. B. P. Inorg. Chim. Acta 2011, 374, 606-619.

45. Marelius, D. C.; Bhagan, S.; Charboneau, D. J.; Schroeder, K. M.; Kamdar, J. M.; McGettigan, A. R.; Freeman, B. J.; Moore, C. E.; Rheingold, A. L.; Cooksy, A. L.; Smith, D. K.; Paul, J. J.; Papish, E. T.; Grotjahn, D. B. Eur. J. Inorg. Chem. 2014, 676-689.

46. APEX3, Bruker Inc., Madison, WI, 2017.

47. Sheldrick, G. M. Acta Crystallogr. Sect. C. 2015, C71, 3.

48. Dolomanov, O. V.; Bourhis, L. J.; Gildea, R. J.; Howard, J. A. K.; Puschmann, H. J. Appl. Cryst. 2009, 42, 339-341.

49. Hübschle, C. B.; Sheldrick, G. M.; Dittrich, B. J. Appl. Cryst. 2011, 44, 12811284.

50. Krause, L.; Herbst-Irmer, R.; Sheldrick, G. M.; Stalke, D. J. Appl. Cryst. 2015, 48, 
$3-10$.

51. Yanagida, S.; Yu, Y.; Manseki, K. Acc. Chem. Res. 2009, 42, 1827-1838.

52. Boschloo, G.; Hagfeldt, A. Acc. Chem. Res. 2009, 42, 1819-1826.

53. Elgrishi, N.; Chambers, M. B.; Wang, X.; Fontecave, M. Chem. Soc. Rev. 2017, 46, 761-796.

54. Tong, L.; Thummel, R. P. Chem. Sci. 2016, 7, 6591-6603.

55. Sun, Q.; Mosquera-Vazquez, S.; Suffren, Y.; Hankache, J.; Amstutz, N.; Max, L.; Daku, L.; Vauthey, E.; Hauser, A. Coord. Chem. Rev. 2015, 282, 87-99.

56. Housecroft, C. E. Cryst. Eng. Comm. 2015, 17, 7461-7468.

57. Sakamoto, R.; Wu, K.-H.; Matsuoka, R.; Maeda, H.; Nishihara, H. Chem. Soc. Rev. 2015, 44, 7698-7714.

58. Gorczynski, A.; Harrowfield, J. M.; Patroniak, V.; Stefankiewicz, A. R. Chem. Rev. 2016, 116, 14620-14674.

59. Meyer, T. Acc. Chem. Res. 1989, 22, 163-170.

60. Ishida, H.; Terada, T.; Tanaka, K. Inorg. Chem. 1990, 29, 905-911.

61. Akimov, A. V.; Asahi, R.; Jinnouchi, R.; Prezhdo, O. V. J. Am. Chem. Soc. 2015, $137,11517-11525$.

62. Ossipov, D.; Pradeepkumar, P. I.; Holmer, M.; Chattopadhyaya, J. J. Am. Chem. Soc. 2001, 123, 3551-3562.

63. Qu, F.; Park, S.; Martinez, K.; Gray, J. L.; Thowfeik, F. S.; Lundeen, J. A.; Kuhn, A. E.; Charboneau, D. J.; Gerlach, D. L.; Lockart, M. M. Inorg. Chem. 2017, 56, 7519-7532.

64. Li, J.; Yang, C.; Wu, Y.; Wang, B.; Sun, W.; Shao, T. Inorg. Chim. Acta 2016, $441,1-8$.

65. Prier, C. K.; Rankic, D. A.; MacMillan, D. W. C. Chem. Rev. 2013, 113, 53225363.

66. Nazeeruddin, M. K.; Kay, A.; Rodicio, I.; Humphry-Baker, R.; Mueller, E.; Liska, 
P.; Vlachopoulos, N.; Grätzel, M. J. Am. Chem. Soc. 1993, 115, 6382-6390.

67. Furugori, S.; Kobayashi, A.; Watanabe, A.; Yoshida, M.; Kato, M. ACS Omega 2017, 2, 3901-3912.

68. Marin, V.; Holder, E.; Wienk, M. M.; Tekin, E.; Kozodaev, D.; Schubert, U. S. Macromol. Rapid. Commun. 2005, 26, 319-324.

69. Sheridan, M.; Sherman, B.; Marquard, S.; Fang, Z.; Ashford, D.; Wee, K.-R.; Gold, A.; Alibabaei, L.; Rudd, J.; Coggins, M.; Meyer, T. J. J. Phys. Chem. C 2015, 119, 25420-25428.

70. Ashford, D.; Brenneman, M. K.; Brown, R.; Keinan, S.; Concepcion, J.; Papanikolas, P.; Templeton, J.; Meyer, T. J. Inorg. Chem. 2015, 54, 460-469.

71. Tong, L.; Inge, A. K.; Duan, L.; Wang, L.; Zou, X.; Sun, L. Inorg. Chem. 2013, $52,2505-2518$.

72. Baillargeon, J.; Xie, Y.; Hamman, T. W. ACS Appl. Mater. Interfaces 2017, 9, 33544-33548.

73. Feldt, S. M.; Gibson, E. A.; Gabrielsson, E.; Sun, L.; Boschloo, G.; Hagfeldt, A. J. Am. Chem. Soc. 2010, 132, 16714-16724.

74. Bozic-Weber, B.; Constable, E. C.; Hostettler, N.; Housecroft, C. E.; Schmitt, R.; Schönhofer, E. Chem. Commun. 2012, 48, 5727-5729.

75. Dragonetti, C.; Magni, M.; Colombo, A.; Melchiorre, F.; Biagini, P.; Roberto, D. M. ACS Appl. Energy Mater. 2018, 1, 751-756.

76. Stephenson, M. D.; Prior, T. J.; Hardie, M. J. Cryst. Growth Des. 2008, 8, 643653.

77. Burke, M. J.; Nichol, G. S.; Lusby, P. J. J. Am. Chem. Soc. 2016, 138, 9308-9315.

78. Papadopoulos, C. D.; Hatzidimitriou, A. G.; Voutsas, G. P.; Lalia-Kantouri, A. Polyhedron 2007, 26, 1077-1086.

79. Badiei, Y. M.; Wang, W. H.; Hull, J. F.; Szalda, D. J.; Muckerman, J. T.; Himeda, Y.; Fujita, E. Inorg. Chem. 2013, 52, 12576-12586.

80. Yadav, Y. J.; Mastropietro, T. F.; Szerb, E. I.; Talarico, A. M.; Pirillo, S.; Pucci, 
D.; Crispini, A.; Ghedini, M. New J. Chem. 2013, 37, 1486-1493.

81. Das, S.; Bharadwaj, P. K. Inorg. Chem. 2006, 45, 5257-5259.

82. Spek, A. L. Acta Crystallogr. Sect. C: Cryst. Struct. Commun. 2015, C71, 9-18.

83. Nolan, J. P.; Jones, T. W.; Donne, S. W.; Wilson, G. J. Electrochim. Acta 2013, $108,690-697$.

84. Elsbernd, H.; Beatie, K. K. J. Inorg. Nucl. Chem. 1972, 34, 771-774.

85. Lambert, J. B.; Urdaneta-Perez, M. J. Am. Chem. Soc. 1978, 100, 157-162.

86. Hong, Y.-R.; Gorman, C. B. J. Org. Chem. 2003, 68, 9019-9025.

87. Heeger, A. Adv. Mater. 2014, 26, 10-28.

88. Kickelbick, G. Hybrid Mater. 2014, 1, 39-51.

89. Gracia, R.; Mecerreyes, D. Polym. Chem. 2013, 4, 2206-2214.

90. Krasia-Christoforou, T. Organic-Inorganic Polymer Hybrids: Synthetic Strategies and Applications. In Hybrid and Hierarchical Composite Materials; Kim, C. S., Randow, C., Sano, T., Eds.; Springer, Cham, 2015; pp 11-20.

91. Schubert, U. Chem. Mater. 2001, 13, 3487-3494.

92. Lazarou, K.; Raptis, R. G. Unpublished results.

93. Rodríguez-Santiago, A. J.; Cortés, N.; Pham, K.; Miksovska, J.; Raptis, R. G. Polyhedron 2018, No. Accepted for publication, 61-68.

94. Eisenberg, R.; Nocera, D. G. Inorg. Chem. 2005, 44, 6799-6801. 
VITA

\section{ALAN J. RODRÍGUEZ SANTIAGO}

Born, San Juan, Puerto Rico

2009

Undergraduate Award

ACS Analytical Chemistry

University of Puerto Rico

Rio Piedras, Puerto Rico

2010

B.Sc., Chemistry

University of Puerto Rico

Rio Piedras, Puerto Rico

2018

Doctoral Candidate

Florida International University

Miami, Florida

\section{PUBLICATIONS AND PRESENTATIONS}

Selected poster presentations:

$61^{\text {st }}$ SERMACS in San Juan. October 2009. "Validation of External Calibrations in the Analysis of Multiple Metals in Honey by Flame Atomic Absorption. Statistical Comparison of External and Standard Addition Methods" A. J. Rodríguez Santiago, C. Bernal

239th ACS National Meeting in San Francisco. March 2010. "Interdisciplinary experiment on the kinetics of skin delivery from methyl salicylate transdermal patches." A. J. Rodríguez Santiago, C. Bernal

245th ACS National Meeting in New Orleans. March 2013. "History of chemistry capstone course: New solutions to an old problem” A. J. Rodríguez Santiago, I. Montes

255th ACS National Meeting in New Orleans. March 2018. "Preparation and characterization of a new organic-inorganic hybrid material with synergistically combined properties” A. J. Rodríguez Santiago, R. G. Raptis

94th Florida Annual Meeting and Exposition in Tampa. May 2018. "Iron-oxide based clusters for the preparation of hybrid materials" A. J. Rodríguez Santiago, R. G. Raptis 
Selected publications:

Bernal, C.; Rodríguez, A. Chem. Educator 201015 401-405

Bernal, C.; Rodríguez, A. Chem. Educator 201015 435-440

Rodríguez, A. J.; Quirke, J. M. E.; Diouf, A. O. Acta Cryst. 2015, E71, m30.

Rodríguez, A. J.; Acosta, C.; Raptis, R. G. IUCrData 2016, 1 x161029

Rodríguez-Santiago, A. J.; Cortés, N.; Pham, K.; Miksovska, J.; Raptis, R. G. Polyhedron $2018150,61-68$ 